


\section{Prioritisation of antibiotics, antiparasitics, carbamates and NSAIDs for monitoring in horse, goat, sheep and milk}

E.D. van Asselt, M.G. Pikkemaat, L.J.M. Jansen, E.F. Hoek-van den Hil

This research has been carried out by Wageningen Food Safety Research, institute within the legal entity Wageningen Research Foundation funded by the Netherlands Food and Consumer Product Safety Authority (NVWA) (project number WOT-02-002-004). 
Van Asselt, E.D., Pikkemaat, M.G., Jansen, L.J.M., Hoek-van den Hil, E.F., 2020. Prioritisation of antibiotics, antiparasitics, carbamates and NSAIDs for monitoring in horse, goat, sheep and milk. Wageningen, Wageningen Food Safety Research, WFSR report 2020.007. 82 pp.; 3 fig.; 8 tab.; 36 ref.

Project number: 1297371401

BAS-code: WOT-02-002-004

Project title: Beslisbomen Nationaal Plan Residuen (NPR)

Project leader: Esther van Asselt

This report can be downloaded for free at https://doi.org/10.18174/517744 or at www.wur.eu/foodsafety-research (under WFSR publications).

(C) 2020 Wageningen Food Safety Research, institute within the legal entity Wageningen Research Foundation. Hereinafter referred to as WFSR.

The client is allowed to publish or distribute the full report to third parties. Without prior written permission from WFSR it is not allowed to:

a) publish parts of this report;

b) use this report or title of this report in conducting legal procedures, for advertising, acquisition or other commercial purposes;

c) use the name of WFSR other than as the author of this report.

P.O. Box 230, 6700 AA Wageningen, The Netherlands, T +31 (0)317 4802 56, E info.wfsr@wur.nl, www.wur.eu/food-safety-research. WFSR is part of Wageningen University \& Research.

This report from WFSR has been produced with the utmost care. However, WFSR does not accept liability for any claims based on the contents of this report.

WFSR report 2020.007

Distribution list:

- Marca Schrap (NVWA)

- Jacqueline Steenbergen-Biesterbos (NVWA) 


\section{Contents}

$\begin{array}{ll}\text { Summary } & 5\end{array}$

$\begin{array}{ll}\text { Introduction } & 7\end{array}$

$\begin{array}{ll}\text { Materials and Methods } & 11\end{array}$

2.1 Approach 11

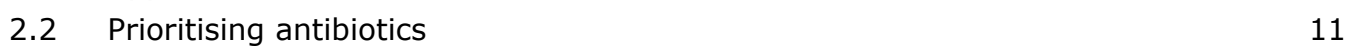

2.3 Prioritising antiparasitics $\quad 12$

2.3.1 Unauthorised antiparasitics $\quad 12$

2.3.2 Authorised antiparasitics $\quad 12$

2.4 Prioritising carbamates $\quad 13$

2.4.1 Unauthorised carbamates $\quad 13$

2.4.2 Authorised carbamates 14

$\begin{array}{lll}2.5 & \text { Prioritising NSAIDs } & 15\end{array}$

2.5.1 Unauthorised NSAIDs $\quad 15$

2.5.2 Authorised NSAIDs $\quad 15$

2.6 Matrix for analysis (of residues in animals) 16

3

$\begin{array}{ll}\text { Results } & 17\end{array}$

$\begin{array}{lll}3.1 & \text { Antibiotics } & 17\end{array}$

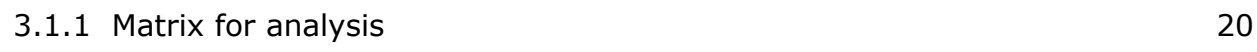

$\begin{array}{lll}3.2 & \text { Antiparasitic agents } & 20\end{array}$

3.2.1 Prioritisation of unauthorised antiparasitics using decision tree I $\quad 20$

3.2.2 Prioritisation of authorised antiparasitics using decision tree III $\quad 21$

$\begin{array}{ll}3.2 .3 \text { Matrix for analysis } & 23\end{array}$

$\begin{array}{lll}3.3 & \text { Carbamates } & 23\end{array}$

3.3.1 Prioritisation of unauthorised carbamates using decision tree I 23

3.3.2 Prioritisation of authorised carbamates using decision tree II 26

3.3.3 Matrix for analysis 26

$\begin{array}{lll}3.4 & \text { NSAIDs } & 26\end{array}$

3.4.1 Prioritisation of unauthorised NSAIDs using decision tree I 27

3.4.2 Prioritisation of authorised NSAIDs using decision tree III 28

$\begin{array}{ll}3.4 .3 \text { Matrix for analysis } & 30\end{array}$

4

Discussion $\quad 31$

4.1 Discussion on antibiotics $\quad 32$

4.2 Discussion on antiparasitics $\quad 32$

4.3 Discussion on carbamates $\quad 33$

4.4 Discussion on NSAIDs $\quad 33$

4.5 Discussion on the matrix $\quad 34$

$5 \quad$ Conclusions and recommendations $\quad 35$

$\begin{array}{ll}\text { Acknowledgements } & \mathbf{3 7}\end{array}$

$\begin{array}{ll}\text { References } & 38\end{array}$ 
Annex 2 Prioritisation of unauthorised antiparasitics using decision tree I for animal products in general

Annex 3 Prioritisation of authorised antiparasitics using decision tree III 53

Annex 4 Prioritisation of unauthorised carbamates using decision tree I 61

Annex 5 Prioritisation of unauthorised NSAIDs using decision tree I 72

Annex 6 Prioritisation of authorised NSAIDs using decision tree III $\quad 76$

Annex 7 List of substances essential for treatment of equidae and substances bringing added clinical benefit according to EU $122 / 2013$ 


\section{Summary}

Regulation (EU) 2017/625 prescribes that monitoring of residues in animal products should be performed on a risk basis. However, the regulation does not indicate how such risk-based monitoring should be established. Therefore, the Office for Risk Assessment \& Research of the Netherlands Food and Consumer Product Safety Authority (NVWA-BuRO) asked Wageningen Food Safety Research (WFSR) to develop an approach that allows for prioritising substances for monitoring. As a result, three decision trees have been established previously: I. Prohibited substances; II. Natural substances, contaminants and residues of pesticides and III. Authorised active ingredients of veterinary medicines and feed additives. The decision trees have been applied to bovine, porcine and poultry products in a previous project. The aim of the current project was to prioritise antibiotics, antiparasitics, carbamates and NSAIDs in horse, goat and sheep products and in (cow's) milk.

The same list of substances as evaluated previously were run through the appropriate decision trees for the specified animal species. In total, 68 authorised antibiotics, 32 authorised antiparasitics, 4 authorised carbamates and 13 authorised NSAIDs were prioritised using decision tree III. Decision tree I was used to prioritise unauthorised substances, which in this case were 19 antiparasitics, 50 carbamates and 18 NSAIDs. The questions in the decision trees were answered using national and EU monitoring data, indications for use (e.g. based on antibiotic use data or veterinary drug sales data) and information on human health aspects based on EFSA reports. This allowed for a prioritisation of the list of substances in high, medium and low priority for monitoring in horse, goat, sheep products and milk. Since there were no non-compliances found for the unauthorised antiparasitics and for 36 carbamates in the animal products studied, the prioritisation was identical as the one established for bovine, porcine and poultry products in the previous study. For the other substances, non-compliances were found depending on the animal species studied. It is recommended to include substances with a medium and high priority for monitoring in the National Plan (NP) Residues.

The study showed that there is a general lack of data especially for goat and sheep. Furthermore, a distinction between these species was also not always possible. As a result, the prioritisation performed in this study should be seen as a worst-case approach. When more monitoring data become available for these species, the prioritisation can be better substantiated. Furthermore, this study showed that a wide range of veterinary medicinal products (VMPs) are available for the treatment of horses, which are currently not all in the analytical scope. Although VMP use should be reported in the horse's passport, fraud may occur, and dedicated monitoring is thus recommended.

Apart from a prioritisation of substances using the three decision trees, the matrix for analysis was studied for antibiotics, antiparasitics, carbamates and NSAIDs. The currently used matrix was indicated and compared to matrices used in other EU member states. The theoretically preferred matrix may in reality not be the matrix of choice due to practical reasons or analytical limitations. The evaluation showed that there are currently no reasons to adapt the matrix for analysis of antibiotics, antiparasitics and NSAIDs. However, for carbamates, it is recommended to use liver samples for analysis rather than meat samples.

The outcome of this study may be used to optimise the NP Residues using the results of the prioritisation as indicated in Tables 1-8 of this report. 


\section{Introduction}

Regulation (EU) 2017/625 prescribes that member states (MSs) need to establish and regularly revise a multi-annual national monitoring program using a risk-based approach. This Regulation applies since December 14, 2019 and repeals (amongst others) Directive 96/23/EC, the current Directive aimed at harmonising the control by member states of veterinary drug and banned substances residues in animal products. The regulation, however, does not specify how monitoring plans should be made risk based.

Therefore, in order to categorize chemical substances in animal products, decision trees have been established previously (van Asselt et al., 2018b; van Asselt et al., 2018c). The decision trees prioritise substances into low, medium and high priority for monitoring based on the possible occurrence of substances in animal products and the severity of potential health effects caused by the substances. Three separate decision trees were established for the evaluation of: I. Prohibited substances; II. Natural substances, contaminants and residues of pesticides, and III. Authorised active ingredients of veterinary medicinal products (VMPs) and feed additives.

Substances are classified in the decision trees as follows (van Asselt et al., 2018a; van Asselt et al., 2018c):

- High priority: this substance/group of substances has high priority for inclusion in a risk-based monitoring plan for animal matrices because of potential risks to human health.

- Medium priority: this substance/group of substances has medium priority for inclusion in a riskbased monitoring plan for animal matrices because of potential risks to human health.

- Low priority: this substance/group of substances has low priority for inclusion in a risk-based monitoring plan for animal matrices because of the very low or negligible risk it poses to human health. However, if this substance/group of substances is already included in a chemical-analytical multi-method for substances/groups of substances with high or medium priority, there is no reason for it to be removed unless precisely that substance limits the scope or the sensitivity of the method.

In a previous project for the Office for Risk Assessment \& Research of the Netherlands Food and Consumer Product Safety Authority (NVWA-BuRO), four groups of substances being antibiotics, antiparasitic agents, carbamates and non-steroidal anti-inflammatory drugs (NSAIDs) were prioritised for bovine animals, porcine animals, poultry and eggs. These four substances groups were based on the classification of group B substances in the draft annex of Regulation (EU) 2017/625 at the time the research started (SANTE 11987-2017Rev1). A list of substances to prioritise was established based on substances listed in Regulation (EU) 37/2010, substances currently in the national monitoring program, substances used in registered VMPs and non-compliances reported within the EU. Additionally for NSAIDs, substances were included that are recommended by the CRL guidance paper (BVL-CRL et al., 2007). For carbamates, a list of substances was established based on carbamates mentioned by Alan Wood (http://www.alanwood.net/pesticides). For all these substances, the questions in the decision trees were answered using monitoring data, data on possible use and information on withdrawal periods (if appropriate). The research showed that substances could be classified as high, medium or low priority for monitoring using the predefined decision trees (van Asselt et al., 2019). However, this project also showed that the information needed to answer the questions was not always available. For example, the question on occurrence of non-compliant results could not always be answered as it was not always evident that substances were within the (inter)national scope of methods used for analysis. Furthermore, data on potential use of substances were often limited. As a result, the original decision trees were adapted, including the possibility to answer 'unknown' to several of the questions (Figures 1-3). 


\section{Group I: prohibited substances}

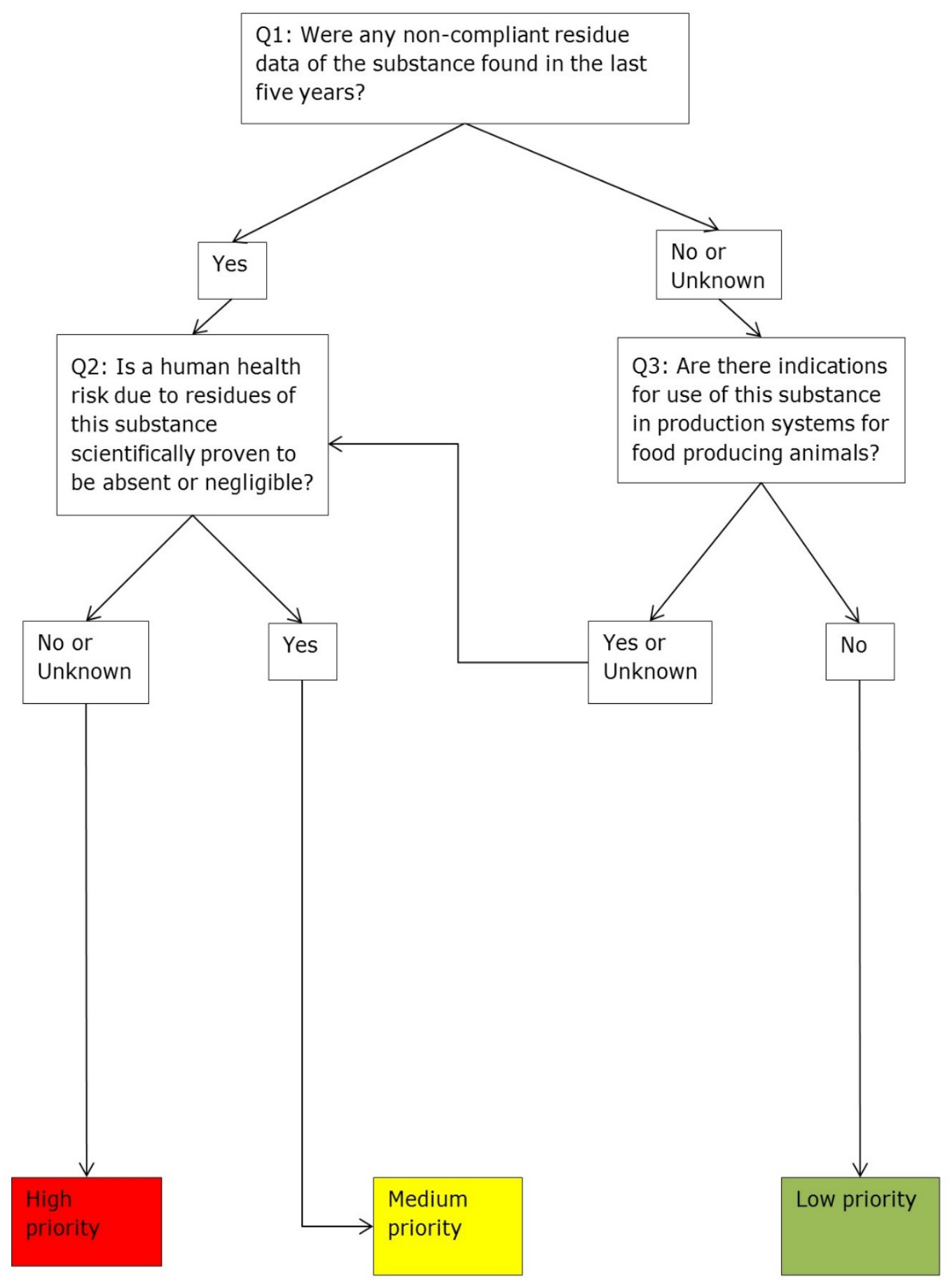

Figure 1 Decision tree I for forbidden substances (updated from van Asselt et al. (2018b)). 


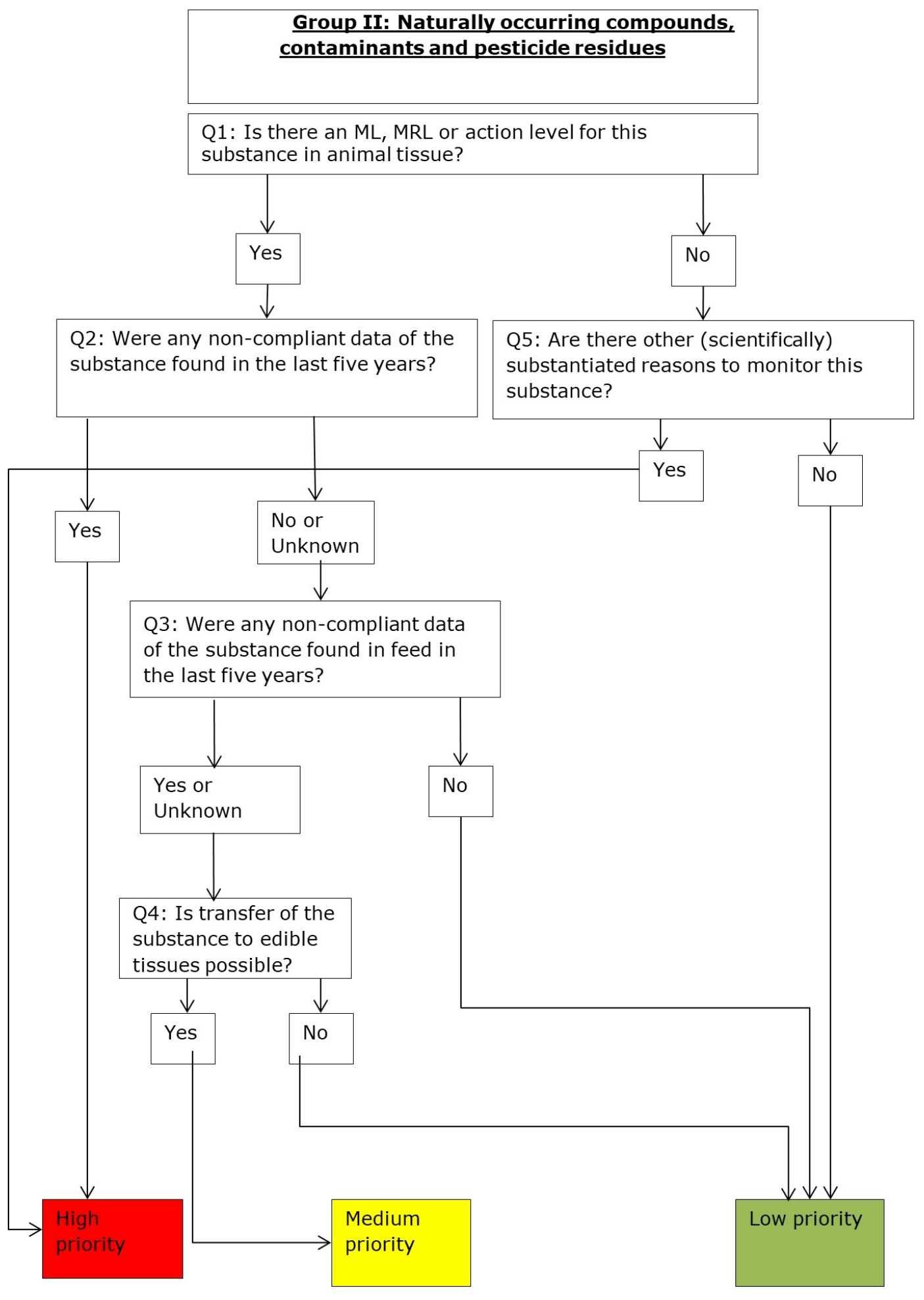

Figure 2 Decision tree II for naturally occurring substances, contaminants and pesticide residues (updated from van Asselt et al. (2018b)). In this report only applied for a limited number of substances, i.e. the authorised carbamates. 


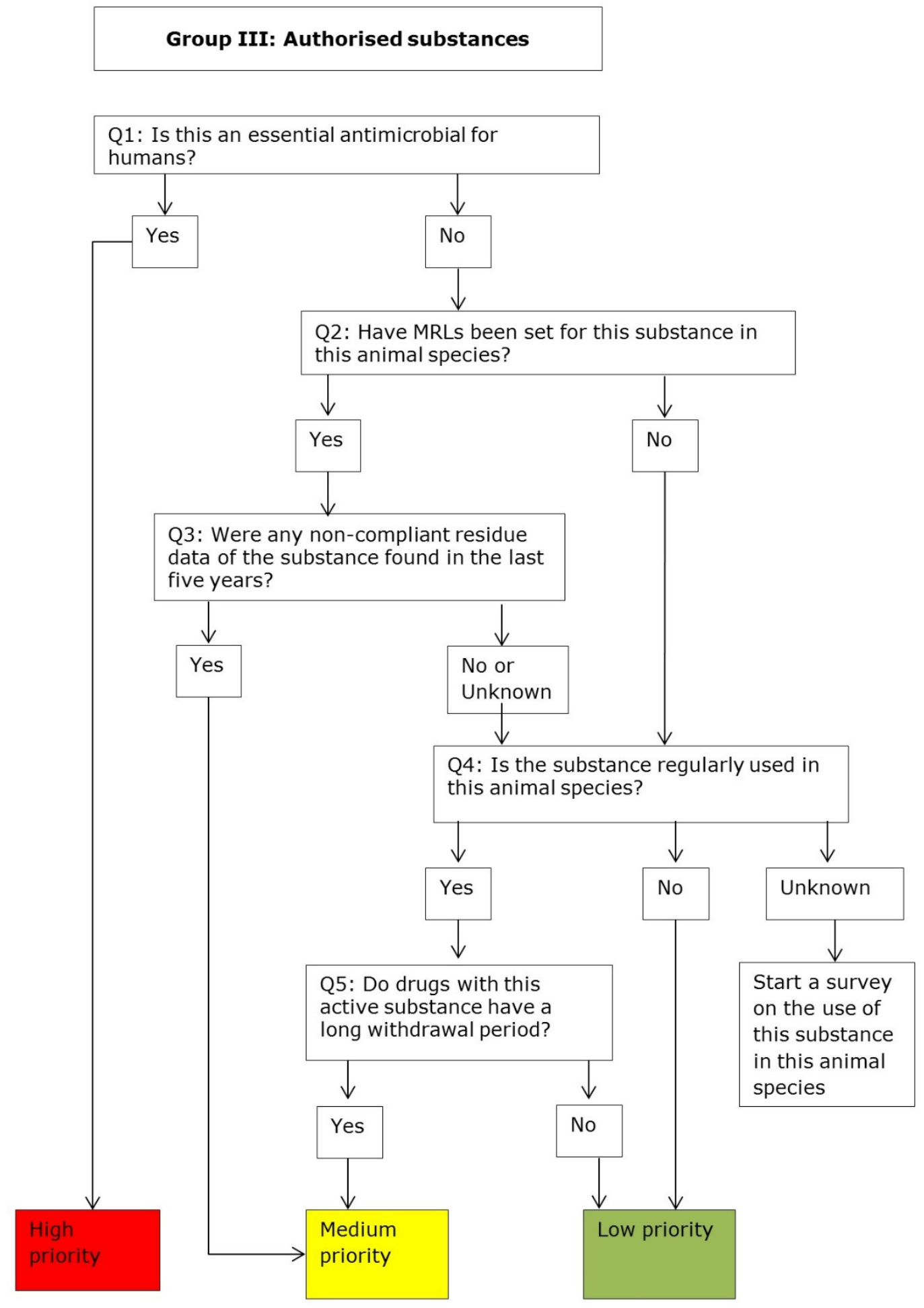

Figure 3 Decision tree III for authorised substances (updated from van Asselt et al. (2018b)).

The aim of the current project was to prioritise the same four groups of substances (antibiotics, antiparasitic agents, carbamates and NSAIDs) for a set of additional animal derived products, namely those of horse, goat and sheep and for (cow) milk. 


\section{Materials and Methods}

\subsection{Approach}

A list of substances to be prioritised within antibiotics, antiparasitics, carbamates and NSAIDs has been established previously. For details on how these lists were obtained, we refer to van Asselt et al. (2019). In the previous report, bovine and porcine products as well as poultry meat and eggs were evaluated. In this report, products of horse, goat and sheep were evaluated as well as milk. The latter evaluation primarily, but not exclusively, focused on cow milk. In the Netherlands, around $2.5 \%$ of total milk production is accounted for by goat, which should be represented in the ratio in the monitoring of milk. In case information on milk was exclusively related to a species other than cow, this was explicitly mentioned in the evaluation. For each of the four groups of VMPs, the selected substances were run through the decision trees per animal species in order to classify their individual priority for monitoring. For this purpose, the results of Dutch and EU monitoring programs were used as well as information on the use of the substances (e.g. from SDa data on antibiotics use, and data for other substances from FIDIN) and on their possible human health effects using EFSA or JECFA reports. The specific data sources used are indicated below for each group of substances.

\subsection{Prioritising antibiotics}

The previously established list of substances was evaluated using decision tree III for authorised substances. Each question was answered using the following information:

1. Is this an essential antimicrobial for humans?

For this question, the 2017 WHO report was used to identify the highest priority critically important (HPCI) antimicrobials for human medicine. These antimicrobials included quinolones, $3^{\text {rd }}$ and higher generation cephalosporins, macrolides and ketolides, glycopeptides and polymyxins (WHO, 2017).

2. Have MRLs been set for this substance in this animal species or for this animal product? This question was answered using Table 1 in the Annex of Regulation (EU) 37/2010 (latest consolidated version 03/03/2019). The extrapolation of MRLs in species with MRLs to species without MRLs as outlined in Regulation (EU) 2017/880 was not taken into account. Therefore, if no MRL was indicated for the animal product in Regulation (EU) 37/2010, the question was answered negatively.

3. Were any non-compliant residue data of the substance found in the last five years?

In order to answer this question, monitoring data on residues of the substances were used. EFSA reports on the results from the monitoring of VMP residues and other substances in live animals and animal products were used for the years 2013-2017 in order to identify non-compliances in EU Member States (EFSA, 2015b, 2016b, 2017b, 2018b, 2019b), as well as RASFF notifications (2014-2018, https://webgate.ec.europa.eu/rasff-window/portal). Furthermore, national monitoring data were extracted from the Dutch Quality Program for Agricultural Products (KAP), which is an extensive cooperation between the Dutch government and Dutch agribusiness (www.chemkap.rivm.nl). Data originated from Wageningen Food Safety Research and the NVWA, and were available for the years 2012, 2013 and 2017. Since this dataset was not complete, data from our laboratory information management system (LIMS) for 2013-2017 were used.

Furthermore, information on non-compliances was obtained from reports on the analytical results obtained within the National Residue Monitoring Plan.

4. Is the substance regularly used in this animal species?

This question was answered by using data on the use of antibiotics as collected by the Netherlands Veterinary Medicines Institute (SDa, https://www.autoriteitdiergeneesmiddelen.nl) for 2017 and additional dedicated surveys. For milk, the data for dairy cattle were used. As a cut-off value, a DDDA ('Defined Daily Dose Animal', the defined average dose of a specified medicine per kg of a 
specified animal per day, applied for its main indication (Postma et al., 2014; EMA, 2015)) of 50,000 was set, similar to the approach in the previous report (van Asselt et al., 2019). Unlike the previously assessed animal species, the SDa does not structurally monitor antibiotic use in sheep, goat and horse. Alternatively, possible antibiotic use for goat and sheep was based on two dedicated surveys (Santman et al., 2013; Verkaik et al., 2015). Details are described in 3.1. Antibiotic use in horse was based on the data underlying the SDA survey 'Antibioticum gebruik bij paarden' (SDa, 2016).

5. Do drugs with this active substance have a long withdrawal period?

Withdrawal periods were obtained from the product specifications retrieved from the VMP database of the Medicines Evaluation Board of the College ter Beoordeling van Geneesmiddelen (CBG-MEB) database. In case the longest withdrawal time was longer than 10 days for the respective species and longer than 5 days for milk (Danaher et al., 2016), this question was answered with a 'yes'.

\subsection{Prioritising antiparasitics}

\subsubsection{Unauthorised antiparasitics}

The previously established list of substances not included in Regulation (EU) 37/2010 and therefore not authorised for use in livestock animals (van Asselt et al., 2019), was run through decision tree I.

The following questions were answered:

1. Were any non-compliant data on residues of the substance found in the last five years? In order to answer this question, monitoring data on residues of the substances were used. EFSA reports on the results from the monitoring of VMP residues and other substances in live animals and animal products were used for the years 2013-2017 to identify unauthorised use in EU member states (EU MSs) (EFSA, 2015b, 2016b, 2017b, 2018b, 2019b) as well as RASFF notifications (2014-2018, https://webgate.ec.europa.eu/rasff-window/portal). Furthermore, national monitoring data were extracted from the Dutch Quality Program for Agricultural Products (KAP; www.chemkap.rivm.nl). Data originated from Wageningen Food Safety Research and the NVWA and were available for the years 2012, 2013 and 2017. Since this dataset was not complete, LIMS data for 2013-2017 were used. Furthermore, information on non-compliances were obtained from reports on the analytical results obtained within the NP Residues.

2. Is a human health risk due to residues of the substance scientifically proven to be absent or negligible?

Reports from EFSA, JECFA and scientific papers were checked for the potential effects of the substance on human health. In case adverse effects were shown to be absent or negligible, this question was answered with a 'yes'.

3. Are there indications for use of this substance in production systems for food producing animals? In case the antiparasitic is registered for use in companion animals, this question was answered positively as the antiparasitic is then freely available on the market. Use in livestock outside the $\mathrm{EU}$ and use as a pesticide were also evaluated to answer this question. If pesticide monitoring data were available for the substance showing no residues were found, the question was answered negatively.

\subsubsection{Authorised antiparasitics}

The previously established list of substances included in Regulation (EU) 37/2010 (van Asselt et al., 2019) was evaluated using decision tree III for authorised substances. Each question was answered using the following information:

1. Is this an essential antimicrobial for humans?

This question is not relevant for antiparasitics. The answer to this question is therefore 'No' for all substances.

2. Have MRLs been set for this substance in this animal species?

This question is answered using Table 1 in the Annex of Regulation (EU) 37/2010 (latest consolidated version 03/03/2019). The extrapolation of MRLs in species with MRLs to species without MRLs as outlined in Regulation (EU) 2017/880 was not taken into account. Therefore, if no 
MRL was indicated for the animal product in Regulation (EU) 37/2010, the question was answered negatively.

3. Were any non-compliant residue data of the substance found in the last five years?

In order to answer this question, monitoring data on residues of the substances were used. EFSA reports on the results from the monitoring of VMP residues and other substances in live animals and animal products were used for the years 2013-2017 to identify non-compliances in EU MSs (EFSA, 2015b, 2016b, 2017b, 2018b, 2019b) as well as RASFF notifications (2014-2018, https://webgate.ec.europa.eu/rasff-window/portal). Furthermore, national monitoring data were extracted from the Dutch Quality Program for Agricultural Products (KAP), which is an extensive cooperation between the Dutch government and Dutch agribusiness (www.chemkap.rivm.nl). Data originated from Wageningen Food Safety Research and the NVWA and was available for the years 2012, 2013 and 2017. Since this dataset was not complete, LIMS data for 2013-2017 were used. Furthermore, information on non-compliances were obtained from reports on the analytical results obtained within the NP Residues.

4. Is the substance regularly used in this animal species?

This question was answered by determining whether registered VMPs were available for the substances (listed in the database of CBG-MEB). Data on antiparasitic use in sheep were derived from a dedicated survey (Verkaik et al., 2015). Since this survey was limited to a single year (2013) and comprised $~ 130$ farmers, all substances reported were considered relevant. No specific data were available for goat. Therefore, treatment guidelines/recommendations provided by GD Animal Health and the EU project WORMCOPS were taken into account. Furthermore, the most recent sales data (2013-2017) from the Association of Netherlands Manufacturers and Importers of Veterinary Drugs (FIDIN) were used to identify which substances were regularly used in horse and bovine. It should be noted that sales data for bovine do not allow for differentiation between meat and dairy cattle and thus are likely to represent an overestimation of the use in dairy cattle. They do on the other hand also include the use in sheep and goat, but this is estimated to represent only a minor fraction (FIDIN, personal communication). As a cut-off value, an amount of $100 \mathrm{~kg}$ was used, since this was the median value of the total antiparasitics sales data. The FIDIN data for horse showed that the amounts sold were much lower than for bovine, porcine and poultry. Using the median value of the horse sales data, the cut-off value for horse was set at $10 \mathrm{~kg}$. Therefore, in case more than $100 \mathrm{~kg}$ of a substance was sold for bovine in a year or more than $10 \mathrm{~kg}$ for horse, the question was answered with 'yes'.

5. Do drugs with this active substance have a long withdrawal period?

Withdrawal periods were obtained from product specifications retrieved from the CBG-MEB VMP database. In case withdrawal times were longer than 10 days for horse, goat and sheep and longer than 5 days for milk (Danaher et al., 2016), this question was answered with 'yes'.

\subsection{Prioritising carbamates}

\subsubsection{Unauthorised carbamates}

The established list of carbamates (van Asselt et al., 2019) contained several unauthorised substances, which were run through decision tree I.

The following questions were answered for these substances:

1. Were any non-compliant residue data of the substance found in the last five years? In order to answer this question, monitoring data on residues of the substances were used. European monitoring data of VMP residues and other substances in animal products (EFSA, 2015b, 2016b, 2017b, 2018b, 2019b), the European monitoring of pesticide residues in food (EFSA, 2015a, 2016a, 2017a, 2018a, 2019a) and RASFF notifications (2014-2018, https://webgate.ec. europa.eu/rasff-window/portal) were used to identify non-compliances in EU MSs. Furthermore, national monitoring data were extracted from the Dutch Quality Program for Agricultural Products (KAP), which is an extensive cooperation between the Dutch government and Dutch agribusiness (www.chemkap.rivm.nl). Data originated from WFSR- Wageningen UR and the NVWA and were available for the years 2012, 2013 and 2017. Since this dataset was not complete, LIMS data for 
2013-2017 were used. Furthermore, information on non-compliances were obtained from reports on the analytical results obtained within the National Monitoring Plan Residues.

2. Is a human health risk due to residues of the substance scientifically proven to be absent or negligible?

Reports from EFSA, JECFA and scientific papers were checked for the effect of residues of the substance on human health. In case no human health risks were reported, this question was answered with 'yes'.

3. Are there indications for use of this substance in production systems for food producing animals? In case laboratory results or data from other EU MSs showed that residues were found, this question was answered positively (EFSA, 2015a, 2016a, 2017a, 2018a, 2019a). Some carbamates will break down into other carbamates; then monitoring data of the break-down products were used to answer this question. In case the average number of analysed samples in the Dutch monitoring data over the years 2013-2017 was less than 10 per year, the question was answered as 'unknown' and other indicators were checked.

If the carbamates were listed in the pesticide manual (Turner, 2015) or in the pesticide properties database (PPDB, https://sitem.herts.ac.uk/aeru/ppdb/en/atoz.htm) as obsolete, this question was answered negatively. Furthermore the PPDB, PAN pesticide database

(http://www.pesticideinfo.org/), Codex, Australian registrations (https://apvma.gov.au/), and FAO report on hazardous pesticides in Asia (FAO, 2015) were used to check for indications of use in countries outside Europe. The CBG-MEB database was checked as well as the internet (alibaba.com) for available products containing the substance.

\subsubsection{Authorised carbamates}

Animals may be exposed to carbamates through residues in feed. These substances have an MRL according to Regulation (EC) 396/2005. This was the case for methiocarb, oxamyl, pirimicarb and methomyl. For these substances, decision tree II was used for prioritisation. Since these carbamates are not used for a crop specifically cultured for a certain animal type, the decision tree was answered in general (not separately for poultry, cows and pigs).

The following questions were answered:

1. Is there an ML, MRL or action level for this substance in this animal tissue? This question is answered using Regulation (EC) 396/2005.

2. Were any non-compliant residue data of the substance found in the last five years? In order to answer this question, monitoring data on residues of the substances were used. European monitoring data of VMP residues and other substances in animal products (EFSA, 2015b, 2016b, 2017b, 2018b, 2019b) and in the European monitoring of pesticide residues in food (EFSA, 2015a, 2016a, 2017a, 2018a, 2019a) were used to identify non-compliances in EU MSs. RASFF notifications (2014-2018, https://webgate.ec.europa.eu/rasff-window/portal) were also used for this purpose. Furthermore, national monitoring data were extracted from the Dutch Quality Program for Agricultural Products (KAP), which is an extensive cooperation between the Dutch government and Dutch agribusiness (www.chemkap.rivm.nl). Data originated from WFSRWageningen UR and the NVWA and was available for the years 2012, 2013 and 2017. Since this dataset was not complete, LIMS data for 2013-2017 were used. Furthermore, information on noncompliances were obtained from reports on the analytical results obtained within the NP Residues.

3. Were any non-compliant residue data of the substance found in feed in the last five years? This question was also answered using RASFF data (2014-2018) and the KAP database (20132017).

4. Is transfer of the substance to edible tissues possible? Reports from EFSA and FAO/WHO were checked for information on metabolism and feeding studies in livestock animals.

5. Are there other (scientifically) substantiated reasons to monitor this substance? There was no need to answer this question for the four carbamates run through decision tree II. 


\subsection{Prioritising NSAIDs}

\subsubsection{Unauthorised NSAIDs}

NSAIDs not listed in Table 1 of the Annex of Regulation (EU) 37/2010, and therefore not authorised for use in livestock animals, were run through decision tree I for which the following questions were answered:

1. Were any non-compliant residue data of the substance found in the last five years? In order to answer this question, monitoring data on residues of the substances were used. EFSA reports on the results from the monitoring of VMP residues and other substances in live animals and animal products were used for the years 2013-2017 to identify non-compliances in EU MSs (EFSA, 2015b, 2016b, 2017b, 2018b, 2019b). Also, RASFF notifications (2014-2018, https://webgate.ec.europa.eu/rasff-window/portal) were used. Furthermore, national monitoring data were extracted from the Dutch Quality Program for Agricultural Products (KAP), which is an extensive cooperation between the Dutch government and Dutch agribusiness (www.chemkap.rivm.nl). Data originated from Wageningen Food Safety Research and the NVWA and was available for the years 2012, 2013 and 2017. Since this dataset was not complete, LIMS data for 2013-2017 were used. Furthermore, information on non-compliances were obtained from reports on the analytical results obtained within the NP Residues.

2. Is a human health risk due to residues of the substance scientifically proven to be absent or negligible?

Reports from EFSA, JECFA and scientific papers were checked for the effect of the substance on human health. In case human health effects could not be excluded, the question was answered with 'no'.

3. Are there indications for use of this substance in production systems for food producing animals? In case national monitoring results or data from other EU MSs showed that residues were found in other animals, this question was answered positively as follows: non-compliances in any mammal were seen as a possible indication for use in horse, non-compliances in any mammal except horse was seen as possible indication for use in goat and sheep (as in horse more substances are being used than is likely to be used in goat and sheep) and non-compliances in any milk-producing animal is seen as indications for possible residues in milk. For substances that are currently not monitored, for which no non-compliances for other mammals were found or for which the average number of analysed samples over the years 2013 - 2017 was less than 10 per year, the possible availability on the market was checked. For this purpose, the CBG-MEB database was checked to determine whether products are authorised for other animal species, such as companion animals, as well as the internet (ebay.com and alibaba.com).

\subsubsection{Authorised NSAIDs}

NSAIDs that are listed in Regulation (EU) 37/2010 and are thus authorised for use in animals were run through decision tree III. For these substances, the following questions were answered:

1. Is this an essential antimicrobial for humans?

This question is not relevant for NSAIDs. The answer to this question is therefore 'No' for all substances.

2. Have MRLs been set for this substance in this animal species?

This question is answered using Table 1 in the Annex of Regulation (EU) 37/2010 (latest consolidated version 29/09/2018). The extrapolation of MRLs (except for milk and egg) in species with MRLs to species without MRLs as outlined in Regulation (EU) 2017/880 was not taken into account. Therefore, if no MRL was indicated for the animal product in Regulation (EU) 37/2010, the question was answered negatively.

3. Were any non-compliant residue data of the substance found in the last five years? In order to answer this question, monitoring data on residues of the substances were used. EFSA reports on the results from the monitoring of VMP residues and other substances in live animals and animal products were used for the years 2013-2017 to identify non-compliances in EU MSs (EFSA, 2015b, 2016b, 2017b, 2018b, 2019b) as well as RASFF notifications (2014-2018, https://webgate.ec.europa.eu/rasff-window/portal)). Furthermore, national monitoring data were extracted from the Dutch Quality Program for Agricultural Products (KAP), which is an extensive 
cooperation between the Dutch government and Dutch agribusiness (www.chemkap.rivm.nl). Data originated from Wageningen Food Safety Research and the NVWA and was available for the years 2012, 2013 and 2017. Since this dataset was not complete, LIMS data for 2013-2017 were used. Furthermore, information on non-compliances were obtained from reports on the analytical results obtained within the NP Residues.

4. Is the substance regularly used in this animal species?

To answer this question, firstly non-compliances were checked based on RASFF, KAP data and EFSA data. In case a monitored substance is found non-compliant, regular use is indicated, answering the question positively. In case no non-compliances were found, this question was answered by determining whether registered VMP were available for the substances. Furthermore, products were searched on websites like alibaba.com and ebay.com to check the availability in case no registration was found. Additionally, for horse and cows, sales data from FIDIN for 2017 were used to identify which substances were regularly used. As a cut-off value, an amount of $100 \mathrm{~kg}$ was used for milk and $10 \mathrm{~kg}$ for horse analogous to the approach for antiparasitics (see section 2.3.2).

5. Do drugs with this active substance have a long withdrawal period? Withdrawal periods were obtained from the CBG-MEB site. In case products are registered for an animal species, the longest withdrawal period found was considered. In case no products are registered, the standard cascade withdrawal period was used.

In case withdrawal times were longer than 10 days for horse, goat and sheep and longer than 5 days for milk (Danaher et al., 2016), this question was answered with 'yes'.

\subsection{Matrix for analysis (of residues in animals)}

Current matrices used in the monitoring to check for the presence of the four groups of substances were identified, as well as the rationale for the choice of this matrix. The latter was based on WFSR expert consultation. Furthermore, the joint report of the EU Reference Laboratories (EURLs) was consulted for more information on matrices for analysis (Federol Office of Consumer Protection and Food Safety (BVL) et al., 2019). The current matrices used for official control in the Netherlands were compared with practices used within other EU countries. Deviations between NL and EU monitoring were discussed with WFSR experts in order to identify the most appropriate matrix. The outcome is thus based on internal expertise and was not further substantiated using residue kinetics. 


\section{Results}

The lists of substances for antibiotics, antiparasitics, carbamates and NSAIDs were evaluated using the established decision trees (Figures 1-3). The results of this evaluation are described below. In case questions were answered as 'unknown', a worst-case approach was followed, which for unauthorised substances led to a high priority classification. These results were marked with an asterisk to distinguish these substances from substances that were classified as high priority based on available data. In case of authorised substances, unknown answers did not result in a high priority but rather in a recommendation to start a survey. The reasoning behind this difference in categorisation is that authorised substances have undergone a toxicological evaluation prior to authorization. When applied correctly, these substances thus do not result in human health risks. The recommended survey should fill the existing data gap and enable differentiation between low and medium prioritisation in future evaluations.

\subsection{Antibiotics}

In total, 68 antibiotics were evaluated according to decision tree III for authorised substances. An overview of the prioritisation is given in Table 1 and a more detailed overview of the results is provided in Annex 1. Irrespective of the animal product, a total of 18 antibiotics were classified as high priority after answering Q1 - is the substance an essential antimicrobial for human (classified as highest priority critically important antimicrobials for human medicine (WHO, 2017)). These antimicrobials comprised the veterinary approved quinolones, $3^{\text {rd }}$ and $4^{\text {th }}$ generation cephalosporins, macrolides and colistin. It is important to keep in mind that the high priority classification does not necessarily imply a high risk of occurrence of residues of these substances in animal products. Actually the opposite is more likely, since the use of these substances (except for macrolides) is discouraged and application in food producing species shows a decreasing trend (SDa, 2018).

The remaining substances were subjected to Q2 - have MRLs been set for this substance in this animal species. For around half of the antibiotic substances evaluated in this report, a generic MRL has been established: MRLs apply to all (mammalian) food producing species, occasionally with exception of milk and eggs. Assuming that any substance used in bovine has the potential to end up in milk, Q2 for milk is answered combining milk and bovine MRLs meaning that if an MRL was available in either milk or bovine, the question was answered positively. The animal species addressed in this report, however, are species for which the availability of VMPs is limited, because of the limited size of the potential market for these products. VMPs, nevertheless, may be prescribed under the cascade. The cascade is a risk-based decision tree that allows the prescribing of VMPs for the use in other species than described in the product information, enabling the treatment of an animal when there is no authorised VMP available for this species. Cascade prescription can explain the occurrence of noncompliances of substances without MRL in a particular animal product.

In case non-compliances were reported for a substance (Q3), this directly resulted in classifying the substance as medium priority. Q3 was evaluated according to KAP data, RASFF notifications and EFSA annual reports on national monitoring results. A complication in answering Q3 for goat and sheep is that EFSA reports these as a single category 'sheep/goats'. Only in some cases, additional information is available on the precise animal species for which the non-compliance was reported. However, in case no further specification was provided, the non-compliant result was taken into account for both species as a worst-case approach. For the evaluation of sheep/goat, non-compliances reported for sheep and/or goat milk were also taken into account, since the presence of residues in tissue in these cases cannot be excluded. Also, there is no structural data collection for antibiotic use in goat and sheep, impeding the evaluation of Q4 - is the substance regularly used in this animal species. Data were, therefore, derived from two individual national surveys. The first one was on the use of antibiotics in sheep and goat farming, commissioned by the SDa and executed by GD Animal Health (Santman et al., 2013). Data were collected from 12 veterinary practices supporting a total of 
5399 farms keeping small ruminants during 2011 and 2012. This was estimated to represent $16 \%$ of the total number of animals. The second survey was a follow up study performed by WUR (Verkaik et al., 2015) on prescriptions during 2013 only including sheep. For this survey, individual sheep farmers were asked to provide information on antibiotic (and antiparasitic) usage. A total of 127 responses were obtained, representing $\sim 1,5 \%$ of the number of sheep farms. Due to this much lower number, these data were only used to support a decision in case the 2011-2012 data were indecisive.

Prescription frequency was used as a determinant. A cut off of 10 prescriptions per product was used for 2011 and 2012 data. If only in one of the 2 years this threshold was exceeded, additionally the 2013 data were used (if the number of prescriptions $\geq 1$, Q4 'is the substance regularly used in this species' was answered positively). Unfortunately, Santman et al. (2013) only provided data for 'small ruminants', precluding a differentiation between sheep and goat. We, therefore, had to use the same data for answering Q4 for goat and sheep, which inevitably results in an overrepresentation of some substances for one of the two species. For all but one (florfenicol in sheep) of the substances reported to be regularly prescribed for sheep and/or goat (Q4: Y) no species specific VMP is available, implying cascade prescription. The minimum statutory withdrawal period associated with cascade prescription is 7 days for eggs and milk and 28 days for meat. So Q5 - 'do drugs with this active substance have a long withdrawal period?' is answered positively for these substances, yielding a medium priority classification for all substances regularly used. Due to the limited possibilities to discriminate between these two species, the outcome of the evaluation is essentially identical. The only difference in prioritisation concerns sulfadimethoxin, due to a non-compliant result in sheep (originating from France). For phenoxypenicillin, also a non-compliance in sheep was reported (2013, Spain), while no MRL has been set for this species. As a result, Q4 on possible use was answered positively, resulting in a classification as medium priority.

Besides the antibiotic substances included in the evaluation, the prescriptions in the survey also showed that several substances were used that are NOT allowed for food producing species (clindamycin, orbifloxacin, polymyxin, fusidic acid, chloramphenicol and metronidazole). These prescriptions ( $3 \%$ of all prescriptions) probably concern topical sprays, dermal, ear and eye products. Although, considering the route of administration, the risk for residues in edible tissue is probably limited, this is a matter of concern, in particular for chloramphenicol and metronidazole, which are prohibited (A6) substances.

For horse, only a very limited number of non-compliances was reported. Amoxicillin, benzylpenicillin, lincomycin, as well as three sulphonamides, end up as medium priority because of a positive Q3 answer. Other non-compliances reported for horse concerned substances that already received high priority based on Q1. A dihydrostreptomycin non-compliant result has to be attributed to cascade use, since no MRL is established for this substance in horse. Similar to the previous category of animal species, the answer to Q4 - is the substance regularly used in this animal-, is based on data from an SDa survey in which 24 veterinary practices provided information on prescribed antibiotics during the years 2012-2014 (SDa, 2016). The conclusion of the report was that overall antibiotic use in horses is low, DDDA representing an average treatment of 5.6 days per 10 years. Underlying substance specific data were used to answer Q4, though it should be taken into account that these data on VMP use are somewhat outdated. The data show that for the majority of the substances for which substantial use is reported (> 50,000 DDDA), no product registered for horses is available. This implies that these substances are applied through cascade prescription and end up as medium priority based on the associated withdrawal time of at least 28 days. For some substances, prescription can be accounted for by their mentioning in the 'Formularium Paard' (WVAB, 2016), but there is a considerable number of additional substances (such as neomycin, dihydrostreptomycin, marbofloxacin, enrofloxacin, ceftiofur and tulathromycin) for which this does not apply. It should be noted that this concerns several high priority substances.

With respect to milk, medium priority was assigned to 16 substances based on the outcome of Q3 (non-compliances). Among these were two substances without an MRL in milk: doxycycline and florfenicol. These findings make sense assuming that substances regularly used in bovine may end up in the milk, even though they are not to be used in animals producing milk for human consumption. Medium priority was assigned additionally to cefapirin, neomycin, sulfadiazin and sulfadoxin as they are regularly used in dairy cows (Q4), even though no non-compliances in milk were reported. 
Sulfamethoxazole obtained a low priority. However, the antibiotic use data from SDa show an increasing trend, which in the upcoming years may result in a medium priority.

Table 1 Prioritisation of antibiotics per animal product using decision tree III.

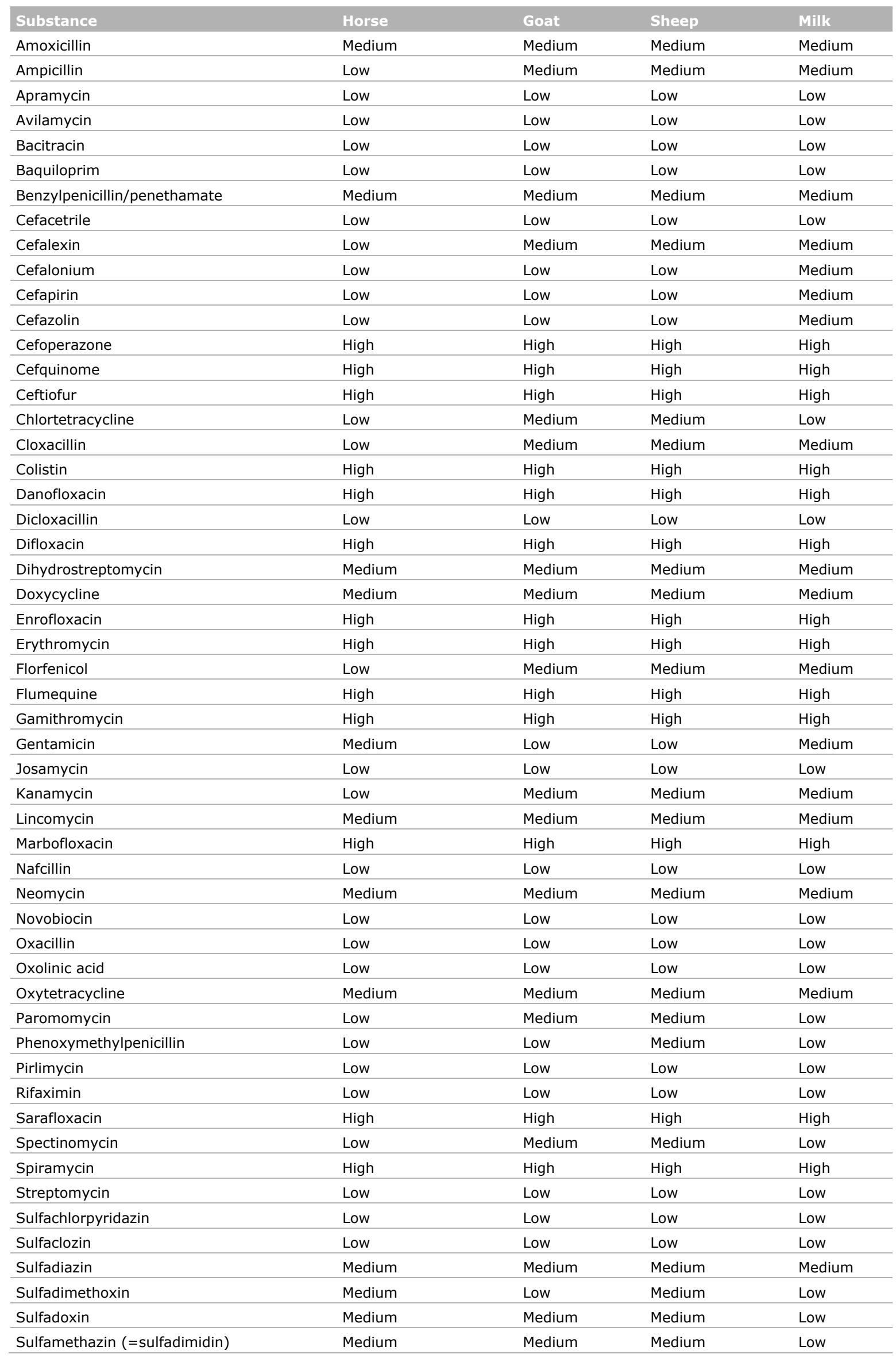




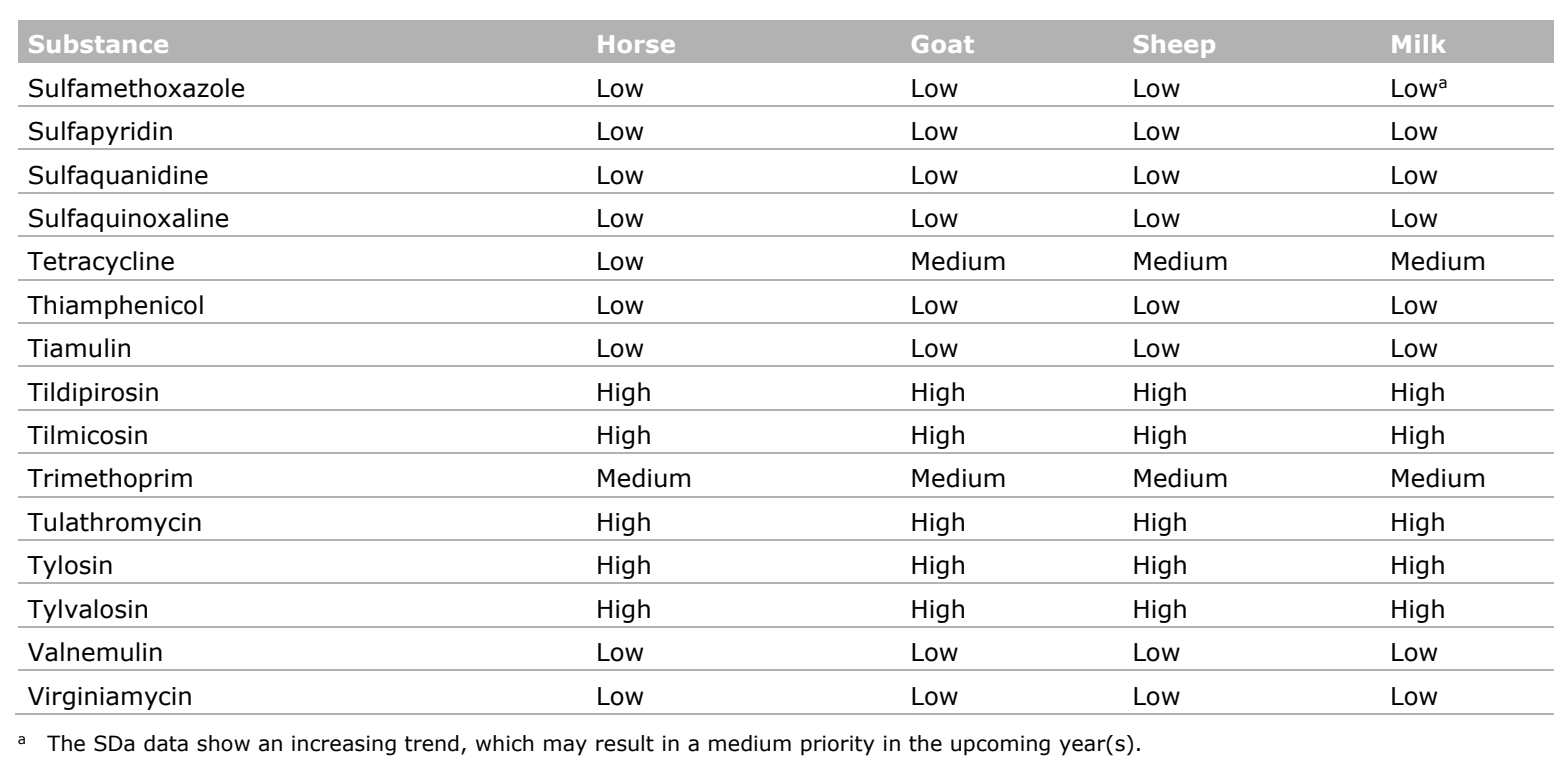

\subsubsection{Matrix for analysis}

Antibiotic residue screening in slaughter animals (includes bovine, porcine, ovine, caprine and equidae) in the Netherlands is performed using the Nouws Antibiotic Test (NAT) (Pikkemaat et al., 2008). The initial screening method is based on the analysis of renal pelvis fluid (pre-urine) and is complemented with analysis of kidney and meat in case the initial screening yields an indication for the presence of antibiotics. The renal pelvis fluid is collected with paper disks that are placed in the incised kidney. The paper disks are subsequently analysed with a microbial growth inhibition method. The main reasons for choosing this strategy are two-fold: 1 ) it is a very efficient method that is easy to scale to medium-throughput and 2) residue concentrations in this matrix are high compared to muscle. Alternatively, a consideration to focus on muscle could be the higher priority with respect to human consumption, as it represents a bigger portion of the human diet. The EURL evaluation of the National Residue Control Plan (NRCP) does not provide recommendations with respect to the preferred matrix, nor an overview of the species and matrices monitored by other EU MSs for the (B1) antibiotic residues (Federol Office of Consumer Protection and Food Safety (BVL) et al., 2019).

\subsection{Antiparasitic agents}

In total, 51 antiparasitic agents were evaluated. These comprise agents acting against endoparasites (anthelmintics) and ectoparasites (insecticides, acaricides), with the exception of parasiticides belonging to chemical classes of the carbamates (evaluated elsewhere in this report), pyrethroids, organophosphorus substances and anticoccidials (antiprotozoals).

The substances were subdivided in four groups: the two major chemical groups of avermectins and benzimidazoles, and two chemically diverse groups of 'other substances', one group with and one group without MRL (of which the last group is not included in Regulation (EU) 37/2010). The first three subgroups were evaluated according to decision tree III for authorised substances. The fourth subgroup was evaluated according to decision tree I for prohibited substances.

\subsubsection{Prioritisation of unauthorised antiparasitics using decision tree I}

Since there were no non-compliances or there was no information on non-compliances for the animal species studied, the prioritisation of the unauthorised substances is identical to the previous set of animal products evaluated (van Asselt et al., 2019). The results of the prioritisation are shown in Table 2 and Annex 2. Since the national residue monitoring programs primarily focus on authorized antiparasitics, these substances are not generally included in monitoring programs of animal products, explaining the absence of non-compliances. 
Table 2 Prioritisation of antiparasitic agents for animal products (including horse, goat, sheep and milk) using decision tree $I$.

\begin{tabular}{|c|c|}
\hline Substance & Prioritisation \\
\hline Afoxolaner & High* \\
\hline Bithionol & Low \\
\hline Fipronil & High \\
\hline Imidacloprid & High \\
\hline Lotilaner & High* \\
\hline Lufenuron & High \\
\hline Methoprene & High \\
\hline Milbemectin & Low \\
\hline Oxantel & High* \\
\hline Pyriprole & High* \\
\hline Pyriproxyfen & Medium \\
\hline Sarolaner & High* \\
\hline Selamectin & High* \\
\hline Spinosad & Low \\
\hline
\end{tabular}

* These substances only have the classification of high priority because there are limited data or information available to answer the questions.

\subsubsection{Prioritisation of authorised antiparasitics using decision tree III}

The results of the prioritisation of avermectins, benzimidazoles and other authorised antiparasitics are indicated in Table 3. More detailed information on the evaluations can be found in Annex 3. Some of the substances (albendazole(oxide)/netobimine and fenbendazole/oxfendazole/febantel) are metabolized in vivo to the same marker residue(s). In the evaluation, these substances were combined since the analytical method used in the monitoring targets the metabolite(s).

Antiparasitics do not concern essential antimicrobials for humans; Q1 is, therefore, answered with 'No' for all substances and all of them subsequently are prioritised either medium or low.

In particular for horse, the number of substances with an MRL (Q2) is very limited. The only noncompliances reported for horse concerned closantel and oxyclozanide, which both lack an MRL for horse. These non-compliances were thus interpreted as a possible use, resulting in a positive answer for Q4. From an application perspective (FIDIN data), the substances that could be of concern for horse are ivermectin, moxidectin, fenbendazole, praziquantel and pyrantel. For the first three substances, usage is substantial and exceeds the threshold of $10 \mathrm{~kg} / \mathrm{year}$ in 2017 . For praziquantel and pyrantel, usage is high, but an MRL is not required since these substances are rapidly excreted, and residues are thus not likely to occur.

For goat, suitable data were virtually lacking. The KAP database yielded one result on abamectin and one on moxidectin in goat milk, but none of the sources used for answering Q3 indicated non-compliant results for the animal itself. Also, information on usage is not available. Since in the Netherlands, goats are primarily kept for milking and the majority is kept indoors, the risk for parasite infections is considered relatively low (https://www.gddiergezondheid.nl/wormen). The VMPs suggested by the GD for treatment of goats are identical to sheep, though none of the substances suggested for deworming of goat has a formal product registration for this animal species. Apart from this, there is one pour-on product containing eprinomectin registered for goat (and bovine and sheep, Eprinex Multi). Considering the lack of data, for all substances suggested for treatment of goats in the guidelines/recommendations provided by GD Animal Health and the EU project WORMCOPS (https://edepot.wur.nl/115690), Q4 was answered positively. Since these substances will be used under cascade, their minimum withdrawal period is 7 days. As a result, these were subsequently assigned a medium priority. 
For sheep, the number of substances for which non-compliances have been reported, and thus end up as medium priority, is substantial. It should be noted that these non-compliances are almost exclusively originating from Ireland and the UK. The availability of usage data for these substances in sheep in the Netherlands is limited to a one year survey for sheep (Verkaik et al., 2015). Based on this survey, the following substances were answered positively for Q4: doramectin, moxidectin mebendazole and monepantel. Of these substances, only monepantel has a short withdrawal time and, therefore, ends up as a low priority.

With respect to milk, the Q2 answer is the result of combining milk and bovine MRLs, assuming that any substance used in bovine has the potential to end up in milk. The non-compliant results for milk (Q3) clearly show the legitimacy of this assumption, since several of the reported substances do not have an MRL in milk. In total, 12 substances were classified as medium priority. The majority was resulting from non-compliant EFSA data. Abamectin and moxidectin were included based on findings in goat milk reported in KAP. Two more substances, oxfendazole and amitraz were considered because their use in bovine is above the cut-off (FIDIN data). Amitraz, however, only has a short withdrawal period and subsequently was assigned a low priority.

Table 3 Prioritisation of antiparasitic agents per animal product in decision tree III.

\begin{tabular}{|c|c|c|c|c|}
\hline Substance & Horse & Goat & Sheep & Milk \\
\hline Ivermectin & Medium & Medium & Medium & Medium \\
\hline Doramectin & Low & Medium & Medium & Medium \\
\hline Moxidectin & Medium & Medium & Medium & Medium $^{\mathrm{a}}$ \\
\hline Emamectin & Low & Low & Low & Low \\
\hline $\begin{array}{l}\text { Fenbendazole/febantel/ } \\
\text { Oxfendazole }\end{array}$ & Medium & Low & Medium & Medium \\
\hline Oxibendazole & Low & Low & Low & Low \\
\hline Mebendazole & Low & Low & Medium & Low \\
\hline Triclabendazol & Low & Low & Medium & Medium \\
\hline Amitraz & Low & Low & Low & Low \\
\hline Clorsulon & Low & Low & Low & Medium \\
\hline Closantel & Medium & Medium & Medium & Medium \\
\hline Cyromazine & Low & Low & Low & Low \\
\hline Derquantel & Low & Low & Low & Low \\
\hline Dicyclanil & Low & Low & Low & Low \\
\hline Diflubenzuron & Low & Low & Low & Low \\
\hline Fluazuron & Low & Low & Low & Low \\
\hline Praziquantel & Low & Low & Low & Low \\
\hline Pyrantel & Low & Low & Low & Low \\
\hline Rafoxanide & Low & Low & Medium & Medium \\
\hline Sisapronil & Low & Low & Low & Low \\
\hline
\end{tabular}

a Medium priority for goat milk only. 


\subsubsection{Matrix for analysis}

Antiparasitics are analysed using LC-MS/MS. For animals, liver is considered the preferred matrix for analysis, since highest levels are to be expected in this matrix. The EURL NRCP evaluation recommends monitoring these substances in either liver or muscle. From an inventory of the species and matrices monitored for anthelmintics by the EU MS, it can be concluded that most countries focus on the analysis of liver (Federol Office of Consumer Protection and Food Safety (BVL) et al., 2019).

\subsection{Carbamates}

In total, 54 carbamates were included in the prioritisation. Four carbamates are approved in the EU as plant protection product: methyocarb, oxamyl, pirimicarb and methomyl. These substances were evaluated using decision tree II. The other carbamates are not approved in the EU and therefore evaluated with decision tree I.

\subsubsection{Prioritisation of unauthorised carbamates using decision tree I}

An overview of the evaluation of carbamates in decision tree I can be found in Table 4. A more detailed table can be found in Annex 4. For all unauthorised carbamates, no non-compliant residue data were found in the last 5 years in the KAP database, RASFF notifications and European monitoring data of VMP residues and other substances in animal products (EFSA, 2015b, 2016b, 2017b, 2018b, $2019 \mathrm{~b}$ ) and in the European monitoring of pesticide residues in food (EFSA, 2015a, 2016a, 2017a, 2018a, 2019a). Therefore, the first question, if there are non-compliant residue data found, is negatively answered and Q3 needs to be answered first for all substances. This question relates to indications for use in production systems for food producing animals.

For many of the carbamates, prioritisation of the carbamates did not differ between the individual animal species. Therefore, the prioritisation for these substances was the same for horse, sheep, goat products and milk as done previously for bovine, porcine and poultry products (van Asselt et al., 2019). These results are presented in Table 4. The carbamates in Table 4 are currently not included in the NP Residues. Results of this NP could thus not be used to get an indication for possible use and other data sources were used to answer Q3. The Pesticide Manual (Turner, 2015) and the Pesticide Properties Database (https://sitem.herts.ac.uk/aeru/ppdb/en/atoz.htm) were used to identify carbamates that are obsolete meaning they are no longer manufactured or marketed for crop protection use and thus not available for use. As a result, these carbamates obtained a low priority for monitoring. For carbamates not listed in the Pesticide Properties Database, their use in the US and other countries was evaluated as well as their availability on alibaba.com. Carbamates not used in countries outside the EU and not available on internet were prioritised as low priority. In case carbamates were available, but the European pesticide monitoring data of 2013-2017 (EFSA, 2015a, 2016a, 2017a, 2018a, 2019a) did not reveal presence of these carbamates in all monitored animal products, they were also classified as low priority. For some carbamates, Q3 was answered as 'unknown'. For these substances, Q2 on human health effects was answered. In case a human health effect could not be excluded, the substance was classified as a high priority. An asterisk was added to highlight that these substances only have the classification 'high priority' because there is no data or information available to answer the questions. 
Table 4 Prioritisation of unauthorised carbamates in animal products currently not included in the NP Residues. See also (van Asselt et al., 2019).

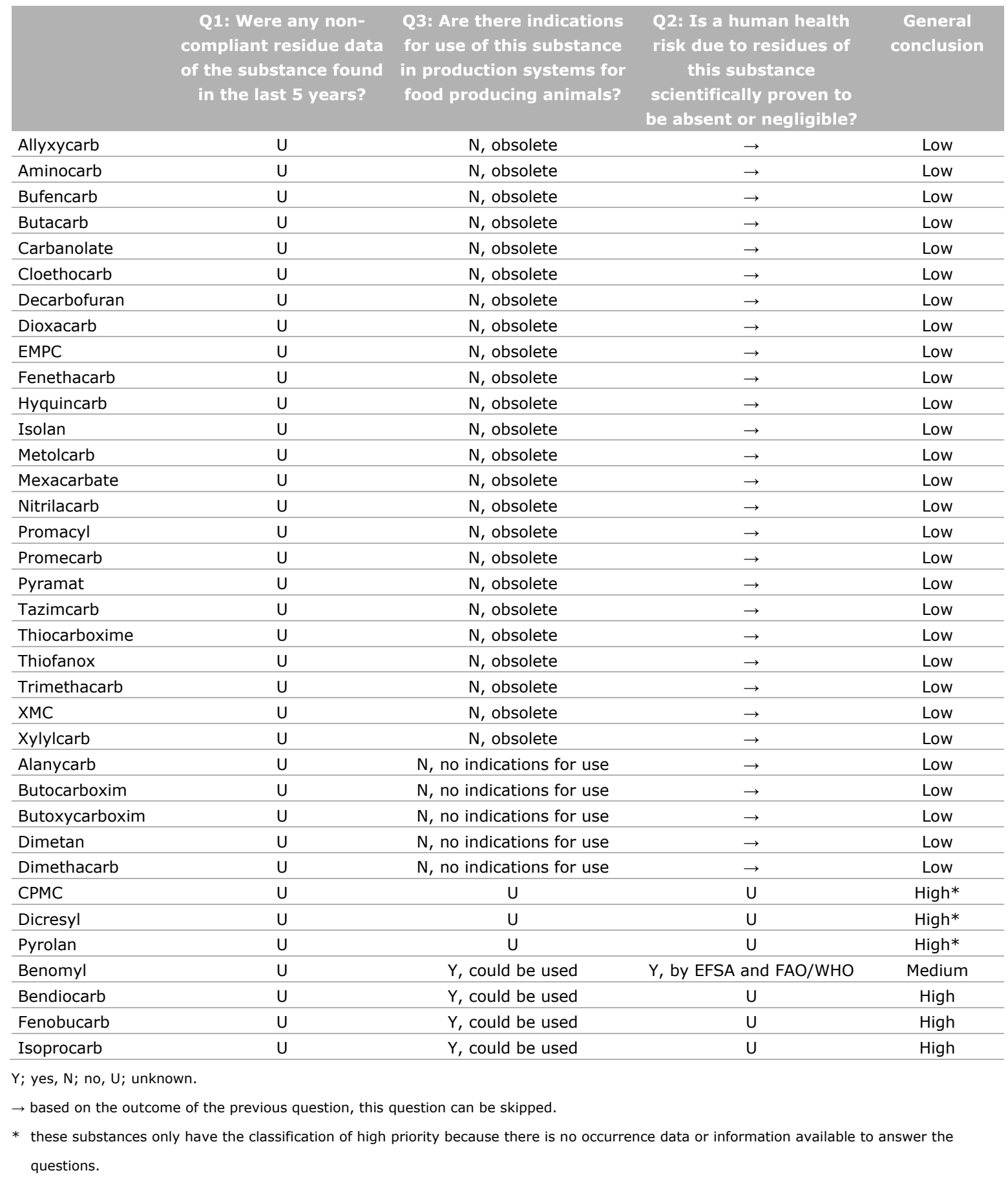

Eleven carbamates were included in the Dutch monitoring, of which ten were evaluated in decision tree I. The other carbamate (methomyl) is authorised in the EU and is therefore evaluated in decision tree II. Monitoring data for the ten unauthorised substances were used to answer Q1 separately for horse, goat, sheep and milk. The final prioritisation for these animal products thus differed, which is why they were included in a separate table (Table 5). Some carbamates will break down into other carbamates. For these carbamates, data of the break-down products were used to answer Q3. In case no residues were found in the monitoring program, this was considered as no indication for use, provided at least 10 samples were taken per year. This resulted in a 'low priority' for carbaryl, ethiofencarb, ethiofencarb-sulfone, ethiofencarb-sulfoxide, and propoxur in horse, sheep and milk. In case the number of samples was too limited to answer Q3, availabilities and registrations in other countries were used to answer this question as well as residues found in plant products. This resulted in a positive answer for Q3 for the following substances in goat: aldicarb and its metabolites aldicarb sulfoxide and aldicarb sulfone, carbaryl, ethiofencarb and its metabolites ethiofencarb-sulfone, 
ethiofencarb-sulfoxide and propoxur and thiodicarb, which metabolises into methomyl. For horse and sheep, 3-hydroxycarbofuran and carbofuran, Q3 was also answered positively based on availability. For all substances that were answered with 'Yes' or 'Unknown' in Q3, possible human health effects needed to be established (Q2).

3-hydroxy carbofuran is a metabolite of carbofuran. Carbofuran can also be used as a plant protection product and was, therefore, evaluated by EFSA. EFSA has indicated that carbofuran is very toxic by ingestion and has a low ARfD of $0.00015 \mathrm{mg} / \mathrm{kg}$ bw/day. It is not scientifically proven that a human health risk is absent or negligible (EFSA, 2009). Therefore, Q2 is negatively answered for carbofuran and 3-hydroxy carbofuran and these substances are classified as 'high priority' for horse, sheep, goat and milk products.

Furathiocarb, benfuracarb and carbosulfan all break down into carbofuran, which was evaluated by EFSA (2009) as described above and were therefore classified as 'high priority' for horse, sheep, goat and milk products.

Aldicarb sulfoxide and aldicarb sulfone are metabolites of aldicarb. Aldicarb was evaluated by EFSA (EFSA, 2006b), because of its use as pesticide on vegetables and citrus fruits. No data on livestock metabolism or residues in livestock or other relevant data were available. Therefore, Q2 was answered with 'unknown' for aldicarb, aldicarb sulfoxide and aldicarb sulfone and these substances are classified as 'high priority' for goat. An asterisk is added to highlight that these substances only have the classification 'high priority' because there is limited information available to answer the questions.

Carbaryl and its use as pesticide were evaluated by EFSA. However, it was concluded that metabolism and feeding studies in livestock were not needed, because the expected animal exposure from apples was considered to be very low. The evaluation was only done for the use of carbaryl as growth regulator (EFSA, 2006a). Therefore, Q2 was answered with 'unknown', and carbaryl classified as 'high priority' with an asterisk for goat.

Ethiofencarb and its metabolites ethiofencarb-sulfone, ethiofencarb-sulfoxide and propoxur were not evaluated by EFSA or JECFA and therefore it was not demonstrated that residues of these substances do not cause adverse effect to the consumer and Q2 was answered with 'unknown'. These substances are classified as 'high priority' with an asterisk for goat.

Thiodicarb breaks down into methomyl, for which EFSA concluded that residues in livestock are not expected. Metabolism studies have shown that methomyl is extensively degraded when this substance is fed to livestock. The parent substance and metabolites were absent in products and tissues (EFSA, 2015c). Therefore, Q2 was positively answered and thiodicarb was classified as 'medium priority' for sheep, goat and milk products.

Table 5 Evaluation of unauthorised carbamates that are currently included in the NP Residues using decision tree $I$.

\begin{tabular}{|c|c|c|c|c|}
\hline Substance & Horse & Goat & Sheep & Milk \\
\hline 3-Hydroxy carbofuran & High & High & High & High \\
\hline Aldicarb & Low & High* & Low & Low \\
\hline Aldoxycarb (aldicarb-sulfoxide) & Low & High* & Low & Low \\
\hline Benfuracarb & High & high & High & High \\
\hline Carbosulfan & High & High & High & High \\
\hline Ethiofencarb & Low & High* & Low & Low \\
\hline Ethiofencarb (ethiofencarb-sulfone) & Low & High* & Low & Low \\
\hline Ethiofencarb (ethiofencarb-sulfoxide) & Low & High* & Low & Low \\
\hline
\end{tabular}

* these substances only have the classification of high priority because there is no occurrence data or information available to answer the questions. 


\subsubsection{Prioritisation of authorised carbamates using decision tree II}

An overview of the evaluation of carbamates in decision tree II can be found in Table 6 . Of the four carbamates approved in the EU, methomyl is not approved in the Netherlands. All four carbamates have an MRL for products of animal origin (Q1).

No non-compliances were found for methiocarb, oxamyl and pirimicarb using RASFF notifications, EFSA reports on VMPs in animal products (EFSA, 2015b, 2016b, 2017b, 2018b, 2019b) and on pesticide residues in food (EFSA, 2015a, 2016a, 2017a, 2018a, 2019a. Since it is unclear whether these substances are included in the EU MSs monitoring programs, Q2 was answered as 'Unknown'. However, these substances are not included in the Dutch monitoring on feed and RASFF showed no non-compliances in feed. Therefore, Q3 on non-compliances in feed was also answered as 'Unknown'. Possible transfer to edible tissues was evaluated using EFSA and FAO/WHO reports. These reports showed that transfer to edible tissues is not to be expected for these substances (see van Asselt et al. (2019) for more details). Therefore, Q4 could be answered negatively and methiocarb, oxamyl and pirimicarb obtained a low priority for monitoring.

Methomyl is included in the Dutch monitoring showing no non-compliances (Q2). Furthermore, no non-compliances in feed were reported (Q3). However, for goat, sheep and milk, this was based on less than 10 measurements per year. Therefore, possible transfer of the substance to edible tissues was checked (Q4). EFSA concluded that residues in livestock are not expected. Metabolism studies have shown that methomyl is extensively degraded when this substance is fed to livestock. The parent substance and metabolites were absent in products and tissues (EFSA, 2015c). Therefore, this substance obtained a low priority for monitoring.

Table 6 Prioritisation of authorised carbamates using decision tree II.

\begin{tabular}{|c|c|c|c|c|c|c|c|c|c|c|}
\hline \multirow[t]{2}{*}{ Carbamates } & \multirow{2}{*}{$\begin{array}{l}\text { Q1. Is there an } \\
\text { ML, MRL or } \\
\text { action limit for } \\
\text { this substance } \\
\text { in animal } \\
\text { tissue? } \\
\text { (EC) } \\
396 / 2005\end{array}$} & \multicolumn{4}{|c|}{$\begin{array}{l}\text { Q2. Were any non-compliant } \\
\text { data of the substance found in } \\
\text { the last five years? }\end{array}$} & \multicolumn{3}{|c|}{$\begin{array}{l}\text { Q3. Were any non- } \\
\text { compliant data of the } \\
\text { substance found in feed in } \\
\text { the last five years? }\end{array}$} & \multirow{2}{*}{$\begin{array}{l}\text { Q4. Is } \\
\text { transfer of } \\
\text { the } \\
\text { substance to } \\
\text { edible tissues } \\
\text { possible? }\end{array}$} & \multirow{2}{*}{$\begin{array}{l}\text { General } \\
\text { conclusion } \\
\\
\text { Priority }\end{array}$} \\
\hline & & EFSA & RASFF & $N P$ & Conclusion & $\begin{array}{l}\text { RASFF } \\
\text { feed }\end{array}$ & NP & Conclusion & & \\
\hline Methiocarb & $Y$ & $\mathrm{~N}$ & $\mathrm{~N}$ & $U$ & U & $\mathrm{N}$ & $U$ & U & $\mathrm{N}$ & Low \\
\hline Oxamyl & Y & $\mathrm{N}$ & $\mathrm{N}$ & $U$ & $\mathrm{U}$ & $\mathrm{N}$ & U & U & $\mathrm{N}$ & Low \\
\hline Pirimicarb & $Y$ & $\mathrm{~N}$ & $\mathrm{~N}$ & $U$ & U & $\mathrm{N}$ & $U$ & $U$ & $\mathrm{~N}$ & Low \\
\hline Methomyl & $\mathrm{Y}$ & $\mathrm{N}$ & $\mathrm{N}$ & $\begin{array}{c}\text { U, } \\
<10 / y\end{array}$ & U & $\mathrm{N}$ & $\begin{array}{c}\text { U, } \\
<10 / y\end{array}$ & U & $\mathrm{N}$ & Low \\
\hline
\end{tabular}

\subsubsection{Matrix for analysis}

Carbamates are currently analysed using LC-MS/MS in meat samples. This matrix is historically set and has been used for some years. Since levels in liver are expected to be higher, liver would be a more appropriate matrix. Using liver samples instead of meat samples is expected to increase the probability of detection. In the past 5 years, no non-compliances for carbamates have been found in the NP Residues. Therefore, it is recommended to use a broad screening method prior to a confirmation method.

\subsection{NSAIDs}

In total, 31 NSAIDs were included in the prioritisation. The NSAIDs that are registered for use and as such included in Regulation (EU) 37/2010 were prioritised using decision tree III $(n=13)$. The NSAIDs that are not mentioned in Regulation (EU) 37/2010 and therefore not allowed for use in food producing animals, were prioritised using decision tree $I(n=18)$. 


\subsubsection{Prioritisation of unauthorised NSAIDs using decision tree I}

This decision tree was used on four different animal products: horse, sheep, goat and milk products. In Table 7, the priority for each animal product is listed. The rationale for these conclusions can be found in Annex 5.

Table 7 Prioritisation of unauthorised NSAIDs per animal product using decision tree $I$.

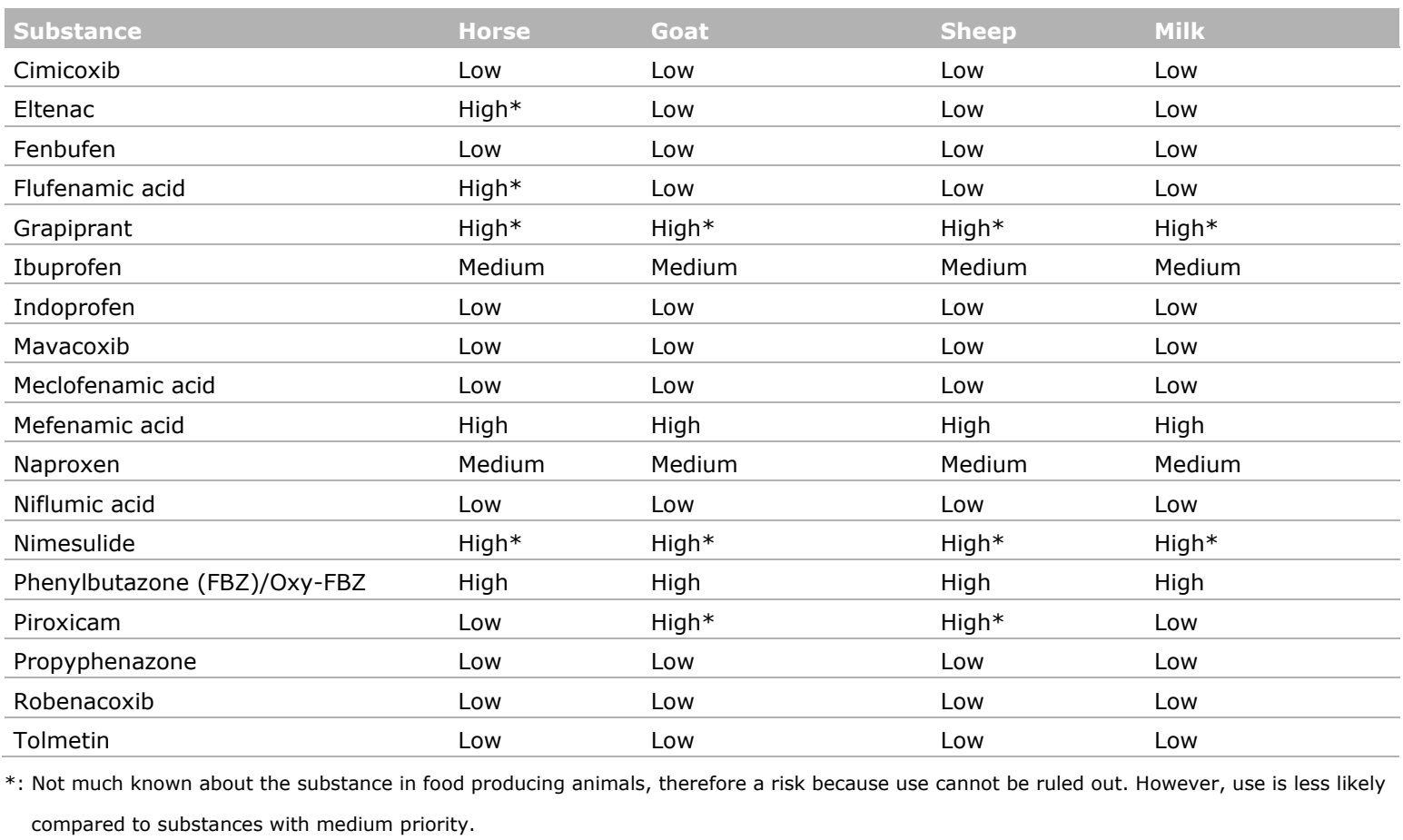

Six of the substances listed in Table 7 were not included in the national monitoring program, nor reported in RASFF or EFSA reports, so Q1 on non-compliances was answered as 'unknown' for all 4 of the animal products. These substances are eltenac, nimesulide, cimicoxib, grapiprant, robenacoxib and mavacoxib.

For the remaining 12 substances, several non-compliant results were found in the animal products horse, sheep and milk in the EFSA reports on veterinary medicinal product residues and other substances in animal products for the period 2013 - 2017 (EFSA, 2015b, 2016b, 2017b, 2018b, 2019b). In the years 2013 - 2017, NSAIDs were not analysed in goat or goat milk according to the Dutch National Plan. Other countries may have analysed goat. This data is, however, unknown as goat is combined with sheep in the EFSA reports. The priority in tree 1 for goat was based on whether there were indications of use of the substances in production systems for food producing animals. In case a non-compliance was indicated for the goat/sheep group, they were included both for goat and for sheep, presenting a worse-case situation. This was the case for mefenamic acid. Furthermore, for sheep, a non-compliance was reported for ibuprofen and mefenamic acid. EFSA reported noncompliances in horse and milk for the substances ibuprofen and phenylbutazone.

For the period 2014-2018, 1 non-compliance for naproxen in horse meat from Brazil was notified in RASFF, 1 non-compliance for flufenamic acid in chilled horse carcass from Belgium and multiple noncompliances for phenylbutazone in different horse meat products were reported by different member states. No non-compliances were reported in the other animal products in RASFF.

The KAP database did not show additional non-compliances for the other substances in tree I.

For the substances which were found non-compliant, Q1 was answered positively; for the other substances, Q1 was answered negatively. 
For the six substances currently not included in the NP Residues, nor found in EFSA reports or RASFF notifications and for monitored substances with no non-compliances, Q3 about the indications of use needed to be answered. First, non-compliances in other animal products were checked. Mefenamic acid had a non-compliant result in bovine and sheep/goat, which was seen as indication for use for horse and milk and Q3 was subsequently answered positively for this substance. For naproxen and phenylbutazone, non-compliances were found in bovine (van Asselt et al., 2019). This was seen as an indication for use in goat and sheep as well, resulting in a positive answer for Q3. In case there were no non-compliances in other animals, the number of samples included in the NP residues was checked. If less than ten samples were taken per year, a possible use could not be excluded (sample size was assumed to be too limited to draw conclusions). This was the case for goat and sheep. For these substances and for substances currently not in the NP Residues, registrations in companion animals and availability on eBay were checked. For the six substances not in the NP residues, only eltenac has a registration in horse, but not for horses used for human consumption. Nevertheless, the registration indicates that use is possible in horses. Therefore, Q3 was answered positively for eltenac in horse. The other 5 substances have a registration in dog and robenacoxib also in cat but are only available on prescription. This alone was not seen as an indication of use. Nevertheless, since nimesulide and grapiprant are available through eBay, Alibaba or elsewhere on the internet, Q3 was answered positively for these substances, as this indicates possible use in food producing animals. For piroxicam, no non-compliances were found in other mammals, resulting in a low priority for horse and milk. However, due to a lack of data for goat and sheep, indication of use was determined. Since piroxicam can be ordered online there is an indication of use, resulting in a positive answer on Q3 for goat and sheep. For all other substances, there was no indication of use found and Q3 was answered negatively, resulting in a low priority.

For the substances with a positive answer on Q1 or Q3, Q2 regarding the human health risk due to residues of this substance needed to be answered. In case of ibuprofen in horse, sheep and milk and naproxen in horse, Q2 was answered positively, resulting in medium priority. These substances are available without prescription in The Netherlands and sold over the counter. This indicates a lower risk when using the product compared to substances that are prescription only. EFSA has performed a risk assessment on residues of phenylbutazone in horse meat and concluded that there was a risk for consumers. Therefore this substance should not be used in animals that enter the food chain (EFSA, 2013). Therefore, Q2 for phenylbutazone in horse, sheep, goat and milk was answered negatively, resulting in a high priority. Kamour et al. (2017) reported that the mefenamic acid toxicity risk in humans is higher compared to other used NSAIDs. Because residues of mefenamic acid has been found before in food producing animals, Q2 was answered negatively, resulting in a high priority. Both for eltenac and for flufenamic acid, there are no studies regarding the safety for humans due to residues of this substance in meat. Therefore, a human health risk is unknown. To make a distinction of a high priority classification based on a lack of data on human health risk from residues in food producing animals, an asterisk is added to the classification in Table 7 (High*). Q2 also needed to be answered for nimesulide and grapiprant for all animal products and piroxicam for goat and sheep. In Europe, the use of human nimesulide products has been restricted because of side effects affecting the liver (EMA, 2012). Piroxicam for humans is also under restricted use (EMA, 2007). Grapiprant is only authorised as a veterinary drug for dogs. A human health risk due to residues of nimesulide, piroxicam and grapiprant in animal products is, however, unknown. This results in the classification High*.

\subsubsection{Prioritisation of authorised NSAIDs using decision tree III}

As mentioned in section 2.5.2, Question 1 of this tree is not relevant for NSAIDs. Therefore, none of the authorised NSAIDs will have a high priority. A total of 13 NSAIDs were evaluated using tree III in the animal products horse, goat, sheep and milk. In Table 8, the priority for each animal species is listed. The rationale for these conclusions can be found in Annex 6 . 
Table 8 Prioritisation of authorised NSAIDs per animal product using decision tree III.

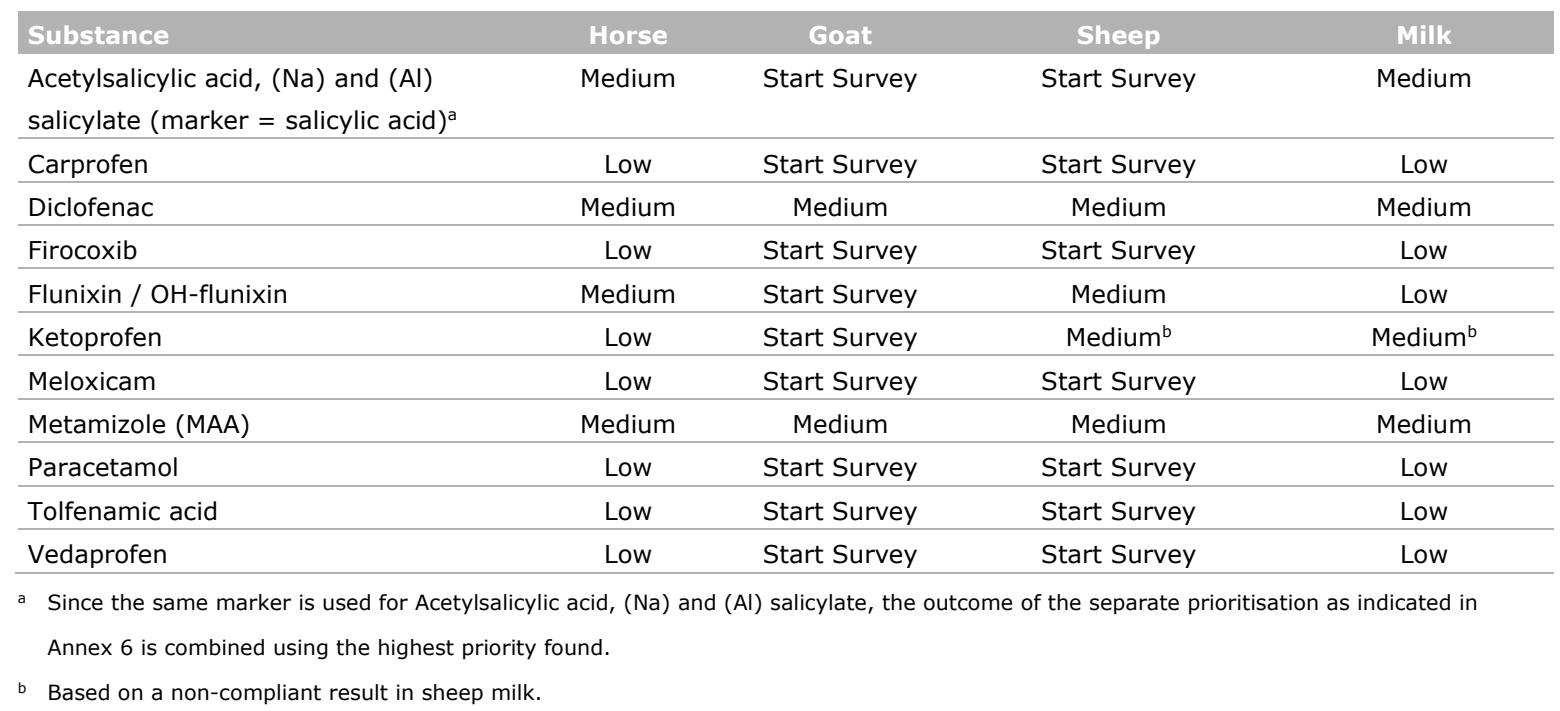

Q2 was evaluated based on the presence or absence of an MRL for the animal species studied. Acetylsalicylic acid, ketoprofen and paracetamol were included in Regulation (EU) 31/2010, but are listed as 'no MRL necessary', while at the same time this classification is limited to specific animal species. These substances do fit in this tree as they are included in the regulation. Q2 was answered negatively in these cases for all animal products, after which Q4 needed to be answered. For sheep, Q2 was answered negatively for all substances and for goat, only meloxicam has an MRL.

For the substances with an MRL in Table 1 of the Annex of regulation (EU) 37/2010, Q3 was answered regarding whether non-compliances were found in the animal product. For acetylsalicylic acid, sodium (Na) salicylate and aluminium (Al) salicylate, the same marker is used (salicylic acid). Since no distinction can be made, monitoring results (non-compliances) for salicylic acid were used for all substances. For horse, salicylic acid and metamizole were found non-compliant, resulting in medium priority for these substances. For milk, salicylic acid and diclofenac were found non-compliant, resulting in medium priority. In case no non-compliances were found for the substances or if it was unknown (due to limited or no sampling), Q4 regarding regular use needed to be answered.

First of all, non-compliances for the animal species were checked. In case a substance was found noncompliant, it resulted in a positive answer for Q4, after which Q5 needed to be answered. For horse, this was the case for diclofenac and salicylic acid. Unspecified non-compliances were found for sheep/goat for diclofenac and metamizole. In this case, a worst-case scenario was assumed, meaning the non-compliance was included both for goat and sheep. Additionally for sheep, diclofenac and flunixin were reported non-compliant. Ketoprofen was found non-compliant in sheep milk and was, therefore also considered for sheep. For milk (bovine), salicylic acid was found non-compliant.

Additionally, ketoprofen was found non-compliant in sheep milk. These non-compliances resulted in a positive answer on Q4. In case no non-compliances were found, registrations in the EU and FIDIN data were consulted. The substances firocoxib, flunixin, ketoprofen, meloxicam and vedaprofen have an EU registration for horse. Additionally, FIDIN data were used to establish whether these were regularly used ( $>100 \mathrm{~kg} /$ year for milk and $>10 \mathrm{~kg} /$ year for horse). This was only the case for flunixin and meloxicam in horse. For goat and sheep, due to lack of monitoring and FIDIN data, usage is unknown, resulting in the conclusion to start a survey for these animal species. For milk, regular use based on EU registration and FIDIN data was determined for meloxicam and metamizole, resulting in a positive answer for Q4 for these substances. For the remaining substances, Q4 was answered negatively, resulting in a low priority for these substances.

In case Q4 was answered positively, Q5 regarding the withdrawal times was answered. In case no withdrawal time has been set for the specific animal species, cascade withdrawal times were taken into account. For horse, Q5 was answered positively for the substances salicylic acid, diclofenac and 
flunixin, resulting in medium priority. For goat, diclofenac and metamizole were answered positively. For sheep, diclofenac, flunixin, ketoprofen and metamizole were answered positively. For milk, Q5 was answered positively for salicylic acid, ketoprofen and metamizole. This results in a medium priority for these substances. Note that the non-compliance for ketoprofen was in sheep milk. Since there is no registration in sheep milk, cascade withdrawal time applies, resulting in medium priority. There is a withdrawal time in cow's milk of 0 hours, resulting in low priority. Based on these data, the worst-case approach was chosen. For all other substances, the questions were answered negatively, resulting in a low priority.

\subsubsection{Matrix for analysis}

Currently, meat is used as the matrix of analysis for NSAIDs. Comparison with other EU MSs shows that meat is the most commonly used matrix for analysis. Some MSs also use kidney or plasma as matrices for horse, sheep and goat. BVL, the EURL for NSAIDs, indicated that the matrix should be selected such that it fulfils the aim. Therefore, targeted sensitive detection of banned substances should be performed in liver and kidney. Detection of banned substances in live animals can be done by examining plasma, serum, blood or milk. Furthermore, the importance of the matrix with respect to human nutrition (e.g. frequency of consumption, baby food) should be taken into account (Federol Office of Consumer Protection and Food Safety (BVL) et al., 2019). 


\section{Discussion}

In this study, a previously established set of substances comprising four groups (antibiotics, antiparasitic agents, carbamates and NSAIDs) were prioritised for an additional set of animal derived products, namely those of horse, goat and sheep and for (cow) milk. The study showed that, in general, there was a lack of data for the animal species studied. For example, in contrast to the animal species studied in the previous report, no structural SDa antibiotic use data were available for goat, sheep and horse. For these animal species, only data from a few confined surveys were available for antibiotics and antiparasitics. Sales data for VMPs could also not be specified for goat and sheep. Sales data for bovine VMPs were available, but differentiation between beef and dairy cows was not possible. SDa antibiotic consumption data were available for dairy cows, but also includes antibiotics provided to the calves on these farms. Furthermore, residue monitoring data in most cases did not differentiate between goat and sheep. On EU level, sheep/goat are also generally categorized as a single species, which is arguable, since in the Netherlands sheep are primarily kept outside for meat production, while goats are primarily kept indoors for milk production. This inevitably will result in differences with respect to VMP use in these species. Goat in this respect will more likely resemble dairy cows. Whenever lack of information precluded further differentiation, a worst-case approach was applied, taking the available data into account for either species.

In conclusion, data for the minor production animal species studied in this research are limited, which may have resulted in an overestimation of the priority class for some species/substance combinations. More accurate prioritisation is only possible when more (structural) residue monitoring and use data become available. Furthermore, it is important to note that only a limited number of VMPs is available to treat these minor species, resulting in relatively frequent cascade application. Finally, for horses, specific legislation applies, which requires further attention (as indicated below).

Horses

With respect to veterinary drug prescriptions in horses, it should be noted that the situation differs significantly from the species dealt with so far. Horses are in principle classified as food producing species but can be excluded from human consumption. Additional to the substances included in Regulation (EU) 37/2010, a 'positive list', i.e. a list of substances essential for the treatment of horses, was established in Commission Regulation (EU) 122/2013 (see Annex 7). For these substances, a withdrawal period of 6 months applies, after which the animal remains acceptable for human consumption. These substances, however, have not been evaluated by the Committee for Medicinal Products for Veterinary Use (CVMP). In the Netherlands, only three of the substances from the list are available as VMP for horse: buprenorphine, acepromazine and guaifenesin. For these substances, CBG-MEB decided to renounce (EC) 122/2013 and to exclude a treated horse from human consumption. If a veterinarian decides to treat an animal with other therapeutic substances, e.g. registered for companion animals, the particular horse also has to be excluded for food production. Administration of drugs to enhance sporting performance (doping) might form another unexpected category of chemical substances that could occur in horses (https://inside.fei.org/fei/cleansport/ad-

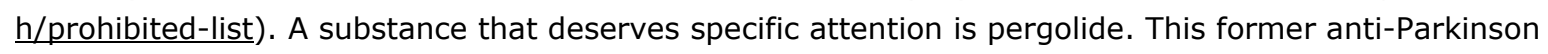
drug is used to treat horses suffering from Pituitary Pars Intermedia Dysfunction (PPID), or Cushing's disease. This is a very common endocrine disorder in aging horses (>20\%) and requires lifelong daily administration of pergolide. Sales data show a steady increase over the years, and in 2019 a second VMP based on this substance was registered. These VMPs are not approved for use in horses intended for human consumption.

The exclusion of a horse from the food chain is effectuated by recording of the treatment in an identification document (passport) for equidae and marking the animal as not intended for slaughter for human consumption (as set out in Regulation (EC) 504/2008). Obviously, considering the information above, the portfolio of available VMPs for horses comprises substances beyond the regular scope applying to food producing species. These products are accessible, as their use is often legal. 
However, fraud with the passport system and identification may occur, therefore dedicated monitoring is recommended.

\subsection{Discussion on antibiotics}

All HPCI classified antibiotics in the evaluated list were categorised as high priority antibiotics. However, as indicated in the previous report (van Asselt et al., 2019), the probability of detecting these residues in animal derived products is expected to be low, since their use has been diminished as a result of increased awareness on the associated resistance risks and restrictive policies with respect to the veterinary use of these antibiotics. However, in our study, risk is defined as a combination of probability and severity. Therefore, although the probability of occurrence may be low, the severity of the presence of these antibiotics is high and these substances thus are classified as high priority.

The availability of VMPs for the minor species dealt with in this report, is problematic. According to the CBG-MEB database, in particular for goat, only a very limited number of products $(n=5)$ is available, containing only two active substances (tylosin and enrofloxacin, both HPCI substances). For sheep, a total of 15 antibiotic substances is available, essentially concerning VMPs for bovine that are also registered for use in sheep. Besides the antibiotic substances included in the current evaluation (substances included in Regulation (EU) 37/2010), the survey on antibiotic prescriptions for small ruminants (Santman et al., 2013), also yielded a number of antibiotics ( $3 \%$ of all prescriptions) NOT allowed for food producing species: clindamycin, orbifloxacin, polymyxin, fusidic acid, chloramphenicol and metronidazole. The risk for residues in edible tissue is expected to be limited, since it probably concerns non-systemic use and treatment of individual animals. Nevertheless, this is a matter of concern, in particular for chloramphenicol and metronidazole, which are prohibited (A6) substances. This implies that any detection of residues has serious enforcement consequences.

For horses, only VMPs containing ampicillin, penicillin, sulfadiazin and sulfadoxin combined with trimethoprim are available for systemic use. This implies cascade use is substantial. Additionally, thiamphenicol, chlortetracycline and cloxacillin are available for topical or ocular use. Several antibiotics that are not included in the current evaluation, because they are not included in Regulation (EU) 37/2010, may be of concern. Ensuing Regulation (EU) 122/2013, horses can be treated with some additional antibiotics not allowed for other food producing species: ticarcillin, azithromycin, rifampicin, amikacin and polymyxin, under the condition of a 6-month withdrawal period. Of these substances, according to SDa data, only (minor) use of azithromycin is reported. Interestingly, the 'Formularium Paard' additionally suggests systemic (cascade) application of clarithromycin (a human antibiotic of the macrolide class) and metronidazole (which belongs to the A6 category of banned substances), emphasizing the animal should be excluded from human consumption (WVAB, 2016). The SDa data indicate a substantial use of the prohibited (A6) substance metronidazole, which could be a concern in case of failing identification systems.

With respect to antibiotics in milk, it should be noted that the EFSA reports contain significant numbers of non-compliances, while in the Netherlands over the reference period all milk samples analysed in the framework of the national control program were found compliant. This may at least partially be attributed to the $100 \%$ control of farm milk by the Dutch Dairy Association (NZO), executed by Qlip. Non-compliances observed in this private sector monitoring program would provide valuable additional input for the evaluation.

\subsection{Discussion on antiparasitics}

In general, increasing drug resistance against these VMPs is being reported, in particular the benzimidazole resistance in helminths is of increasing concern, which might induce increasing use of other substances. It is, therefore, relevant to consult the FIDIN (sales) data regularly to keep track of trends in the use of alternative substances. 
With respect to horses, apparently there is little reason for concern, considering the very limited number of non-compliances. Nevertheless, in particular the deworming of horses is routine practice, which is reflected by substantial usage figures. Veterinarians tend to advice standard deworming in autumn, so it could be considered to focus monitoring for these anthelmintics in that specific period of the year. The same accounts for sheep. As indicated above, the rearing systems between sheep and goat are different in the Netherlands implying anthelmintics use in sheep is more likely than in goat.

Remarkably, the vast majority of the substances ending up with medium priority in milk were classified as such because of the occurrence of non-compliances, even though the substances are not to be used in animals producing milk for human consumption. It would be interesting to determine to what extent these non-compliances originate from young animals that were treated before starting of lactation, as these typically concern long-acting substances. Recently, MRLs have been established for sisapronil for bovine and caprine species. Sisapronil is a new phenylpyrazole (fipronil-like substance) intended for use as a long-acting injectable ectoparasiticide. Although the substance is not to be used in animals producing milk for human consumption, it is recommended to include this substance in the analytical scope and monitoring of milk, in view of its long-acting nature.

\subsection{Discussion on carbamates}

Compared to the other groups of substances evaluated in this study (i.e. antibiotics, antiparasitics an NSAIDs), carbamates seem to be less important to include in the NP Residues. First of all, most carbamates $(n=50)$ are not approved in Europe. Furthermore, the limited scope within the current NP Residues (10 carbamates) did not show any non-compliances (not even any detects) in the past 5 years. Moreover, other EU countries also did not report non-compliances in animal products in the past 5 years. These are all indications that non-compliances for carbamates are less likely to occur. Nevertheless, outside the EU carbamates may still be used, so imported animal products could contain carbamate residues.

Since no non-compliances were found for carbamates, additional information was used to evaluate possible use in animal species: whether the substance was listed as obsolete, the substance's availability and registration in other countries, the online availability (e.g. alibaba.com) and whether residues were found in other food products (fruits and vegetables). For some carbamates, only limited or no information was available to answer the question on possible use. Furthermore, human health effects could not be excluded due to a lack of robust assessments from trustworthy organizations. This resulted in a high priority classification. To indicate that this classification was based on a lack of data, an asterisk was added.

Benomyl is a benzimidazole with a carbamate group. However, it has no cholinesterase inhibitor activity and as such, its use as antiparasitic agent is less likely. Nevertheless, since it belongs to the carbamates, a possible use cannot be excluded. Due to a negligible effect on human health, benomyl was subsequently classified as a medium priority for monitoring.

\subsection{Discussion on NSAIDs}

Within the group of NSAIDs, Na-salicylate, Al-salicylate and acetylsalicylic acid have the same marker residue (salicylic acid). In case a non-compliance is found for salicylic acid, all substances were taken into account. A worst-case approach was used, setting the highest found priority for all substances.

The occurrence of salicylic acid in (cow's) milk should be considered with care, as it is known that this substance can be formed naturally in this matrix.

In 2018, monitoring of NSAIDs in goat and goat milk has been included in the national monitoring plan for the first time. Since the evaluation period was 2013-2017, no national monitoring data for this species was used. Thus, it is recommended to re-evaluate the listed substances for goat when more 
monitoring data are available. For sheep, less than 10 samples are analysed annually for NSAIDs. This is not enough to prioritise substances in sheep using the decision trees. Therefore, it is recommended to start a survey in sheep.

Besides the authorised NSAIDs which are evaluated in tree III in this report, some unauthorised NSAIDs that are evaluated in decision tree I are also listed as controlled medication for horses in the prohibited list of the Fédération Équestre Internationale (FEI); i.e. (oxy)phenylbutazone, ibuprofen, eltenac, meclofenamic acid, naproxen and piroxicam. 'Controlled Medication' are substances that are deemed by the FEI to have therapeutic value and/or be commonly used in equine medicine. This is in line with some of the European prescriptions found for horses not intended for human consumption. Note that some other substances of tree I are listed as banned medication. NSAIDs listed as controlled medication which are available for oral administration but were not included in the prioritisation in this report are deracoxib, indomethacin and suxibuzone. These were not included in the current evaluation as they are not in the original list but could be of concern for residue monitoring in horses, in particular in case of failing identification systems.

\subsection{Discussion on the matrix}

The matrix to be analysed depends on several factors, such as the sampling location (farm or slaughterhouse), feasibility of sampling, practical aspects regarding analyses and the likelihood of detection. The preferred matrix for analysis ideally should be based on residue kinetics allowing to establish the matrix with the highest likelihood of detection. However, over the years, the scope of analytical methods has extended and although the likelihood of detection may differ between substances, for practical reasons, usually the same matrix is used for a broad range of substances. The evaluation of matrices currently used show that some matrices have been selected for historical reasons. This is for example the case for the carbamates, which are currently analysed in meat whereas liver would be a more appropriate matrix. For the other groups of substances, there are currently no reasons to adapt the matrix for analysis. 


\section{$5 \quad$ Conclusions and recommendations}

This study showed that the decision trees could be used to classify substances into low, medium and high priority for monitoring. However, compared to the previous study (van Asselt et al., 2019), the available data for horse, goat and sheep were much more limited. Therefore, many questions had to be answered with 'unknown' resulting in a higher priority than might be needed if data would be available (a worst-case approach was used). Furthermore, only a limited number of VMPs is available to treat these minor species, resulting in relatively frequent cascade application. Moreover, in many cases, a distinction between goat and sheep data was impossible, as these are often considered as a single category in reports on monitoring data or on antibiotics use. Therefore, given the lack of data, the prioritisation of substances for these animal species should be seen as a worst-case classification. Once more (specific) data become available, the prioritisation could be updated and will become more realistic.

The high priority antibiotics were the same as in the previous study, since these are based on the HPCI classification from the WHO and thus independent of the animal species studied. The prioritisation of the unauthorised antiparasitics and the 36 unauthorised carbamates was also the same as in the previous study, since the input data in the current study were similar to the previous study. For the remaining substances in the group of antibiotics, antiparasitics, carbamates and NSAIDs, prioritisation in some cases differed from the previous study. The results of the classifications can be found in Tables 1-8 of this report.

Considerations for focussing residue monitoring on a particular matrix can be diverse: the matrix contains the highest residue concentrations so is considered easiest or most likely to detect noncompliances in, the matrix is logistically and/or technically the most attractive, or the matrix is considered most relevant from a consumption perspective. Theoretically, the 'best' matrix could differ between substances in a single chemical group (results from residue kinetics combined with MRL concentration in specific matrices), but from a cost-effectiveness point of view it is profitable to include as many substances as possible in a multi-residue method targeting a single matrix. Regarding the matrix used for analysis of a particular group of substances, the Dutch national monitoring program is in line with the majority of the EU member states.

Based on the results of this study, we recommend the following:

- Substances with a medium or high priority should be included in the national monitoring program. In case multi-methods are used, the low priority substances included in the method can remain within the scope.

- The prioritisation should be updated regularly (preferably every five years) using recent residue monitoring and usage data. The more data is available, the more accurate the substances can be classified using the decision trees. This is especially the case for substances for which there is currently a lack of data resulting in either a 'High*' classification or in a recommendation to 'start a survey'. Such a survey will result in more data allowing for a more realistic classification of substances.

- The structural monitoring of antibiotics usage (by SDa) should be expanded with horse, sheep and goat, since these data are essential for an accurate prioritisation.

- Additionally, it is recommended to extend data collection on VMP use to all prescription-only VMPs (URA, UDA and UDD) in order to obtain an accurate insight in other VMP categories.

- Since a survey on small ruminants showed that around $3 \%$ of the prescriptions involves unauthorised antibiotics, more awareness should be raised among veterinarians and farmers on the reasons for prohibiting A6 substances, emphasising the consequences/risks of usage.

- Substances ensuing Regulation (EU) 122/2013 and the FEI prohibited substances list should be surveyed additionally for horses. A dedicated monitoring for horse is recommended to obtain more information on the VMP residues found. 
- Monitoring for residues of anthelmintics should (at least partially) focus on the autumn when most deworming is performed.

- Carbamates should preferably be analysed in liver samples instead of the currently used meat samples since levels in liver are expected to be higher.

- New developments relevant for prioritising hazards should be followed closely, such as the introduction of new VMPs, amongst others as a response to emerging diseases, resistance development and other livestock farming related problems.

- Besides the prioritised National Residue Control Plan, regular 'random' surveys should be performed to prevent overlooking emerging hazards. Preferably, broad screening techniques are used for this purpose. 


\section{Acknowledgements}

Marca Schrap and Jacqueline Steenbergen-Biesterbos (NVWA-BuRO) are kindly thanked for their input to this research. Maryvon Noordam, Ron Hoogenboom, Ine van der Fels-Klerx and Bjorn Berendsen (WFSR) are kindly thanked for critically reading this report. Marlou van Iersel (WFSR) is kindly thanked for providing us information on the national monitoring program and for valuable discussions on the project. Tina Zuidema (WFSR) is acknowledged for her input in the evaluation of the matrices for analysis of the four studied groups of substances. Inge van Geijlswijk (SDa) and Marijn Poldermans (FIDIN) are kindly thanked for providing us the necessary data for our research. 


\section{References}

BVL-CRL, RIVM-CRL and AFSSA-LERMVD-CRL, 2007. CRL Guidance Paper - CRLs view on state of the art analytical methods for national residuecontrol plans.

Danaher M, Shanahan C, Butler F, Evans R, O'Sullivan D, Glynn D, Camon T, Lawlor P and O'Keeffe M, 2016. Risk-based approach to developing a national residue sampling plan for testing under European Union regulation for veterinary medicinal products and coccidiostat feed additives in domestic animal production. Food Additives \& Contaminants: Part A, 1-11.

EFSA, 2006a. Conclusion regarding the peer review of the pesticide risk assessment of the active substance carbaryl. EFSA Journal, 4, 80r.

EFSA, 2006b. Opinion of the Scientific Panel on Plant protection products and their residues (PPR) related to the safety of aldicarb MRLs. EFSA Journal, 4, 409.

EFSA, 2009. Conclusion on pesticide peer review regarding the risk assessment of the active substance carbofuran. EFSA Journal, 7, 310r.

EFSA, 2013. Joint Statement of EFSA and EMA on the presence of residues of phenylbutazone in horse meat. EFSA Journal, 11, 3190.

EFSA, 2015a. The 2013 European Union report on pesticide residues in food. EFSA Journal, 13, 4038.

EFSA, 2015b. Report for 2013 on the results from the monitoring of veterinary medicinal product residues and other substances in live animals and animal products. EFSA Supporting Publications, $12,723 \mathrm{E}$.

EFSA, 2015c. Review of the existing maximum residue levels for methomyl according to Article 12 of Regulation (EC) No 396/2005. EFSA Journal, 13, 4277.

EFSA, 2016a. The 2014 European Union Report on Pesticide Residues in Food. EFSA Journal, 14, e04611.

EFSA, 2016b. Report for 2014 on the results from the monitoring of veterinary medicinal product residues and other substances in live animals and animal products. EFSA Supporting Publications, 13, 923E.

EFSA, 2017a. The 2015 European Union report on pesticide residues in food. EFSA Journal, 15, e04791.

EFSA, 2017b. Report for 2015 on the results from the monitoring of veterinary medicinal product residues and other substances in live animals and animal products. EFSA Supporting Publications, $14,1150 \mathrm{E}$.

EFSA, 2018a. The 2016 European Union report on pesticide residues in food. EFSA Journal, 16, e05348.

EFSA, 2018b. Report for 2016 on the results from the monitoring of veterinary medicinal product residues and other substances in live animals and animal products. EFSA Supporting Publications, $15,1358 \mathrm{E}$.

EFSA, 2019a. The 2017 European Union report on pesticide residues in food. EFSA Journal, 17, 152 p.

EFSA, 2019b. Report for 2017 on the results from the monitoring of veterinary medicinal product residues and other substances in live animals and animal products. EFSA Supporting Publications, EN-1578, $88 \mathrm{p}$.

EMA, 2007. Questions and Answers on the Review of Piroxicam. EMEA/264578/2007.

EMA, 2012. Assessment report for Nimesulide containing medicinal products for systemic use, accessed at: https://www.ema.europa.eu/documents/referral/nimesulide-article-31-referralassessment-report_en.pdf. EMA/73856/2012.

EMA, 2015. Principles on assignment of defined daily dose for animals 4 (DDDA) and defined course dose for animals (DCDA) - draft. Available at: https://www.ema.europa.eu/en/documents/scientific-guideline/principles-assignment-defineddaily-dose-animals-defined-course-dose-animals-draft_en.pdf.

FAO, 2015. PROGRESS IN PESTICIDE RISK ASSESSMENT AND PHASING-OUT OF HIGHLY HAZARDOUS PESTICIDES IN ASIA. accessed at: http://www.fao.org/3/a-i4362e.pdf.

Federol Office of Consumer Protection and Food Safety (BVL), Wageningen Food Safety Research (WFSR), Danish Technical University (DTU) and French Agency for Food EaOHSA 2019. Joint 
Report - NRCP Evaluation 2019 of the EURLs for Pharmacologically Active Substances in Berlin, Fougeres, Kgs. Lyngby and Wageningen. 518 p.

Kamour A, Crichton S, Cooper G, Lupton DJ, Eddleston M, Vale JA, Thompson JP and Thomas SHL, 2017. Central nervous system toxicity of mefenamic acid overdose compared with other NSAIDs: an analysis of cases reported to the United Kingdom National Poisons Information Service. British journal of clinical pharmacology, 83, 855-862.

Pikkemaat MG, Dijk SO-v, Schouten J, Rapallini M and van Egmond HJ, 2008. A new microbial screening method for the detection of antimicrobial residues in slaughter animals: The Nouws antibiotic test (NAT-screening). Food Control, 19, 781-789.

Postma M, Sjölund M, Collineau L, Lösken S, Stärk KDC, Dewulf J and consortium obotM, 2014. Assigning defined daily doses animal: a European multi-country experience for antimicrobial products authorized for usage in pigs. Journal of Antimicrobial Chemotherapy, 70, 294-302.

Santman I, Luttikholt S, van den Brom R, Gonggrijp M, Hage H and Vellema P $(G D$,$) , 2013. Nulmeting$ antibioticagebruik bij kleine herkauwers. 33 p.

SDa 2016. Antibioticumgebruik bij paarden - Uitkomsten van een survey onder dierenartsenpraktijken over de jaren 2012 t/m 2014. 23 p.

SDa 2018. Usage of Antibiotics in Agricultural Livestock in the Netherlands in 2017 - Trends and benchmarking of livestock farms and veterinarians. $100 \mathrm{p}$.

Turner JA, 2015. Pesticide Manual. 17th Edition.

van Asselt ED, Noordam MY, Pikkemaat MG and Dorgelo FO, 2018a. Risk-based monitoring of chemical substances in food: prioritization by decision trees. Food Control.

van Asselt ED, Noordam MY, Pikkemaat MG and Dorgelo FO, 2018b. Risk-based monitoring of chemical substances in food: Prioritization by decision trees. Food Control, 93, 112-120.

van Asselt ED, Noordam MY, Pikkemaat MG, van Ginkel LA and Sterk SS (RIKILT Wageningen University and Research), 2018c. Revision of the National Residue Control Plan - Application on the Red Meat Supply Chain. 2018.003, 66 p.

van Asselt ED, Pikkemaat MG, Jansen L and Hoek- van den Hil EF (RIKILT), 2019. Prioritisation of chemical substances for national monitoring - Applied to antibiotics, antiparasitic agents, carbamates and non-steroidal anti-inflammatory drugs (NSAIDs). 2019.008, 76 p.

Verkaik JC, Antonis AFG, Ploeger H, Vellema P and Bokma-Bakker MH (Wageningen UR Livestock Research), 2015. Een verdiepend onderzoek naar het medicijngebruik in de Nederlandse schapenhouderij: aanknopingspunten voor verdere optimalisatie.

WHO (World Health Organization), 2017. Critically important antimicrobials for human medicine -5 th revision. $48 \mathrm{p}$.

WVAB 2016. Formularium Paard. 34 p. 


\section{Annex 1 Prioritisation of antibiotics using decision tree III}

Table A1.1 Prioritisation of antibiotics in horse.

\begin{tabular}{|c|c|c|c|c|c|c|c|c|c|c|c|c|}
\hline \multirow{2}{*}{$\begin{array}{l}\text { Italics: not commonly } \\
\text { included in scope } \\
\text { Substance }\end{array}$} & \multirow{2}{*}{$\begin{array}{l}\text { Q1: is this an } \\
\text { essential } \\
\text { antimicrobial for } \\
\text { humans? } \\
\text { Concl Q1 }\end{array}$} & \multirow{2}{*}{$\begin{array}{l}\text { Q2: Have MRLs been } \\
\text { set for this } \\
\text { substance in this } \\
\text { animal species? } \\
\text { Concl Q2 }\end{array}$} & \multicolumn{4}{|c|}{$\begin{array}{l}\text { Q3: were any non-compliant residue } \\
\text { data of the substance found in the last } \\
\text { five years? }\end{array}$} & \multicolumn{3}{|c|}{$\begin{array}{l}\text { Q4: Is the substance } \\
\text { regularly used in this animal } \\
\text { species? }\end{array}$} & \multicolumn{2}{|c|}{$\begin{array}{l}\text { Q5: Do drugs with this active } \\
\text { substance have a long } \\
\text { withdrawal period? }\end{array}$} & \multirow{2}{*}{$\begin{array}{c}\begin{array}{c}\text { Conclusion } \\
\text { priority }\end{array} \\
\text { Horse }\end{array}$} \\
\hline & & & KAP & RASFF & EFSA & Concl Q3 & NC & $\begin{array}{c}\text { SDa } \\
(>50000 \\
\text { DDDA })\end{array}$ & Concl Q4 & $\begin{array}{l}\text { Withdrawal } \\
\text { time }\end{array}$ & Concl Q5 & \\
\hline amoxicillin & $\mathrm{N}$ & $Y$ & & & $\mathrm{Y}$ & $\mathrm{Y}$ & $\rightarrow$ & $\rightarrow$ & $\rightarrow$ & $\rightarrow$ & $\rightarrow$ & medium \\
\hline ampicillin & $\mathrm{N}$ & $\mathrm{Y}$ & & & & $\mathrm{N}$ & $\mathrm{N}$ & $\mathrm{Y}$ & $\mathrm{Y}$ & $\mathrm{N}$ & $\mathrm{N}$ & low \\
\hline apramycin & $\mathrm{N}$ & $\mathrm{N}$ & $\rightarrow$ & $\rightarrow$ & $\rightarrow$ & $\rightarrow$ & $\mathrm{N}$ & $\mathrm{N}$ & $\mathrm{N}$ & $\rightarrow$ & $\rightarrow$ & low \\
\hline avilamycin & $\mathrm{N}$ & $\mathrm{N}$ & $\rightarrow$ & $\rightarrow$ & $\rightarrow$ & $\rightarrow$ & $\mathrm{N}$ & $\mathrm{N}$ & $\mathrm{N}$ & $\rightarrow$ & $\rightarrow$ & low \\
\hline bacitracin & $\mathrm{N}$ & $\mathrm{N}$ & $\rightarrow$ & $\rightarrow$ & $\rightarrow$ & $\rightarrow$ & $\mathrm{N}$ & $\mathrm{N}$ & $\mathrm{N}$ & $\rightarrow$ & $\rightarrow$ & low \\
\hline baquiloprim & $\mathrm{N}$ & $\mathrm{N}$ & $\rightarrow$ & $\rightarrow$ & $\rightarrow$ & $\rightarrow$ & $\mathrm{N}$ & $\mathrm{N}$ & $\mathrm{N}$ & $\rightarrow$ & $\rightarrow$ & low \\
\hline benzylpenicillin/penethamate & $\mathrm{N}$ & $\mathrm{Y}$ & & $\mathrm{Y}$ & & $\mathrm{Y}$ & $\rightarrow$ & $\rightarrow$ & $\rightarrow$ & $\rightarrow$ & $\rightarrow$ & medium \\
\hline cefacetril & $\mathrm{N}$ & $\mathrm{N}$ & $\rightarrow$ & $\rightarrow$ & $\rightarrow$ & $\rightarrow$ & $\mathrm{N}$ & $\mathrm{N}$ & $\mathrm{N}$ & $\rightarrow$ & $\rightarrow$ & low \\
\hline cefalexine & $\mathrm{N}$ & $\mathrm{N}$ & $\rightarrow$ & $\rightarrow$ & $\rightarrow$ & $\rightarrow$ & $\mathrm{N}$ & $\mathrm{N}$ & $\mathrm{N}$ & $\rightarrow$ & $\rightarrow$ & low \\
\hline cefalonium & $\mathrm{N}$ & $\mathrm{N}$ & $\rightarrow$ & $\rightarrow$ & $\rightarrow$ & $\rightarrow$ & $N$ & $\mathrm{~N}$ & $\mathrm{~N}$ & $\rightarrow$ & $\rightarrow$ & low \\
\hline cefapirin & $\mathrm{N}$ & $\mathrm{N}$ & $\rightarrow$ & $\rightarrow$ & $\rightarrow$ & $\rightarrow$ & $N$ & $\mathrm{~N}$ & $\mathrm{~N}$ & $\rightarrow$ & $\rightarrow$ & low \\
\hline cefazolin & $\mathrm{N}$ & $\mathrm{N}$ & $\rightarrow$ & $\rightarrow$ & $\rightarrow$ & $\rightarrow$ & $\mathrm{N}$ & $\mathrm{N}$ & $\mathrm{N}$ & $\rightarrow$ & $\rightarrow$ & low \\
\hline cefoperazon & $\mathrm{Y}$ & $\rightarrow$ & $\rightarrow$ & $\rightarrow$ & $\rightarrow$ & $\rightarrow$ & $\rightarrow$ & $\rightarrow$ & $\rightarrow$ & $\rightarrow$ & $\rightarrow$ & high \\
\hline cefquinome & $\mathrm{Y}$ & $\rightarrow$ & $\rightarrow$ & $\rightarrow$ & $\rightarrow$ & $\rightarrow$ & $\rightarrow$ & $\rightarrow$ & $\rightarrow$ & $\rightarrow$ & $\rightarrow$ & high \\
\hline ceftiofur & $Y$ & $\rightarrow$ & $\rightarrow$ & $\rightarrow$ & $\rightarrow$ & $\rightarrow$ & $\rightarrow$ & $\rightarrow$ & $\rightarrow$ & $\rightarrow$ & $\rightarrow$ & high \\
\hline chlortetracycline & $\mathrm{N}$ & $Y$ & & & & $\mathrm{~N}$ & $N$ & $\mathrm{~N}$ & $\mathrm{~N}$ & $\rightarrow$ & $\rightarrow$ & low \\
\hline cloxacillin & $\mathrm{N}$ & $Y$ & & & & $\mathrm{~N}$ & $N$ & $\mathrm{~N}$ & $\mathrm{~N}$ & $\rightarrow$ & $\rightarrow$ & low \\
\hline colistin & $Y$ & $\rightarrow$ & $\rightarrow$ & $\rightarrow$ & $\rightarrow$ & $\rightarrow$ & $\rightarrow$ & $\rightarrow$ & $\rightarrow$ & $\rightarrow$ & $\rightarrow$ & high \\
\hline danofloxacin & $Y$ & $\rightarrow$ & $\rightarrow$ & $\rightarrow$ & $\rightarrow$ & $\rightarrow$ & $\rightarrow$ & $\rightarrow$ & $\rightarrow$ & $\rightarrow$ & $\rightarrow$ & high \\
\hline dicloxacillin & $\mathrm{N}$ & $\mathrm{Y}$ & & & & $\mathrm{N}$ & & $\mathrm{N}$ & $\mathrm{N}$ & $\rightarrow$ & $\rightarrow$ & low \\
\hline difloxacin & $\mathrm{Y}$ & $\rightarrow$ & $\rightarrow$ & $\rightarrow$ & $\rightarrow$ & $\rightarrow$ & $\rightarrow$ & $\rightarrow$ & $\rightarrow$ & $\rightarrow$ & $\rightarrow$ & high \\
\hline dihydrostreptomycin & $\mathrm{N}$ & $\mathrm{N}$ & $\rightarrow$ & $\rightarrow$ & $\rightarrow$ & $\rightarrow$ & $\mathrm{Y}$ & $\mathrm{Y}$ & $\mathrm{Y}$ & cascade & $\mathrm{Y}$ & medium \\
\hline doxycyclin & $\mathrm{N}$ & $\mathrm{N}$ & $\rightarrow$ & $\rightarrow$ & $\rightarrow$ & $\rightarrow$ & $N$ & $\mathrm{Y}$ & $\mathrm{Y}$ & cascade & $\mathrm{Y}$ & medium \\
\hline
\end{tabular}




\begin{tabular}{|c|c|c|c|c|c|c|c|c|c|c|c|c|}
\hline \multirow{2}{*}{$\begin{array}{l}\text { Italics: not commonly } \\
\text { included in scope } \\
\text { Substance }\end{array}$} & \multirow{2}{*}{$\begin{array}{l}\text { Q1: is this an } \\
\text { essential } \\
\text { antimicrobial for } \\
\text { humans? } \\
\text { Concl Q1 }\end{array}$} & \multirow{2}{*}{$\begin{array}{l}\text { Q2: Have MRLs been } \\
\text { set for this } \\
\text { substance in this } \\
\text { animal species? } \\
\text { Concl Q2 }\end{array}$} & \multicolumn{4}{|c|}{$\begin{array}{l}\text { Q3: were any non-compliant residue } \\
\text { data of the substance found in the last } \\
\text { five years? }\end{array}$} & \multicolumn{3}{|c|}{$\begin{array}{l}\text { Q4: Is the substance } \\
\text { regularly used in this animal } \\
\text { species? }\end{array}$} & \multicolumn{2}{|c|}{$\begin{array}{l}\text { Q5: Do drugs with this active } \\
\text { substance have a long } \\
\text { withdrawal period? }\end{array}$} & \multirow[t]{2}{*}{$\begin{array}{c}\text { Conclusion } \\
\text { priority }\end{array}$} \\
\hline & & & KAP & RASFF & EFSA & Concl Q3 & NC & $\begin{array}{l}\text { SDa } \\
(>50000 \\
\text { DDDA) }\end{array}$ & Concl Q4 & $\begin{array}{l}\text { Withdrawal } \\
\text { time }\end{array}$ & Concl Q5 & \\
\hline enrofloxacin & Y & $\rightarrow$ & $\rightarrow$ & $\rightarrow$ & $\rightarrow$ & $\rightarrow$ & $\rightarrow$ & $\rightarrow$ & $\rightarrow$ & $\rightarrow$ & $\rightarrow$ & high \\
\hline erythromycin & Y & $\rightarrow$ & $\rightarrow$ & $\rightarrow$ & $\rightarrow$ & $\rightarrow$ & $\rightarrow$ & $\rightarrow$ & $\rightarrow$ & $\rightarrow$ & $\rightarrow$ & high \\
\hline florfenicol & $\mathrm{N}$ & Y & & & & $\mathrm{N}$ & $\mathrm{N}$ & N & $\mathrm{N}$ & $\rightarrow$ & $\rightarrow$ & low \\
\hline flumequine & $\mathrm{Y}$ & $\rightarrow$ & $\rightarrow$ & $\rightarrow$ & $\rightarrow$ & $\rightarrow$ & $\rightarrow$ & $\rightarrow$ & $\rightarrow$ & $\rightarrow$ & $\rightarrow$ & high \\
\hline gamithromycin & Y & $\rightarrow$ & $\rightarrow$ & $\rightarrow$ & $\rightarrow$ & $\rightarrow$ & $\rightarrow$ & $\rightarrow$ & $\rightarrow$ & $\rightarrow$ & $\rightarrow$ & high \\
\hline gentamicin & $\mathrm{N}$ & Y & & & & $\mathrm{N}$ & $\mathrm{N}$ & $Y$ & Y & cascade & $\mathrm{Y}$ & medium \\
\hline josamycin & $\mathrm{N}$ & $\mathrm{N}$ & $\rightarrow$ & $\rightarrow$ & $\rightarrow$ & $\rightarrow$ & $\mathrm{N}$ & $N$ & $\mathrm{~N}$ & $\rightarrow$ & $\rightarrow$ & low \\
\hline kanamycin & $\mathrm{N}$ & Y & & & & $\mathrm{N}$ & $\mathrm{N}$ & $\mathrm{N}$ & $\mathrm{N}$ & $\rightarrow$ & $\rightarrow$ & low \\
\hline lincomycin & $\mathrm{N}$ & $Y$ & & & $\mathrm{Y}$ & $Y$ & $\rightarrow$ & $\rightarrow$ & $\rightarrow$ & $\rightarrow$ & $\rightarrow$ & medium \\
\hline marbofloxacin & $\mathrm{Y}$ & $\rightarrow$ & $\rightarrow$ & $\rightarrow$ & $\rightarrow$ & $\rightarrow$ & $\rightarrow$ & $\rightarrow$ & $\rightarrow$ & $\rightarrow$ & $\rightarrow$ & high \\
\hline nafcillin & $\mathrm{N}$ & $\mathrm{N}$ & $\rightarrow$ & $\rightarrow$ & $\rightarrow$ & $\rightarrow$ & $\mathrm{N}$ & $\mathrm{N}$ & $\mathrm{N}$ & $\rightarrow$ & $\rightarrow$ & low \\
\hline neomycin & $\mathrm{N}$ & $\mathrm{Y}$ & & & & $\mathrm{N}$ & $\mathrm{N}$ & Y & $\mathrm{Y}$ & cascade & $\mathrm{Y}$ & medium \\
\hline novobiocin & $\mathrm{N}$ & $\mathrm{N}$ & $\rightarrow$ & $\rightarrow$ & $\rightarrow$ & $\rightarrow$ & $\mathrm{N}$ & $\mathrm{N}$ & $\mathrm{N}$ & $\rightarrow$ & $\rightarrow$ & low \\
\hline oxacillin & $\mathrm{N}$ & $\mathrm{Y}$ & & & & $\mathrm{N}$ & $\mathrm{N}$ & $\mathrm{N}$ & $\mathrm{N}$ & $\rightarrow$ & $\rightarrow$ & low \\
\hline oxolinic acid & $\mathrm{N}$ & $\mathrm{Y}$ & & & & $\mathrm{N}$ & $\mathrm{N}$ & $\mathrm{N}$ & $\mathrm{N}$ & $\rightarrow$ & $\rightarrow$ & low \\
\hline oxytetracycline & $\mathrm{N}$ & Y & & & & N & $\mathrm{N}$ & Y & Y & cascade & $\mathrm{Y}$ & medium \\
\hline paromomycin & $\mathrm{N}$ & Y & & & & N & $\mathrm{N}$ & N & $\mathrm{N}$ & $\rightarrow$ & $\rightarrow$ & low \\
\hline phenoxymethylpenicillin & $\mathrm{N}$ & $\mathrm{N}$ & $\rightarrow$ & $\rightarrow$ & $\rightarrow$ & $\rightarrow$ & $\mathrm{N}$ & N & $\mathrm{N}$ & $\rightarrow$ & $\rightarrow$ & low \\
\hline pirlimycin & $\mathrm{N}$ & $\mathrm{N}$ & $\rightarrow$ & $\rightarrow$ & $\rightarrow$ & $\rightarrow$ & $\mathrm{N}$ & N & $\mathrm{N}$ & $\rightarrow$ & $\rightarrow$ & low \\
\hline rifaximin & $\mathrm{N}$ & $\mathrm{N}$ & $\rightarrow$ & $\rightarrow$ & $\rightarrow$ & $\rightarrow$ & $\mathrm{N}$ & $\mathrm{N}$ & $\mathrm{N}$ & $\rightarrow$ & $\rightarrow$ & low \\
\hline sarafloxacin & $\mathrm{Y}$ & $\rightarrow$ & $\rightarrow$ & $\rightarrow$ & $\rightarrow$ & $\rightarrow$ & $\rightarrow$ & $\rightarrow$ & $\rightarrow$ & $\rightarrow$ & $\rightarrow$ & high \\
\hline spectinomycin & $\mathrm{N}$ & $Y$ & & & & $\mathrm{~N}$ & $\mathrm{~N}$ & N & $\mathrm{N}$ & $\rightarrow$ & $\rightarrow$ & low \\
\hline spiramycin & $\mathrm{Y}$ & $\rightarrow$ & $\rightarrow$ & $\rightarrow$ & $\rightarrow$ & $\rightarrow$ & $\rightarrow$ & $\rightarrow$ & $\rightarrow$ & $\rightarrow$ & $\rightarrow$ & high \\
\hline streptomycin & $\mathrm{N}$ & $\mathrm{N}$ & $\rightarrow$ & $\rightarrow$ & $\rightarrow$ & $\rightarrow$ & $\mathrm{N}$ & $\mathrm{N}$ & $\mathrm{N}$ & $\rightarrow$ & $\rightarrow$ & low \\
\hline sulfachlorpyridazin & $\mathrm{N}$ & Y & & & & $\mathrm{N}$ & $\mathrm{N}$ & $\mathrm{N}$ & $\mathrm{N}$ & $\rightarrow$ & $\rightarrow$ & low \\
\hline sulfaclozin & $\mathrm{N}$ & $\mathrm{Y}$ & & & & $\mathrm{N}$ & $\mathrm{N}$ & $\mathrm{N}$ & $\mathrm{N}$ & $\rightarrow$ & $\rightarrow$ & low \\
\hline sulfadiazin & $\mathrm{N}$ & $\mathrm{Y}$ & & & Y & Y & $\rightarrow$ & $\rightarrow$ & $\rightarrow$ & $\rightarrow$ & $\rightarrow$ & medium \\
\hline sulfadimethoxin & $\mathrm{N}$ & Y & & & Y & Y & $\rightarrow$ & $\rightarrow$ & $\rightarrow$ & $\rightarrow$ & $\rightarrow$ & medium \\
\hline sulfadoxin & $\mathrm{N}$ & $\mathrm{Y}$ & & & & $\mathrm{N}$ & $\mathrm{N}$ & $\mathrm{Y}$ & $\mathrm{Y}$ & $10 d$ & $\mathrm{Y}$ & medium \\
\hline sulfamethazin (sulfadimidin) & $\mathrm{N}$ & Y & & & Y & Y & $\rightarrow$ & $\rightarrow$ & $\rightarrow$ & $\rightarrow$ & $\rightarrow$ & medium \\
\hline sulfamethoxazol & $\mathrm{N}$ & $\mathrm{Y}$ & & & & $\mathrm{N}$ & $\mathrm{N}$ & $\mathrm{N}$ & $\mathrm{N}$ & $\rightarrow$ & $\rightarrow$ & low \\
\hline
\end{tabular}




\begin{tabular}{|c|c|c|c|c|c|c|c|c|c|c|c|c|}
\hline \multirow{2}{*}{$\begin{array}{l}\text { Italics: not commonly } \\
\text { included in scope } \\
\text { Substance }\end{array}$} & \multirow{2}{*}{$\begin{array}{l}\text { Q1: is this an } \\
\text { essential } \\
\text { antimicrobial for } \\
\text { humans? } \\
\text { Concl Q1 }\end{array}$} & \multirow{2}{*}{$\begin{array}{l}\text { Q2: Have MRLs been } \\
\text { set for this } \\
\text { substance in this } \\
\text { animal species? } \\
\text { Concl Q2 }\end{array}$} & \multicolumn{4}{|c|}{$\begin{array}{l}\text { Q3: were any non-compliant residue } \\
\text { data of the substance found in the last } \\
\text { five years? }\end{array}$} & \multicolumn{3}{|c|}{$\begin{array}{l}\text { Q4: Is the substance } \\
\text { regularly used in this animal } \\
\text { species? }\end{array}$} & \multicolumn{2}{|c|}{$\begin{array}{l}\text { Q5: Do drugs with this active } \\
\text { substance have a long } \\
\text { withdrawal period? }\end{array}$} & \multirow[t]{2}{*}{$\begin{array}{c}\text { Conclusion } \\
\text { priority }\end{array}$} \\
\hline & & & KAP & RASFF & EFSA & Concl Q3 & NC & $\begin{array}{l}\text { SDa } \\
(>50000 \\
\text { DDDA })\end{array}$ & Concl Q4 & $\begin{array}{l}\text { Withdrawal } \\
\text { time }\end{array}$ & Concl Q5 & \\
\hline sulfapyridine & $\mathrm{N}$ & Y & & & & $\mathrm{N}$ & $\mathrm{N}$ & $\mathrm{N}$ & $\mathrm{N}$ & $\rightarrow$ & $\rightarrow$ & low \\
\hline sulfaquanidin & $\mathrm{N}$ & Y & & & & $\mathrm{N}$ & $\mathrm{N}$ & $\mathrm{N}$ & $\mathrm{N}$ & $\rightarrow$ & $\rightarrow$ & low \\
\hline sulfaquinoxalin & $\mathrm{N}$ & Y & & & & $\mathrm{N}$ & $\mathrm{N}$ & $\mathrm{N}$ & $\mathrm{N}$ & $\rightarrow$ & $\rightarrow$ & low \\
\hline tetracycline & $\mathrm{N}$ & Y & & & & $\mathrm{N}$ & $\mathrm{N}$ & $\mathrm{N}$ & $\mathrm{N}$ & $\rightarrow$ & $\rightarrow$ & low \\
\hline thiamphenicol & N & Y & & & & U & $\mathrm{N}$ & N & $\mathrm{N}$ & $\rightarrow$ & $\rightarrow$ & low \\
\hline tiamulin & $\mathrm{N}$ & $\mathrm{N}$ & $\rightarrow$ & $\rightarrow$ & $\rightarrow$ & $\rightarrow$ & $\mathrm{N}$ & N & $\mathrm{N}$ & $\rightarrow$ & $\rightarrow$ & low \\
\hline tildipirosin & Y & $\rightarrow$ & $\rightarrow$ & $\rightarrow$ & $\rightarrow$ & $\rightarrow$ & $\rightarrow$ & $\rightarrow$ & $\rightarrow$ & $\rightarrow$ & $\rightarrow$ & high \\
\hline tilmicosin & Y & $\rightarrow$ & $\rightarrow$ & $\rightarrow$ & $\rightarrow$ & $\rightarrow$ & $\rightarrow$ & $\rightarrow$ & $\rightarrow$ & $\rightarrow$ & $\rightarrow$ & high \\
\hline trimethoprim & $\mathrm{N}$ & $\mathrm{Y}$ & & & & $\mathrm{N}$ & $\mathrm{N}$ & Y & Y & $10-14 d$ & Y & medium \\
\hline tulathromycin & $\mathrm{Y}$ & $\rightarrow$ & $\rightarrow$ & $\rightarrow$ & $\rightarrow$ & $\rightarrow$ & $\rightarrow$ & $\rightarrow$ & $\rightarrow$ & $\rightarrow$ & $\rightarrow$ & high \\
\hline tylosin & $\mathrm{Y}$ & $\rightarrow$ & $\rightarrow$ & $\rightarrow$ & $\rightarrow$ & $\rightarrow$ & $\rightarrow$ & $\rightarrow$ & $\rightarrow$ & $\rightarrow$ & $\rightarrow$ & high \\
\hline tylvalosin & $Y$ & $\rightarrow$ & $\rightarrow$ & $\rightarrow$ & $\rightarrow$ & $\rightarrow$ & $\rightarrow$ & $\rightarrow$ & $\rightarrow$ & $\rightarrow$ & $\rightarrow$ & high \\
\hline valnemulin & $\mathrm{N}$ & $\mathrm{N}$ & $\rightarrow$ & $\rightarrow$ & $\rightarrow$ & $\rightarrow$ & $\mathrm{N}$ & $\mathrm{N}$ & $\mathrm{N}$ & $\rightarrow$ & $\rightarrow$ & low \\
\hline virginiamycin & $\mathrm{N}$ & $\mathrm{N}$ & $\rightarrow$ & $\rightarrow$ & $\rightarrow$ & $\rightarrow$ & $\mathrm{N}$ & $\mathrm{N}$ & $\mathrm{N}$ & $\rightarrow$ & $\rightarrow$ & low \\
\hline
\end{tabular}

$\rightarrow$ based on the outcome of the previous question, this question can be skipped. 
Table A1.2 Prioritisation of antibiotics in goat.

\begin{tabular}{|c|c|c|c|c|c|c|c|c|c|c|c|c|}
\hline \multirow{2}{*}{$\begin{array}{l}\text { Italics: not commonly } \\
\text { included in scope } \\
\text { Substance }\end{array}$} & \multirow{2}{*}{$\begin{array}{c}\text { Q1: is this an } \\
\text { essential } \\
\text { antimicrobial for } \\
\text { humans? } \\
\text { Concl Q1 }\end{array}$} & \multirow{2}{*}{$\begin{array}{l}\text { Q2: Have MRLs been } \\
\text { set for this substance } \\
\text { in this animal species? } \\
\text { Concl Q2 }\end{array}$} & \multicolumn{4}{|c|}{$\begin{array}{l}\text { Q3: were any non-compliant residue } \\
\text { data of the substance found in the } \\
\text { last five years? }\end{array}$} & \multicolumn{3}{|c|}{$\begin{array}{l}\text { Q4: Is the substance } \\
\text { regularly used in this } \\
\text { animal species? }\end{array}$} & \multicolumn{2}{|c|}{$\begin{array}{l}\text { Q5: Do drugs with this active } \\
\text { substance have a long } \\
\text { withdrawal period? }\end{array}$} & \multirow{2}{*}{$\begin{array}{c}\begin{array}{c}\text { Conclusion } \\
\text { priority }\end{array} \\
\text { Goat }\end{array}$} \\
\hline & & & KAP & RASFF & EFSA & Concl Q3 & NC? & $\begin{array}{l}\text { Survey } \\
\text { results }\end{array}$ & $\begin{array}{c}\text { Concl } \\
\text { Q4 }\end{array}$ & Withdrawal time & Concl Q5 & \\
\hline amoxicillin & $\mathrm{N}$ & $\mathrm{Y}$ & & & $Y^{a}$ & $\mathrm{Y}$ & $\rightarrow$ & $\rightarrow$ & $\rightarrow$ & $\rightarrow$ & $\rightarrow$ & medium \\
\hline ampicillin & $\mathrm{N}$ & $\mathrm{Y}$ & & & $\mathrm{Y}^{\mathrm{b}}$ & $\mathrm{Y}$ & $\rightarrow$ & $\rightarrow$ & $\rightarrow$ & $\rightarrow$ & $\rightarrow$ & medium \\
\hline apramycin & $\mathrm{N}$ & $\mathrm{N}$ & $\rightarrow$ & $\rightarrow$ & $\rightarrow$ & $\rightarrow$ & $\mathrm{N}$ & $\mathrm{N}$ & $\mathrm{N}$ & $\rightarrow$ & $\rightarrow$ & low \\
\hline avilamycin & $\mathrm{N}$ & $\mathrm{N}$ & $\rightarrow$ & $\rightarrow$ & $\rightarrow$ & $\rightarrow$ & $\mathrm{N}$ & $\mathrm{N}$ & $\mathrm{N}$ & $\rightarrow$ & $\rightarrow$ & low \\
\hline bacitracin & $\mathrm{N}$ & $\mathrm{N}$ & $\rightarrow$ & $\rightarrow$ & $\rightarrow$ & $\rightarrow$ & $\mathrm{N}$ & $\mathrm{N}$ & $\mathrm{N}$ & $\rightarrow$ & $\rightarrow$ & low \\
\hline baquiloprim & $\mathrm{N}$ & $\mathrm{N}$ & $\rightarrow$ & $\rightarrow$ & $\rightarrow$ & $\rightarrow$ & $\mathrm{N}$ & $\mathrm{N}$ & $\mathrm{N}$ & $\rightarrow$ & $\rightarrow$ & low \\
\hline benzylpenicillin/penethamate & $\mathrm{N}$ & $\mathrm{Y}$ & & & $Y^{a}$ & $\mathrm{Y}$ & $\rightarrow$ & $\rightarrow$ & $\rightarrow$ & $\rightarrow$ & $\rightarrow$ & medium \\
\hline cefacetril & $\mathrm{N}$ & $\mathrm{N}$ & $\rightarrow$ & $\rightarrow$ & $\rightarrow$ & $\rightarrow$ & $\mathrm{N}$ & $\mathrm{N}$ & $\mathrm{N}$ & $\rightarrow$ & $\rightarrow$ & low \\
\hline cefalexine & $\mathrm{N}$ & $\mathrm{N}$ & $\rightarrow$ & $\rightarrow$ & $\rightarrow$ & $\rightarrow$ & $\mathrm{N}$ & $\mathrm{Y}$ & $\mathrm{Y}$ & cascade & $\mathrm{Y}$ & medium \\
\hline cefalonium & $\mathrm{N}$ & $\mathrm{N}$ & $\rightarrow$ & $\rightarrow$ & $\rightarrow$ & $\rightarrow$ & N & $\mathrm{N}$ & N & $\rightarrow$ & $\rightarrow$ & low \\
\hline cefapirin & $\mathrm{N}$ & $\mathrm{N}$ & $\rightarrow$ & $\rightarrow$ & $\rightarrow$ & $\rightarrow$ & N & $\mathrm{N}$ & N & $\rightarrow$ & $\rightarrow$ & low \\
\hline cefazolin & N & $Y^{c}$ & & & & $\mathrm{~N}$ & N & $\mathrm{N}$ & $\mathrm{N}$ & $\rightarrow$ & $\rightarrow$ & low \\
\hline cefoperazon & $\mathrm{Y}$ & $\rightarrow$ & $\rightarrow$ & $\rightarrow$ & $\rightarrow$ & $\rightarrow$ & $\rightarrow$ & $\rightarrow$ & $\rightarrow$ & $\rightarrow$ & $\rightarrow$ & high \\
\hline cefquinome & $\mathrm{Y}$ & $\rightarrow$ & $\rightarrow$ & $\rightarrow$ & $\rightarrow$ & $\rightarrow$ & $\rightarrow$ & $\rightarrow$ & $\rightarrow$ & $\rightarrow$ & $\rightarrow$ & high \\
\hline ceftiofur & $Y$ & $\rightarrow$ & $\rightarrow$ & $\rightarrow$ & $\rightarrow$ & $\rightarrow$ & $\rightarrow$ & $\rightarrow$ & $\rightarrow$ & $\rightarrow$ & $\rightarrow$ & high \\
\hline chlortetracycline & $\mathrm{N}$ & $Y$ & & & $\mathrm{Y}$ & $\mathrm{Y}$ & $\rightarrow$ & $\rightarrow$ & $\rightarrow$ & $\rightarrow$ & $\rightarrow$ & medium \\
\hline cloxacillin & $\mathrm{N}$ & $Y$ & & $\mathrm{Y}^{\mathrm{b}}$ & $\mathrm{Y}^{\mathrm{b}}$ & $\mathrm{Y}$ & $\rightarrow$ & $\rightarrow$ & $\rightarrow$ & $\rightarrow$ & $\rightarrow$ & medium \\
\hline colistin & $Y$ & $\rightarrow$ & $\rightarrow$ & $\rightarrow$ & $\rightarrow$ & $\rightarrow$ & $\rightarrow$ & $\rightarrow$ & $\rightarrow$ & $\rightarrow$ & $\rightarrow$ & high \\
\hline danofloxacin & $\mathrm{Y}$ & $\rightarrow$ & $\rightarrow$ & $\rightarrow$ & $\rightarrow$ & $\rightarrow$ & $\rightarrow$ & $\rightarrow$ & $\rightarrow$ & $\rightarrow$ & $\rightarrow$ & high \\
\hline dicloxacillin & $\mathrm{N}$ & $Y$ & & & & $\mathrm{~N}$ & $\mathrm{~N}$ & $\mathrm{~N}$ & $\mathrm{~N}$ & $\rightarrow$ & $\rightarrow$ & low \\
\hline difloxacin & $\mathrm{Y}$ & $\rightarrow$ & $\rightarrow$ & $\rightarrow$ & $\rightarrow$ & $\rightarrow$ & $\rightarrow$ & $\rightarrow$ & $\rightarrow$ & $\rightarrow$ & $\rightarrow$ & high \\
\hline dihydrostreptomycin & $\mathrm{N}$ & $Y$ & & & $Y^{a}$ & $\mathrm{Y}$ & $\rightarrow$ & $\rightarrow$ & $\rightarrow$ & $\rightarrow$ & $\rightarrow$ & medium \\
\hline doxycyclin & $\mathrm{N}$ & $\mathrm{N}$ & $\rightarrow$ & $\rightarrow$ & $\rightarrow$ & $\rightarrow$ & $\mathrm{Y}$ & $\rightarrow$ & $\mathrm{Y}$ & cascade & $\rightarrow$ & medium \\
\hline enrofloxacin & $Y$ & $\rightarrow$ & $\rightarrow$ & $\rightarrow$ & $\rightarrow$ & $\rightarrow$ & $\rightarrow$ & $\rightarrow$ & $\rightarrow$ & $\rightarrow$ & $\rightarrow$ & high \\
\hline erythromycin & Y & $\rightarrow$ & $\rightarrow$ & $\rightarrow$ & $\rightarrow$ & $\rightarrow$ & $\rightarrow$ & $\rightarrow$ & $\rightarrow$ & $\rightarrow$ & $\rightarrow$ & high \\
\hline florfenicol & N & $\mathrm{Y}$ & & & & $\mathrm{N}$ & $\mathrm{N}$ & $\mathrm{Y}$ & $\mathrm{Y}$ & cascade & $\mathrm{Y}$ & medium \\
\hline flumequine & $\mathrm{Y}$ & $\rightarrow$ & $\rightarrow$ & $\rightarrow$ & $\rightarrow$ & $\rightarrow$ & $\rightarrow$ & $\rightarrow$ & $\rightarrow$ & $\rightarrow$ & $\rightarrow$ & high \\
\hline gamithromycin & $Y$ & $\rightarrow$ & $\rightarrow$ & $\rightarrow$ & $\rightarrow$ & $\rightarrow$ & $\rightarrow$ & $\rightarrow$ & $\rightarrow$ & $\rightarrow$ & $\rightarrow$ & high \\
\hline gentamicin & $\mathrm{N}$ & $Y$ & & & & $\mathrm{~N}$ & $\mathrm{~N}$ & $\mathrm{~N}$ & $\mathrm{~N}$ & $\rightarrow$ & $\rightarrow$ & low \\
\hline josamycin & $\mathrm{N}$ & $\mathrm{N}$ & $\rightarrow$ & $\rightarrow$ & $\rightarrow$ & $\rightarrow$ & $\mathrm{N}$ & $\mathrm{N}$ & $\mathrm{N}$ & $\rightarrow$ & $\rightarrow$ & low \\
\hline
\end{tabular}




\begin{tabular}{|c|c|c|c|c|c|c|}
\hline \multirow{2}{*}{$\begin{array}{l}\text { Italics: not commonly } \\
\text { included in scope } \\
\text { Substance }\end{array}$} & \multirow{2}{*}{$\begin{array}{l}\text { Q1: is this an } \\
\text { essential } \\
\text { antimicrobial for } \\
\text { humans? } \\
\text { Concl Q1 }\end{array}$} & \multirow{2}{*}{$\begin{array}{l}\text { Q2: Have MRLs been } \\
\text { set for this substance } \\
\text { in this animal species? } \\
\text { Concl Q2 }\end{array}$} & \multicolumn{4}{|c|}{$\begin{array}{c}\text { Q3: were any non-compliant re } \\
\text { data of the substance found in } \\
\text { last five years? }\end{array}$} \\
\hline & & & KAP & RASFF & EFSA & Con \\
\hline kanamycin & $\mathrm{N}$ & $\mathrm{Y}$ & & & & \\
\hline lincomycin & $\mathrm{N}$ & $\mathrm{Y}$ & & & & \\
\hline marbofloxacin & $\mathrm{Y}$ & $\rightarrow$ & $\rightarrow$ & $\rightarrow$ & $\rightarrow$ & \\
\hline nafcillin & $\mathrm{N}$ & $\mathrm{Y}$ & & & & \\
\hline neomycin & $\mathrm{N}$ & $\mathrm{Y}$ & & & & \\
\hline novobiocin & $\mathrm{N}$ & $\mathrm{N}$ & $\rightarrow$ & $\rightarrow$ & $\rightarrow$ & \\
\hline oxacillin & $\mathrm{N}$ & Y & & & & \\
\hline oxolinic acid & $\mathrm{N}$ & Y & & & & \\
\hline oxytetracycline & $\mathrm{N}$ & Y & Y & & Y & \\
\hline paromomycin & $\mathrm{N}$ & Y & & & & \\
\hline phenoxymethylpenicillin & $\mathrm{N}$ & $\mathrm{N}$ & $\rightarrow$ & $\rightarrow$ & $\rightarrow$ & \\
\hline pirlimycin & $\mathrm{N}$ & $\mathrm{N}$ & $\rightarrow$ & $\rightarrow$ & $\rightarrow$ & \\
\hline rifaximin & $\mathrm{N}$ & $\mathrm{N}$ & $\rightarrow$ & $\rightarrow$ & $\rightarrow$ & \\
\hline sarafloxacin & Y & $\rightarrow$ & $\rightarrow$ & $\rightarrow$ & $\rightarrow$ & \\
\hline spectinomycin & $\mathrm{N}$ & Y & & & & \\
\hline spiramycin & $\mathrm{Y}$ & $\rightarrow$ & $\rightarrow$ & $\rightarrow$ & $\rightarrow$ & \\
\hline streptomycin & $\mathrm{N}$ & Y & & & & \\
\hline sulfachlorpyridazin & $\mathrm{N}$ & Y & & & & \\
\hline sulfaclozin & $\mathrm{N}$ & $\mathrm{Y}$ & & & & \\
\hline sulfadiazin & $\mathrm{N}$ & Y & & & Y & \\
\hline sulfadimethoxin & $\mathrm{N}$ & Y & & & & \\
\hline sulfadoxin & $\mathrm{N}$ & $\mathrm{Y}$ & & & & \\
\hline sulfamethazin (sulfadimidin) & $\mathrm{N}$ & Y & & & Y & \\
\hline sulfamethoxazol & $\mathrm{N}$ & $\mathrm{Y}$ & & & & \\
\hline sulfapyridine & $\mathrm{N}$ & Y & & & & \\
\hline sulfaquanidin & $\mathrm{N}$ & Y & & & & \\
\hline sulfaquinoxalin & $\mathrm{N}$ & Y & & & & \\
\hline tetracycline & $\mathrm{N}$ & Y & & & & \\
\hline thiamphenicol & $\mathrm{N}$ & Y & & & & \\
\hline tiamulin & $\mathrm{N}$ & $\mathrm{N}$ & $\rightarrow$ & $\rightarrow$ & $\rightarrow$ & \\
\hline tildipirosin & $\mathrm{Y}$ & $\rightarrow$ & $\rightarrow$ & $\rightarrow$ & $\rightarrow$ & \\
\hline tilmicosin & $\mathrm{Y}$ & $\rightarrow$ & $\rightarrow$ & $\rightarrow$ & $\rightarrow$ & \\
\hline
\end{tabular}

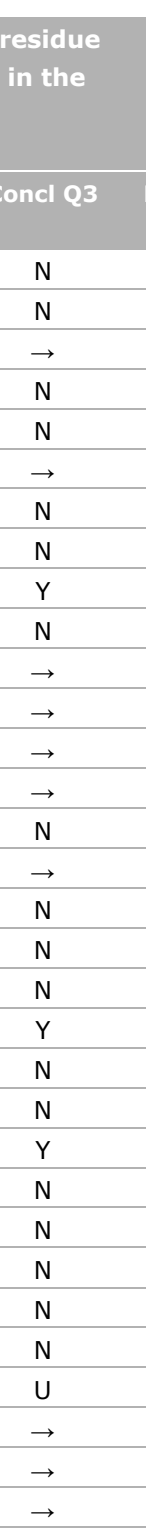

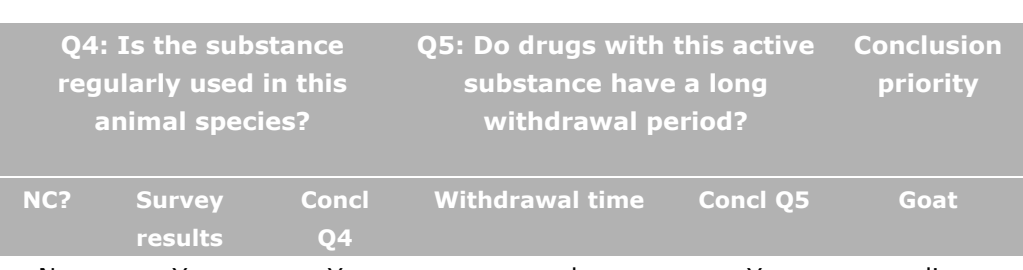

\begin{tabular}{|c|c|c|c|c|c|}
\hline & esults & Q4 & & & \\
\hline$N$ & Y & $Y$ & cascade & $Y$ & medium \\
\hline $\mathrm{N}$ & Y & $\mathrm{Y}$ & cascade & $Y$ & medium \\
\hline$\rightarrow$ & $\rightarrow$ & $\rightarrow$ & $\rightarrow$ & $\rightarrow$ & high \\
\hline $\mathrm{N}$ & $\mathrm{N}$ & $\mathrm{N}$ & $\rightarrow$ & $\rightarrow$ & low \\
\hline $\mathrm{N}$ & Y & $Y$ & cascade & $Y$ & medium \\
\hline $\mathrm{N}$ & $\mathrm{N}$ & $\mathrm{N}$ & $\rightarrow$ & $\rightarrow$ & low \\
\hline $\mathrm{N}$ & $N$ & $\mathrm{~N}$ & $\rightarrow$ & $\rightarrow$ & low \\
\hline $\mathrm{N}$ & $\mathrm{N}$ & $\mathrm{N}$ & $\rightarrow$ & $\rightarrow$ & low \\
\hline$\rightarrow$ & $\rightarrow$ & $\rightarrow$ & $\rightarrow$ & $\rightarrow$ & medium \\
\hline $\mathrm{N}$ & $Y$ & $Y$ & cascade & $Y$ & medium \\
\hline $\mathrm{N}$ & $\mathrm{N}$ & $\mathrm{N}$ & $\rightarrow$ & $\rightarrow$ & low \\
\hline$N$ & $N$ & $\mathrm{~N}$ & $\rightarrow$ & $\rightarrow$ & low \\
\hline$N$ & $\mathrm{~N}$ & $N$ & $\rightarrow$ & $\rightarrow$ & low \\
\hline$\rightarrow$ & $\rightarrow$ & $\rightarrow$ & $\rightarrow$ & $\rightarrow$ & high \\
\hline $\mathrm{N}$ & Y & $Y$ & cascade & $Y$ & medium \\
\hline$\rightarrow$ & $\rightarrow$ & $\rightarrow$ & $\rightarrow$ & $\rightarrow$ & high \\
\hline $\mathrm{N}$ & $\mathrm{N}$ & $\mathrm{N}$ & $\rightarrow$ & $\rightarrow$ & low \\
\hline $\mathrm{N}$ & $\mathrm{N}$ & $\mathrm{N}$ & $\rightarrow$ & $\rightarrow$ & low \\
\hline $\mathrm{N}$ & $\mathrm{N}$ & $\mathrm{N}$ & $\rightarrow$ & $\rightarrow$ & low \\
\hline$\rightarrow$ & $\rightarrow$ & $\rightarrow$ & $\rightarrow$ & $\rightarrow$ & medium \\
\hline$N$ & $N$ & $\mathrm{~N}$ & $\rightarrow$ & $\rightarrow$ & low \\
\hline$N$ & $Y$ & $Y$ & cascade & $Y$ & medium \\
\hline$\rightarrow$ & $\rightarrow$ & $\rightarrow$ & $\rightarrow$ & $\rightarrow$ & medium \\
\hline$N$ & $\mathrm{~N}$ & $\mathrm{~N}$ & $\rightarrow$ & $\rightarrow$ & low \\
\hline $\mathrm{N}$ & $N$ & $\mathrm{~N}$ & $\rightarrow$ & $\rightarrow$ & low \\
\hline $\mathrm{N}$ & $N$ & $\mathrm{~N}$ & $\rightarrow$ & $\rightarrow$ & low \\
\hline$N$ & $\mathrm{~N}$ & $\mathrm{~N}$ & $\rightarrow$ & $\rightarrow$ & low \\
\hline$N$ & $Y$ & $Y$ & cascade & $Y$ & medium \\
\hline$N$ & $\mathrm{~N}$ & $N$ & $\rightarrow$ & $\rightarrow$ & low \\
\hline$N$ & $\mathrm{~N}$ & $\mathrm{~N}$ & $\rightarrow$ & $\rightarrow$ & low \\
\hline$\rightarrow$ & $\rightarrow$ & $\rightarrow$ & $\rightarrow$ & $\rightarrow$ & high \\
\hline$\rightarrow$ & $\rightarrow$ & $\rightarrow$ & $\rightarrow$ & $\rightarrow$ & high \\
\hline
\end{tabular}




\begin{tabular}{|c|c|c|c|c|c|c|c|c|c|c|c|c|}
\hline \multirow{2}{*}{$\begin{array}{l}\text { Italics: not commonly } \\
\text { included in scope } \\
\text { Substance }\end{array}$} & \multirow{2}{*}{$\begin{array}{c}\text { Q1: is this an } \\
\text { essential } \\
\text { antimicrobial for } \\
\text { humans? } \\
\text { Concl Q1 }\end{array}$} & \multirow{2}{*}{$\begin{array}{l}\text { Q2: Have MRLs been } \\
\text { set for this substance } \\
\text { in this animal species? } \\
\text { Concl Q2 }\end{array}$} & \multicolumn{4}{|c|}{$\begin{array}{l}\text { Q3: were any non-compliant residue } \\
\text { data of the substance found in the } \\
\text { last five years? }\end{array}$} & \multicolumn{3}{|c|}{$\begin{array}{l}\text { Q4: Is the substance } \\
\text { regularly used in this } \\
\text { animal species? }\end{array}$} & \multicolumn{2}{|c|}{$\begin{array}{l}\text { Q5: Do drugs with this active } \\
\text { substance have a long } \\
\text { withdrawal period? }\end{array}$} & \multirow{2}{*}{$\begin{array}{c}\begin{array}{c}\text { Conclusion } \\
\text { priority }\end{array} \\
\text { Goat }\end{array}$} \\
\hline & & & KAP & RASFF & EFSA & Concl Q3 & NC? & $\begin{array}{l}\text { Survey } \\
\text { results }\end{array}$ & $\begin{array}{c}\text { Concl } \\
\text { Q4 }\end{array}$ & Withdrawal time & Concl Q5 & \\
\hline trimethoprim & $\mathrm{N}$ & Y & & & & $\mathrm{N}$ & $\mathrm{N}$ & $\mathrm{Y}$ & $\mathrm{Y}$ & cascade & Y & medium \\
\hline tulathromycin & Y & $\rightarrow$ & $\rightarrow$ & $\rightarrow$ & $\rightarrow$ & $\rightarrow$ & $\rightarrow$ & $\rightarrow$ & $\rightarrow$ & $\rightarrow$ & $\rightarrow$ & high \\
\hline tylosin & $\mathrm{Y}$ & $\rightarrow$ & $\rightarrow$ & $\rightarrow$ & $\rightarrow$ & $\rightarrow$ & $\rightarrow$ & $\rightarrow$ & $\rightarrow$ & $\rightarrow$ & $\rightarrow$ & high \\
\hline tylvalosin & Y & $\rightarrow$ & $\rightarrow$ & $\rightarrow$ & $\rightarrow$ & $\rightarrow$ & $\rightarrow$ & $\rightarrow$ & $\rightarrow$ & $\rightarrow$ & $\rightarrow$ & high \\
\hline valnemulin & $\mathrm{N}$ & $\mathrm{N}$ & $\rightarrow$ & $\rightarrow$ & $\rightarrow$ & $\rightarrow$ & $\mathrm{N}$ & $\mathrm{N}$ & $\mathrm{N}$ & $\rightarrow$ & $\rightarrow$ & low \\
\hline virginiamycin & $\mathrm{N}$ & $\mathrm{N}$ & $\rightarrow$ & $\rightarrow$ & $\rightarrow$ & $\rightarrow$ & $\mathrm{N}$ & $\mathrm{N}$ & $\mathrm{N}$ & $\rightarrow$ & $\rightarrow$ & low \\
\hline
\end{tabular}

a No differentiation goat/sheep possible.

b goat/sheep milk.

c MRL in milk only.

$\rightarrow$ based on the outcome of the previous question, this question can be skipped. 
Table A1.3 Prioritisation of antibiotics in sheep.

\begin{tabular}{|c|c|c|c|c|c|c|c|c|c|c|c|c|}
\hline \multirow{2}{*}{$\begin{array}{l}\text { Italics: not commonly } \\
\text { included in scope } \\
\text { Substance }\end{array}$} & \multirow{2}{*}{$\begin{array}{c}\text { Q1: is this an } \\
\text { essential } \\
\text { antimicrobial for } \\
\text { humans? } \\
\text { Concl Q1 }\end{array}$} & \multirow{2}{*}{$\begin{array}{l}\text { Q2: Have MRLs been } \\
\text { set for this substance } \\
\text { in this animal species? } \\
\text { Concl Q2 }\end{array}$} & \multicolumn{4}{|c|}{$\begin{array}{l}\text { Q3: were any non-compliant residue } \\
\text { data of the substance found in the } \\
\text { last five years? }\end{array}$} & \multicolumn{3}{|c|}{$\begin{array}{l}\text { Q4: Is the substance } \\
\text { regularly used in this } \\
\text { animal species? }\end{array}$} & \multicolumn{2}{|c|}{$\begin{array}{l}\text { Q5: Do drugs with this active } \\
\text { substance have a long } \\
\text { withdrawal period? }\end{array}$} & \multirow{2}{*}{$\begin{array}{c}\begin{array}{c}\text { Conclusion } \\
\text { priority }\end{array} \\
\text { Sheep }\end{array}$} \\
\hline & & & KAP & RASFF & EFSA & Concl Q3 & NC? & $\begin{array}{l}\text { Survey } \\
\text { results }\end{array}$ & $\begin{array}{c}\text { Concl } \\
\text { Q4 }\end{array}$ & Withdrawal time & Concl Q5 & \\
\hline amoxicillin & $\mathrm{N}$ & $\mathrm{Y}$ & & & $Y^{a}$ & $\mathrm{Y}$ & $\rightarrow$ & $\rightarrow$ & $\rightarrow$ & $\rightarrow$ & $\rightarrow$ & medium \\
\hline ampicillin & $\mathrm{N}$ & $Y$ & & & $Y^{b}$ & $\mathrm{Y}$ & $\rightarrow$ & $\rightarrow$ & $\rightarrow$ & $\rightarrow$ & $\rightarrow$ & medium \\
\hline apramycin & $\mathrm{N}$ & $\mathrm{Y}$ & & & & $\mathrm{N}$ & $\mathrm{N}$ & $\mathrm{N}$ & $\mathrm{N}$ & $\rightarrow$ & $\rightarrow$ & low \\
\hline avilamycin & $\mathrm{N}$ & $\mathrm{N}$ & $\rightarrow$ & $\rightarrow$ & $\rightarrow$ & $\rightarrow$ & $\mathrm{N}$ & $\mathrm{N}$ & $\mathrm{N}$ & $\rightarrow$ & $\rightarrow$ & low \\
\hline bacitracin & $\mathrm{N}$ & $\mathrm{N}$ & $\rightarrow$ & $\rightarrow$ & $\rightarrow$ & $\rightarrow$ & $\mathrm{N}$ & $\mathrm{N}$ & $\mathrm{N}$ & $\rightarrow$ & $\rightarrow$ & low \\
\hline baquiloprim & $\mathrm{N}$ & $\mathrm{N}$ & $\rightarrow$ & $\rightarrow$ & $\rightarrow$ & $\rightarrow$ & $\mathrm{N}$ & $\mathrm{N}$ & $\mathrm{N}$ & $\rightarrow$ & $\rightarrow$ & low \\
\hline benzylpenicillin/penethamate & $\mathrm{N}$ & $\mathrm{Y}$ & & & Y & $\mathrm{Y}$ & $\rightarrow$ & $\rightarrow$ & $\rightarrow$ & $\rightarrow$ & $\rightarrow$ & medium \\
\hline cefacetril & $\mathrm{N}$ & $\mathrm{N}$ & $\rightarrow$ & $\rightarrow$ & $\rightarrow$ & $\rightarrow$ & $\mathrm{N}$ & $\mathrm{N}$ & $\mathrm{N}$ & $\rightarrow$ & $\rightarrow$ & low \\
\hline cefalexine & $\mathrm{N}$ & $\mathrm{N}$ & $\rightarrow$ & $\rightarrow$ & $\rightarrow$ & $\rightarrow$ & $\mathrm{N}$ & $\mathrm{Y}$ & $\mathrm{Y}$ & cascade & $\mathrm{Y}$ & medium \\
\hline cefalonium & $\mathrm{N}$ & $\mathrm{N}$ & $\rightarrow$ & $\rightarrow$ & $\rightarrow$ & $\rightarrow$ & $\mathrm{N}$ & $\mathrm{N}$ & $\mathrm{N}$ & $\rightarrow$ & $\rightarrow$ & low \\
\hline cefapirin & $\mathrm{N}$ & $\mathrm{N}$ & $\rightarrow$ & $\rightarrow$ & $\rightarrow$ & $\rightarrow$ & $\mathrm{N}$ & $\mathrm{N}$ & N & $\rightarrow$ & $\rightarrow$ & low \\
\hline cefazolin & $\mathrm{N}$ & $Y^{c}$ & & & & $\mathrm{~N}$ & $\mathrm{~N}$ & $\mathrm{~N}$ & $\mathrm{~N}$ & $\rightarrow$ & $\rightarrow$ & low \\
\hline cefoperazon & $\mathrm{Y}$ & $\rightarrow$ & $\rightarrow$ & $\rightarrow$ & $\rightarrow$ & $\rightarrow$ & $\rightarrow$ & $\rightarrow$ & $\rightarrow$ & $\rightarrow$ & $\rightarrow$ & high \\
\hline cefquinome & $\mathrm{Y}$ & $\rightarrow$ & $\rightarrow$ & $\rightarrow$ & $\rightarrow$ & $\rightarrow$ & $\rightarrow$ & $\rightarrow$ & $\rightarrow$ & $\rightarrow$ & $\rightarrow$ & high \\
\hline ceftiofur & $\mathrm{Y}$ & $\rightarrow$ & $\rightarrow$ & $\rightarrow$ & $\rightarrow$ & $\rightarrow$ & $\rightarrow$ & $\rightarrow$ & $\rightarrow$ & $\rightarrow$ & $\rightarrow$ & high \\
\hline chlortetracycline & $\mathrm{N}$ & $Y$ & & & $\mathrm{Y}$ & $\mathrm{Y}$ & $\rightarrow$ & $\rightarrow$ & $\rightarrow$ & $\rightarrow$ & $\rightarrow$ & medium \\
\hline cloxacillin & $\mathrm{N}$ & $Y$ & & $Y^{b}$ & $Y^{b}$ & $Y$ & $\rightarrow$ & $\rightarrow$ & $\rightarrow$ & $\rightarrow$ & $\rightarrow$ & medium \\
\hline colistin & $Y$ & $\rightarrow$ & $\rightarrow$ & $\rightarrow$ & $\rightarrow$ & $\rightarrow$ & $\rightarrow$ & $\rightarrow$ & $\rightarrow$ & $\rightarrow$ & $\rightarrow$ & high \\
\hline danofloxacin & $Y$ & $\rightarrow$ & $\rightarrow$ & $\rightarrow$ & $\rightarrow$ & $\rightarrow$ & $\rightarrow$ & $\rightarrow$ & $\rightarrow$ & $\rightarrow$ & $\rightarrow$ & high \\
\hline dicloxacillin & $\mathrm{N}$ & $Y$ & & & & $\mathrm{~N}$ & $\mathrm{~N}$ & $\mathrm{~N}$ & $\mathrm{~N}$ & $\rightarrow$ & $\rightarrow$ & low \\
\hline difloxacin & $Y$ & $\rightarrow$ & $\rightarrow$ & $\rightarrow$ & $\rightarrow$ & $\rightarrow$ & $\rightarrow$ & $\rightarrow$ & $\rightarrow$ & $\rightarrow$ & $\rightarrow$ & high \\
\hline dihydrostreptomycin & $\mathrm{N}$ & $\mathrm{Y}$ & & & $\mathrm{Y}$ & $\mathrm{Y}$ & $\rightarrow$ & $\rightarrow$ & $\rightarrow$ & $\rightarrow$ & $\rightarrow$ & medium \\
\hline doxycyclin & $\mathrm{N}$ & $\mathrm{N}$ & $\rightarrow$ & $\rightarrow$ & $\rightarrow$ & $\rightarrow$ & $\mathrm{Y}$ & $\rightarrow$ & $Y$ & cascade & $\rightarrow$ & medium \\
\hline enrofloxacin & $Y$ & $\rightarrow$ & $\rightarrow$ & $\rightarrow$ & $\rightarrow$ & $\rightarrow$ & $\rightarrow$ & $\rightarrow$ & $\rightarrow$ & $\rightarrow$ & $\rightarrow$ & high \\
\hline erythromycin & $\mathrm{Y}$ & $\rightarrow$ & $\rightarrow$ & $\rightarrow$ & $\rightarrow$ & $\rightarrow$ & $\rightarrow$ & $\rightarrow$ & $\rightarrow$ & $\rightarrow$ & $\rightarrow$ & high \\
\hline florfenicol & $\mathrm{N}$ & $Y$ & & & & $N$ & $N$ & $\mathrm{Y}$ & $Y$ & $39 d$ & $Y$ & medium \\
\hline flumequine & $Y$ & $\rightarrow$ & $\rightarrow$ & $\rightarrow$ & $\rightarrow$ & $\rightarrow$ & $\rightarrow$ & $\rightarrow$ & $\rightarrow$ & $\rightarrow$ & $\rightarrow$ & high \\
\hline gamithromycin & $\mathrm{Y}$ & $\rightarrow$ & $\rightarrow$ & $\rightarrow$ & $\rightarrow$ & $\rightarrow$ & $\rightarrow$ & $\rightarrow$ & $\rightarrow$ & $\rightarrow$ & $\rightarrow$ & high \\
\hline gentamicin & $\mathrm{N}$ & $\mathrm{Y}$ & & & & $\mathrm{N}$ & $\mathrm{N}$ & $\mathrm{N}$ & $\mathrm{N}$ & $\rightarrow$ & $\rightarrow$ & low \\
\hline josamycin & $\mathrm{N}$ & $\mathrm{N}$ & $\rightarrow$ & $\rightarrow$ & $\rightarrow$ & $\rightarrow$ & $\mathrm{N}$ & $\mathrm{N}$ & $\mathrm{N}$ & $\rightarrow$ & $\rightarrow$ & low \\
\hline
\end{tabular}




\begin{tabular}{|c|c|c|c|c|c|c|c|c|c|c|c|c|}
\hline \multirow{2}{*}{$\begin{array}{l}\text { Italics: not commonly } \\
\text { included in scope } \\
\text { Substance }\end{array}$} & \multirow{2}{*}{$\begin{array}{l}\text { Q1: is this an } \\
\text { essential } \\
\text { antimicrobial for } \\
\text { humans? } \\
\text { Concl Q1 }\end{array}$} & \multirow{2}{*}{$\begin{array}{l}\text { Q2: Have MRLs been } \\
\text { set for this substance } \\
\text { in this animal species? } \\
\text { Concl Q2 }\end{array}$} & \multicolumn{4}{|c|}{$\begin{array}{l}\text { Q3: were any non-compliant residue } \\
\text { data of the substance found in the } \\
\text { last five years? }\end{array}$} & \multicolumn{3}{|c|}{$\begin{array}{l}\text { Q4: Is the substance } \\
\text { regularly used in this } \\
\text { animal species? }\end{array}$} & \multicolumn{2}{|c|}{$\begin{array}{l}\text { Q5: Do drugs with this active } \\
\text { substance have a long } \\
\text { withdrawal period? }\end{array}$} & \multirow{2}{*}{$\begin{array}{c}\begin{array}{c}\text { Conclusion } \\
\text { priority }\end{array} \\
\text { Sheep }\end{array}$} \\
\hline & & & KAP & RASFF & EFSA & Concl Q3 & NC? & $\begin{array}{l}\text { Survey } \\
\text { results }\end{array}$ & $\begin{array}{c}\text { Concl } \\
\text { Q4 }\end{array}$ & Withdrawal time & Concl Q5 & \\
\hline kanamycin & N & Y & & & & $\mathrm{N}$ & N & Y & Y & cascade & Y & medium \\
\hline lincomycin & $\mathrm{N}$ & $Y$ & & & & $\mathrm{~N}$ & $\mathrm{~N}$ & $\mathrm{Y}$ & $Y$ & cascade & $Y$ & medium \\
\hline marbofloxacin & $Y$ & $\rightarrow$ & $\rightarrow$ & $\rightarrow$ & $\rightarrow$ & $\rightarrow$ & $\rightarrow$ & $\rightarrow$ & $\rightarrow$ & $\rightarrow$ & $\rightarrow$ & high \\
\hline nafcillin & $\mathrm{N}$ & $Y$ & & & & $\mathrm{~N}$ & $\mathrm{~N}$ & $\mathrm{~N}$ & $\mathrm{~N}$ & $\rightarrow$ & $\rightarrow$ & low \\
\hline neomycin & $\mathrm{N}$ & $Y$ & $Y$ & & $Y$ & $\mathrm{Y}$ & $\rightarrow$ & $\rightarrow$ & $\rightarrow$ & $\rightarrow$ & $\rightarrow$ & medium \\
\hline novobiocin & $\mathrm{N}$ & $\mathrm{N}$ & $\rightarrow$ & $\rightarrow$ & $\rightarrow$ & $\rightarrow$ & $\mathrm{N}$ & $\mathrm{N}$ & $\mathrm{N}$ & $\rightarrow$ & $\rightarrow$ & low \\
\hline oxacillin & $\mathrm{N}$ & $Y$ & & & & $\mathrm{~N}$ & $\mathrm{~N}$ & $\mathrm{~N}$ & $\mathrm{~N}$ & $\rightarrow$ & $\rightarrow$ & low \\
\hline oxolinic acid & $\mathrm{N}$ & $Y$ & & & & $\mathrm{~N}$ & $\mathrm{~N}$ & $\mathrm{~N}$ & $\mathrm{~N}$ & $\rightarrow$ & $\rightarrow$ & low \\
\hline oxytetracycline & $\mathrm{N}$ & $Y$ & $\mathrm{Y}$ & & $\mathrm{Y}$ & $\mathrm{Y}$ & $\rightarrow$ & $\rightarrow$ & $\rightarrow$ & $\rightarrow$ & $\rightarrow$ & medium \\
\hline paromomycin & $\mathrm{N}$ & $Y$ & & & & $\mathrm{~N}$ & $\mathrm{~N}$ & $Y$ & $\mathrm{Y}$ & cascade & $Y$ & medium \\
\hline phenoxymethylpenicillin & $\mathrm{N}$ & $\mathrm{N}$ & $\rightarrow$ & $\rightarrow$ & $\rightarrow$ & $\rightarrow$ & $\mathrm{Y}$ & $\rightarrow$ & $\rightarrow$ & $\rightarrow$ & $\rightarrow$ & medium \\
\hline pirlimycin & $\mathrm{N}$ & $\mathrm{N}$ & $\rightarrow$ & $\rightarrow$ & $\rightarrow$ & $\rightarrow$ & $\mathrm{N}$ & $\mathrm{N}$ & $\mathrm{N}$ & $\rightarrow$ & $\rightarrow$ & low \\
\hline rifaximin & $\mathrm{N}$ & $\mathrm{N}$ & $\rightarrow$ & $\rightarrow$ & $\rightarrow$ & $\rightarrow$ & N & $\mathrm{N}$ & $\mathrm{N}$ & $\rightarrow$ & $\rightarrow$ & low \\
\hline sarafloxacin & $Y$ & $\rightarrow$ & $\rightarrow$ & $\rightarrow$ & $\rightarrow$ & $\rightarrow$ & $\rightarrow$ & $\rightarrow$ & $\rightarrow$ & $\rightarrow$ & $\rightarrow$ & high \\
\hline spectinomycin & $\mathrm{N}$ & $\mathrm{Y}$ & & & & $\mathrm{N}$ & $\mathrm{N}$ & $\mathrm{Y}$ & $\mathrm{Y}$ & cascade & $\mathrm{Y}$ & medium \\
\hline spiramycin & Y & $\rightarrow$ & $\rightarrow$ & $\rightarrow$ & $\rightarrow$ & $\rightarrow$ & $\rightarrow$ & $\rightarrow$ & $\rightarrow$ & $\rightarrow$ & $\rightarrow$ & high \\
\hline streptomycin & N & Y & & & & $\mathrm{N}$ & $\mathrm{N}$ & $\mathrm{N}$ & $\mathrm{N}$ & $\rightarrow$ & $\rightarrow$ & low \\
\hline sulfachlorpyridazin & $\mathrm{N}$ & $\mathrm{Y}$ & & & & $\mathrm{N}$ & $\mathrm{N}$ & $\mathrm{N}$ & $\mathrm{N}$ & $\rightarrow$ & $\rightarrow$ & low \\
\hline sulfaclozin & $\mathrm{N}$ & $\mathrm{Y}$ & & & & $\mathrm{N}$ & $\mathrm{N}$ & $\mathrm{N}$ & $\mathrm{N}$ & $\rightarrow$ & $\rightarrow$ & low \\
\hline sulfadiazin & $\mathrm{N}$ & $\mathrm{Y}$ & & $\mathrm{Y}$ & $\mathrm{Y}$ & $\mathrm{Y}$ & $\rightarrow$ & $\rightarrow$ & $\rightarrow$ & $\rightarrow$ & $\rightarrow$ & medium \\
\hline sulfadimethoxin & $\mathrm{N}$ & $Y$ & & & $Y$ & $\mathrm{Y}$ & $\rightarrow$ & $\rightarrow$ & $\rightarrow$ & $\rightarrow$ & $\rightarrow$ & medium \\
\hline sulfadoxin & $\mathrm{N}$ & $Y$ & & & & $\mathrm{~N}$ & $\mathrm{Y}$ & $\mathrm{Y}$ & $\mathrm{Y}$ & cascade & $Y$ & medium \\
\hline sulfamethazin (sulfadimidin) & $\mathrm{N}$ & $\mathrm{Y}$ & & & $\mathrm{Y}$ & $\mathrm{Y}$ & $\rightarrow$ & $\rightarrow$ & $\rightarrow$ & $\rightarrow$ & $\rightarrow$ & medium \\
\hline sulfamethoxazol & $\mathrm{N}$ & $\mathrm{Y}$ & & & & $\mathrm{N}$ & $\mathrm{N}$ & $\mathrm{N}$ & $\mathrm{N}$ & $\rightarrow$ & $\rightarrow$ & low \\
\hline sulfapyridine & $\mathrm{N}$ & $\mathrm{Y}$ & & & & $\mathrm{N}$ & $\mathrm{N}$ & $\mathrm{N}$ & $\mathrm{N}$ & $\rightarrow$ & $\rightarrow$ & low \\
\hline sulfaquanidin & $\mathrm{N}$ & $\mathrm{Y}$ & & & & $\mathrm{N}$ & $\mathrm{N}$ & $\mathrm{N}$ & $\mathrm{N}$ & $\rightarrow$ & $\rightarrow$ & low \\
\hline sulfaquinoxalin & $\mathrm{N}$ & $Y$ & & & & $\mathrm{~N}$ & N & $\mathrm{N}$ & $\mathrm{N}$ & $\rightarrow$ & $\rightarrow$ & low \\
\hline tetracycline & $\mathrm{N}$ & Y & & & & $\mathrm{N}$ & N & $Y$ & $Y$ & cascade & $\mathrm{Y}$ & medium \\
\hline thiamphenicol & N & Y & & & & $\mathrm{U}$ & N & $\mathrm{N}$ & $\mathrm{N}$ & $\rightarrow$ & $\rightarrow$ & low \\
\hline tiamulin & N & N & $\rightarrow$ & $\rightarrow$ & $\rightarrow$ & $\rightarrow$ & N & $\mathrm{N}$ & N & $\rightarrow$ & $\rightarrow$ & low \\
\hline tildipirosin & Y & $\rightarrow$ & $\rightarrow$ & $\rightarrow$ & $\rightarrow$ & $\rightarrow$ & $\rightarrow$ & $\rightarrow$ & $\rightarrow$ & $\rightarrow$ & $\rightarrow$ & high \\
\hline tilmicosin & $Y$ & $\rightarrow$ & $\rightarrow$ & $\rightarrow$ & $\rightarrow$ & $\rightarrow$ & $\rightarrow$ & $\rightarrow$ & $\rightarrow$ & $\rightarrow$ & $\rightarrow$ & high \\
\hline
\end{tabular}




\begin{tabular}{|c|c|c|c|c|c|c|c|c|c|c|c|c|}
\hline \multirow{2}{*}{$\begin{array}{l}\text { Italics: not commonly } \\
\text { included in scope } \\
\text { Substance }\end{array}$} & \multirow{2}{*}{$\begin{array}{l}\text { Q1: is this an } \\
\text { essential } \\
\text { antimicrobial for } \\
\text { humans? } \\
\text { Concl Q1 }\end{array}$} & \multirow{2}{*}{$\begin{array}{l}\text { Q2: Have MRLs been } \\
\text { set for this substance } \\
\text { in this animal species? } \\
\text { Concl Q2 }\end{array}$} & \multicolumn{4}{|c|}{$\begin{array}{l}\text { Q3: were any non-compliant residue } \\
\text { data of the substance found in the } \\
\text { last five years? }\end{array}$} & \multicolumn{3}{|c|}{$\begin{array}{l}\text { Q4: Is the substance } \\
\text { regularly used in this } \\
\text { animal species? }\end{array}$} & \multicolumn{2}{|c|}{$\begin{array}{l}\text { Q5: Do drugs with this active } \\
\text { substance have a long } \\
\text { withdrawal period? }\end{array}$} & \multirow{2}{*}{$\begin{array}{l}\begin{array}{c}\text { Conclusion } \\
\text { priority }\end{array} \\
\text { Sheep }\end{array}$} \\
\hline & & & KAP & RASFF & EFSA & Concl Q3 & NC? & $\begin{array}{l}\text { Survey } \\
\text { results }\end{array}$ & $\begin{array}{c}\text { Concl } \\
\text { Q4 }\end{array}$ & Withdrawal time & Concl Q5 & \\
\hline trimethoprim & $\mathrm{N}$ & Y & & & & $\mathrm{N}$ & $\mathrm{N}$ & $\mathrm{Y}$ & Y & cascade & Y & medium \\
\hline tulathromycin & Y & $\rightarrow$ & $\rightarrow$ & $\rightarrow$ & $\rightarrow$ & $\rightarrow$ & $\rightarrow$ & $\rightarrow$ & $\rightarrow$ & $\rightarrow$ & $\rightarrow$ & high \\
\hline tylosin & $Y$ & $\rightarrow$ & $\rightarrow$ & $\rightarrow$ & $\rightarrow$ & $\rightarrow$ & $\rightarrow$ & $\rightarrow$ & $\rightarrow$ & $\rightarrow$ & $\rightarrow$ & high \\
\hline tylvalosin & $Y$ & $\rightarrow$ & $\rightarrow$ & $\rightarrow$ & $\rightarrow$ & $\rightarrow$ & $\rightarrow$ & $\rightarrow$ & $\rightarrow$ & $\rightarrow$ & $\rightarrow$ & high \\
\hline valnemulin & $\mathrm{N}$ & $\mathrm{N}$ & $\rightarrow$ & $\rightarrow$ & $\rightarrow$ & $\rightarrow$ & $\mathrm{N}$ & $\mathrm{N}$ & $\mathrm{N}$ & $\rightarrow$ & $\rightarrow$ & low \\
\hline virginiamycin & $\mathrm{N}$ & $\mathrm{N}$ & $\rightarrow$ & $\rightarrow$ & $\rightarrow$ & $\rightarrow$ & $\mathrm{N}$ & $\mathrm{N}$ & $\mathrm{N}$ & $\rightarrow$ & $\rightarrow$ & low \\
\hline
\end{tabular}

a No differentiation goat/sheep possible.

b goat/sheep milk.

c MRL in milk only.

$\rightarrow$ based on the outcome of the previous question, this question can be skipped. 
Table A1.4 Prioritisation of antibiotics in milk.

\begin{tabular}{|c|c|c|c|c|c|c|c|c|c|c|c|c|c|c|}
\hline \multirow{2}{*}{$\begin{array}{l}\text { Italics: not commonly } \\
\text { included in scope } \\
\text { Substance }\end{array}$} & \multirow{2}{*}{$\begin{array}{l}\text { Q1: is this an } \\
\text { essential } \\
\text { antimicrobial for } \\
\text { humans? } \\
\text { Concl Q1 }\end{array}$} & \multicolumn{3}{|c|}{$\begin{array}{l}\text { Q2: Have MRLs been set for } \\
\text { this substance in this } \\
\text { animal species? }\end{array}$} & \multicolumn{4}{|c|}{$\begin{array}{l}\text { Q3: were any non-compliant residue } \\
\text { data of the substance found in the } \\
\text { last five years? }\end{array}$} & \multicolumn{3}{|c|}{$\begin{array}{l}\text { Q4: Is the substance } \\
\text { regularly used in this } \\
\text { animal species? }\end{array}$} & \multicolumn{2}{|c|}{$\begin{array}{l}\text { Q5: Do drugs with this } \\
\text { active substance have a } \\
\text { long withdrawal period? }\end{array}$} & \multirow{2}{*}{$\begin{array}{c}\begin{array}{c}\text { Conclusion } \\
\text { priority }\end{array} \\
\text { Milk }\end{array}$} \\
\hline & & $\begin{array}{c}\text { MRL } \\
\text { bovine }\end{array}$ & $\begin{array}{l}\text { MRL } \\
\text { milk }\end{array}$ & $\begin{array}{l}\text { Concl } \\
\text { Q2 }\end{array}$ & KAP & RASFF & EFSA & Concl Q3 & NC? & $\begin{array}{c}\text { SDa }(>50000 \\
\text { DDDA })\end{array}$ & $\begin{array}{l}\text { Concl } \\
\text { Q4 }\end{array}$ & Withdrawal time & Concl Q5 & \\
\hline amoxicillin & $\mathrm{N}$ & Y & $\mathrm{Y}$ & $Y$ & & & Y & $\mathrm{Y}$ & $\rightarrow$ & $\rightarrow$ & $\rightarrow$ & $\rightarrow$ & $\rightarrow$ & medium \\
\hline ampicillin & $\mathrm{N}$ & Y & $\mathrm{Y}$ & $\mathrm{Y}$ & & & Y & $\mathrm{Y}$ & $\rightarrow$ & $\rightarrow$ & $\rightarrow$ & $\rightarrow$ & $\rightarrow$ & medium \\
\hline apramycin & $\mathrm{N}$ & Y & $Y$ & Y & & & & $\mathrm{N}$ & $\mathrm{N}$ & $\mathrm{N}$ & $\mathrm{N}$ & $\rightarrow$ & $\rightarrow$ & low \\
\hline avilamycin & $\mathrm{N}$ & $\mathrm{N}$ & $\mathrm{N}$ & $\mathrm{N}$ & $\rightarrow$ & $\rightarrow$ & $\rightarrow$ & $\rightarrow$ & $\mathrm{N}$ & $\mathrm{N}$ & $\mathrm{N}$ & $\rightarrow$ & $\rightarrow$ & low \\
\hline bacitracin & $\mathrm{N}$ & $\mathrm{N}$ & $Y$ & $\mathrm{Y}$ & & & & U & $\mathrm{N}$ & $\mathrm{N}$ & $\mathrm{N}$ & $\rightarrow$ & $\rightarrow$ & low \\
\hline baquiloprim & $\mathrm{N}$ & $Y$ & $Y$ & $\mathrm{Y}$ & & & & $\mathrm{N}$ & $\mathrm{N}$ & $\mathrm{N}$ & $\mathrm{N}$ & $\rightarrow$ & $\rightarrow$ & low \\
\hline benzylpenicillin/penethamate & $\mathrm{N}$ & Y & Y & $\mathrm{Y}$ & & & Y & Y & $\rightarrow$ & $\rightarrow$ & $\rightarrow$ & $\rightarrow$ & $\rightarrow$ & medium \\
\hline cefacetril & $\mathrm{N}$ & $\mathrm{N}$ & Y & $\mathrm{Y}$ & & & & $\mathrm{N}$ & $\mathrm{N}$ & $\mathrm{N}$ & $\mathrm{N}$ & $\rightarrow$ & $\rightarrow$ & low \\
\hline cefalexine & $\mathrm{N}$ & Y & Y & Y & & & Y & Y & $\rightarrow$ & $\rightarrow$ & $\rightarrow$ & $\rightarrow$ & $\rightarrow$ & medium \\
\hline cefalonium & $\mathrm{N}$ & N & Y & Y & & & Y & Y & $\rightarrow$ & $\rightarrow$ & $\rightarrow$ & $\rightarrow$ & $\rightarrow$ & medium \\
\hline cefapirin & $\mathrm{N}$ & Y & Y & Y & & & & $\mathrm{N}$ & $\mathrm{N}$ & Y & Y & $0-33 d$ & $\mathrm{Y}$ & medium \\
\hline cefazolin & $\mathrm{N}$ & $\mathrm{N}$ & Y & Y & & & Y & Y & $\rightarrow$ & $\rightarrow$ & $\rightarrow$ & $\rightarrow$ & $\rightarrow$ & medium \\
\hline cefoperazon & Y & $\rightarrow$ & $\rightarrow$ & $\rightarrow$ & $\rightarrow$ & $\rightarrow$ & $\rightarrow$ & $\rightarrow$ & $\rightarrow$ & $\rightarrow$ & $\rightarrow$ & $\rightarrow$ & $\rightarrow$ & high \\
\hline cefquinome & Y & $\rightarrow$ & $\rightarrow$ & $\rightarrow$ & $\rightarrow$ & $\rightarrow$ & $\rightarrow$ & $\rightarrow$ & $\rightarrow$ & $\rightarrow$ & $\rightarrow$ & $\rightarrow$ & $\rightarrow$ & high \\
\hline ceftiofur & Y & $\rightarrow$ & $\rightarrow$ & $\rightarrow$ & $\rightarrow$ & $\rightarrow$ & $\rightarrow$ & $\rightarrow$ & $\rightarrow$ & $\rightarrow$ & $\rightarrow$ & $\rightarrow$ & $\rightarrow$ & high \\
\hline chlortetracycline & $\mathrm{N}$ & $Y$ & Y & $\mathrm{Y}$ & & & & $\mathrm{N}$ & $\mathrm{N}$ & $\mathrm{N}$ & $\mathrm{N}$ & $\rightarrow$ & $\rightarrow$ & low \\
\hline cloxacillin & $\mathrm{N}$ & $Y$ & $Y$ & $\mathrm{Y}$ & & $Y$ & Y & Y & $\rightarrow$ & $\rightarrow$ & $\rightarrow$ & $\rightarrow$ & $\rightarrow$ & medium \\
\hline colistin & $\mathrm{Y}$ & $\rightarrow$ & $\rightarrow$ & $\rightarrow$ & $\rightarrow$ & $\rightarrow$ & $\rightarrow$ & $\rightarrow$ & $\rightarrow$ & $\rightarrow$ & $\rightarrow$ & $\rightarrow$ & $\rightarrow$ & high \\
\hline danofloxacin & $\mathrm{Y}$ & $\rightarrow$ & $\rightarrow$ & $\rightarrow$ & $\rightarrow$ & $\rightarrow$ & $\rightarrow$ & $\rightarrow$ & $\rightarrow$ & $\rightarrow$ & $\rightarrow$ & $\rightarrow$ & $\rightarrow$ & high \\
\hline dicloxacillin & $\mathrm{N}$ & $Y$ & $Y$ & $\mathrm{Y}$ & & & & $\mathrm{N}$ & $\mathrm{N}$ & $\mathrm{N}$ & $\mathrm{N}$ & $\rightarrow$ & $\rightarrow$ & low \\
\hline difloxacin & $\mathrm{Y}$ & $\rightarrow$ & $\rightarrow$ & $\rightarrow$ & $\rightarrow$ & $\rightarrow$ & $\rightarrow$ & $\rightarrow$ & $\rightarrow$ & $\rightarrow$ & $\rightarrow$ & $\rightarrow$ & $\rightarrow$ & high \\
\hline dihydrostreptomycin & $\mathrm{N}$ & $\mathrm{Y}$ & $Y$ & $\mathrm{Y}$ & & & $\mathrm{Y}$ & $\mathrm{Y}$ & $\rightarrow$ & $\rightarrow$ & $\rightarrow$ & $\rightarrow$ & $\rightarrow$ & medium \\
\hline doxycyclin & $\mathrm{N}$ & Y & $\mathrm{N}$ & $\mathrm{Y}$ & & & Y & Y & $\rightarrow$ & $\rightarrow$ & $\rightarrow$ & $\rightarrow$ & $\rightarrow$ & medium \\
\hline enrofloxacin & Y & $\rightarrow$ & $\rightarrow$ & $\rightarrow$ & $\rightarrow$ & $\rightarrow$ & $\rightarrow$ & $\rightarrow$ & $\rightarrow$ & $\rightarrow$ & $\rightarrow$ & $\rightarrow$ & $\rightarrow$ & high \\
\hline erythromycin & Y & $\rightarrow$ & $\rightarrow$ & $\rightarrow$ & $\rightarrow$ & $\rightarrow$ & $\rightarrow$ & $\rightarrow$ & $\rightarrow$ & $\rightarrow$ & $\rightarrow$ & $\rightarrow$ & $\rightarrow$ & high \\
\hline florfenicol & $\mathrm{N}$ & $\mathrm{Y}$ & $\mathrm{N}$ & Y & & & $\mathrm{Y}$ & $\mathrm{Y}$ & $\rightarrow$ & $\rightarrow$ & $\rightarrow$ & $\rightarrow$ & $\rightarrow$ & medium \\
\hline flumequine & Y & $\rightarrow$ & $\rightarrow$ & $\rightarrow$ & $\rightarrow$ & $\rightarrow$ & $\rightarrow$ & $\rightarrow$ & $\rightarrow$ & $\rightarrow$ & $\rightarrow$ & $\rightarrow$ & $\rightarrow$ & high \\
\hline gamithromycin & $\mathrm{Y}$ & $\rightarrow$ & $\rightarrow$ & $\rightarrow$ & $\rightarrow$ & $\rightarrow$ & $\rightarrow$ & $\rightarrow$ & $\rightarrow$ & $\rightarrow$ & $\rightarrow$ & $\rightarrow$ & $\rightarrow$ & high \\
\hline gentamicin & $N$ & $Y$ & $Y$ & $Y$ & & & $Y$ & $Y$ & $\rightarrow$ & $\rightarrow$ & $\rightarrow$ & $\rightarrow$ & $\rightarrow$ & medium \\
\hline josamycin & $\mathrm{N}$ & $\mathrm{N}$ & $\mathrm{N}$ & $\mathrm{N}$ & $\rightarrow$ & $\rightarrow$ & $\rightarrow$ & $\rightarrow$ & $\mathrm{N}$ & $\mathrm{N}$ & $\mathrm{N}$ & $\rightarrow$ & $\rightarrow$ & low \\
\hline
\end{tabular}




\begin{tabular}{|c|c|c|c|c|c|c|c|c|c|c|}
\hline \multirow{2}{*}{$\begin{array}{l}\text { Italics: not commonly } \\
\text { included in scope } \\
\text { Substance }\end{array}$} & \multirow{2}{*}{$\begin{array}{l}\text { Q1: is this an } \\
\text { essential } \\
\text { antimicrobial for } \\
\text { humans? } \\
\text { Concl Q1 }\end{array}$} & \multicolumn{3}{|c|}{$\begin{array}{l}\text { Q2: Have MRLs been set for } \\
\text { this substance in this } \\
\text { animal species? }\end{array}$} & \multicolumn{4}{|c|}{$\begin{array}{l}\text { Q3: were any non-compliant residue } \\
\text { data of the substance found in the } \\
\text { last five years? }\end{array}$} & \multicolumn{2}{|r|}{$\begin{array}{l}\text { Q4: Is the substance } \\
\text { regularly used in thi } \\
\text { animal species? }\end{array}$} \\
\hline & & $\begin{array}{c}\text { MRL } \\
\text { bovine }\end{array}$ & $\begin{array}{l}\text { MRL } \\
\text { milk }\end{array}$ & $\begin{array}{l}\text { Concl } \\
\text { Q2 }\end{array}$ & KAP & RASFF & EFSA & Concl Q3 & NC? & $\begin{array}{c}\text { SDa }(>50000 \\
\text { DDDA })\end{array}$ \\
\hline kanamycin & N & Y & Y & Y & & & Y & Y & $\rightarrow$ & $\rightarrow$ \\
\hline lincomycin & $\mathrm{N}$ & Y & $\mathrm{Y}$ & $\mathrm{Y}$ & & & $\mathrm{Y}$ & $\mathrm{Y}$ & $\rightarrow$ & $\rightarrow$ \\
\hline marbofloxacin & $\mathrm{Y}$ & $\rightarrow$ & $\rightarrow$ & $\rightarrow$ & $\rightarrow$ & $\rightarrow$ & $\rightarrow$ & $\rightarrow$ & $\rightarrow$ & $\rightarrow$ \\
\hline nafcillin & $\mathrm{N}$ & $Y$ & $\mathrm{Y}$ & $Y$ & & & & $\mathrm{~N}$ & $\mathrm{~N}$ & $\mathrm{~N}$ \\
\hline neomycin & $\mathrm{N}$ & $Y$ & $\mathrm{Y}$ & $Y$ & & & & $\mathrm{~N}$ & $\mathrm{~N}$ & $Y$ \\
\hline novobiocin & $\mathrm{N}$ & $\mathrm{N}$ & $\mathrm{Y}$ & $\mathrm{Y}$ & & & & $\mathrm{N}$ & $\mathrm{N}$ & $\mathrm{N}$ \\
\hline oxacillin & $\mathrm{N}$ & $Y$ & $\mathrm{Y}$ & $Y$ & & & & $\mathrm{~N}$ & $\mathrm{~N}$ & $\mathrm{~N}$ \\
\hline oxolinic acid & $\mathrm{N}$ & Y & $\mathrm{N}$ & $Y$ & & & & $\mathrm{~N}$ & $\mathrm{~N}$ & $\mathrm{~N}$ \\
\hline oxytetracycline & $\mathrm{N}$ & $Y$ & $Y$ & $Y$ & & & Y & $Y$ & $\rightarrow$ & $\rightarrow$ \\
\hline paromomycin & $\mathrm{N}$ & $Y$ & $\mathrm{~N}$ & $Y$ & & & & $\mathrm{~N}$ & $\mathrm{~N}$ & $\mathrm{~N}$ \\
\hline phenoxymethylpenicillin & $\mathrm{N}$ & $\mathrm{N}$ & $\mathrm{N}$ & $\mathrm{N}$ & $\rightarrow$ & $\rightarrow$ & $\rightarrow$ & $\rightarrow$ & $\mathrm{N}$ & $\mathrm{N}$ \\
\hline pirlimycin & $\mathrm{N}$ & Y & $\mathrm{Y}$ & $Y$ & & & & $\mathrm{~N}$ & $\mathrm{~N}$ & N \\
\hline rifaximin & $\mathrm{N}$ & N & $\mathrm{Y}$ & Y & & & & N & $\mathrm{N}$ & N \\
\hline sarafloxacin & Y & $\rightarrow$ & $\rightarrow$ & $\rightarrow$ & $\rightarrow$ & $\rightarrow$ & $\rightarrow$ & $\rightarrow$ & $\rightarrow$ & $\rightarrow$ \\
\hline spectinomycin & $\mathrm{N}$ & Y & $\mathrm{Y}$ & Y & & & & N & $\mathrm{N}$ & N \\
\hline spiramycin & Y & $\rightarrow$ & $\rightarrow$ & $\rightarrow$ & $\rightarrow$ & $\rightarrow$ & $\rightarrow$ & $\rightarrow$ & $\rightarrow$ & $\rightarrow$ \\
\hline streptomycin & $\mathrm{N}$ & Y & $\mathrm{Y}$ & Y & & & & $\mathrm{N}$ & $\mathrm{N}$ & $\mathrm{N}$ \\
\hline sulfachlorpyridazin & $\mathrm{N}$ & $Y$ & $\mathrm{Y}$ & $Y$ & & & & $\mathrm{~N}$ & $\mathrm{~N}$ & $\mathrm{~N}$ \\
\hline sulfaclozin & $\mathrm{N}$ & Y & $\mathrm{Y}$ & $\mathrm{Y}$ & & & & $\mathrm{N}$ & $\mathrm{N}$ & $\mathrm{N}$ \\
\hline sulfadiazin & $\mathrm{N}$ & Y & $\mathrm{Y}$ & $Y$ & & & & $\mathrm{~N}$ & $\mathrm{~N}$ & Y \\
\hline sulfadimethoxin & $\mathrm{N}$ & Y & $\mathrm{Y}$ & $Y$ & & & & $\mathrm{~N}$ & $\mathrm{~N}$ & $\mathrm{~N}$ \\
\hline sulfadoxin & $\mathrm{N}$ & Y & $\mathrm{Y}$ & $\mathrm{Y}$ & & & & $\mathrm{N}$ & $\mathrm{N}$ & Y \\
\hline sulfamethazin (sulfadimidin) & $\mathrm{N}$ & $\mathrm{Y}$ & $\mathrm{Y}$ & $Y$ & & & & $\mathrm{~N}$ & $\mathrm{~N}$ & $\mathrm{~N}$ \\
\hline sulfamethoxazol & $\mathrm{N}$ & $\mathrm{Y}$ & $\mathrm{Y}$ & $\mathrm{Y}$ & & & & $\mathrm{N}$ & $\mathrm{N}$ & $\mathrm{N}$ \\
\hline sulfapyridine & $\mathrm{N}$ & Y & $\mathrm{Y}$ & $\mathrm{Y}$ & & & & $\mathrm{N}$ & $\mathrm{N}$ & $\mathrm{N}$ \\
\hline sulfaquanidin & $\mathrm{N}$ & $\mathrm{Y}$ & $\mathrm{Y}$ & $\mathrm{Y}$ & & & & $\mathrm{N}$ & $\mathrm{N}$ & $\mathrm{N}$ \\
\hline sulfaquinoxalin & $\mathrm{N}$ & Y & $\mathrm{Y}$ & Y & & & & N & $\mathrm{N}$ & $\mathrm{N}$ \\
\hline tetracycline & $\mathrm{N}$ & Y & Y & $Y$ & & Y & Y & Y & $\rightarrow$ & $\rightarrow$ \\
\hline thiamphenicol & $\mathrm{N}$ & Y & $\mathrm{Y}$ & $Y$ & & & & $u$ & $\mathrm{~N}$ & N \\
\hline tiamulin & $\mathrm{N}$ & N & $\mathrm{N}$ & $\mathrm{N}$ & $\rightarrow$ & $\rightarrow$ & $\rightarrow$ & $\rightarrow$ & $\mathrm{N}$ & N \\
\hline tildipirosin & Y & $\rightarrow$ & $\rightarrow$ & $\rightarrow$ & $\rightarrow$ & $\rightarrow$ & $\rightarrow$ & $\rightarrow$ & $\rightarrow$ & $\rightarrow$ \\
\hline tilmicosin & Y & $\rightarrow$ & $\rightarrow$ & $\rightarrow$ & $\rightarrow$ & $\rightarrow$ & $\rightarrow$ & $\rightarrow$ & $\rightarrow$ & $\rightarrow$ \\
\hline
\end{tabular}

\begin{tabular}{|c|c|c|}
\hline \multicolumn{2}{|c|}{$\begin{array}{l}\text { 5: Do drugs with this } \\
\text { tive substance have a } \\
\text { ng withdrawal period? }\end{array}$} & $\begin{array}{c}\text { Conclusior } \\
\text { priority }\end{array}$ \\
\hline hdrawal time & Concl Q5 & Milk \\
\hline$\rightarrow$ & $\rightarrow$ & medium \\
\hline$\rightarrow$ & $\rightarrow$ & medium \\
\hline$\rightarrow$ & $\rightarrow$ & high \\
\hline$\rightarrow$ & $\rightarrow$ & low \\
\hline $36 h-54 d$ & $Y$ & medium \\
\hline$\rightarrow$ & $\rightarrow$ & low \\
\hline$\rightarrow$ & $\rightarrow$ & low \\
\hline$\rightarrow$ & $\rightarrow$ & low \\
\hline$\rightarrow$ & $\rightarrow$ & medium \\
\hline$\rightarrow$ & $\rightarrow$ & low \\
\hline$\rightarrow$ & $\rightarrow$ & low \\
\hline$\rightarrow$ & $\rightarrow$ & low \\
\hline$\rightarrow$ & $\rightarrow$ & low \\
\hline$\rightarrow$ & $\rightarrow$ & high \\
\hline$\rightarrow$ & $\rightarrow$ & low \\
\hline$\rightarrow$ & $\rightarrow$ & high \\
\hline$\rightarrow$ & $\rightarrow$ & low \\
\hline$\rightarrow$ & $\rightarrow$ & low \\
\hline$\rightarrow$ & $\rightarrow$ & low \\
\hline $2-7 d$ & $Y$ & medium \\
\hline$\rightarrow$ & $\rightarrow$ & low \\
\hline $3 d$ & $\mathrm{~N}$ & low \\
\hline$\rightarrow$ & $\rightarrow$ & low \\
\hline$\rightarrow$ & $\rightarrow$ & low \\
\hline$\rightarrow$ & $\rightarrow$ & low \\
\hline$\rightarrow$ & $\rightarrow$ & low \\
\hline$\rightarrow$ & $\rightarrow$ & low \\
\hline$\rightarrow$ & $\rightarrow$ & medium \\
\hline$\rightarrow$ & $\rightarrow$ & low \\
\hline$\rightarrow$ & $\rightarrow$ & low \\
\hline$\rightarrow$ & $\rightarrow$ & high \\
\hline$\rightarrow$ & $\rightarrow$ & high \\
\hline
\end{tabular}




\begin{tabular}{|c|c|c|c|c|c|c|c|c|c|c|c|c|c|c|}
\hline \multirow{2}{*}{$\begin{array}{l}\text { Italics: not commonly } \\
\text { included in scope } \\
\text { Substance }\end{array}$} & \multirow{2}{*}{$\begin{array}{l}\text { Q1: is this an } \\
\text { essential } \\
\text { antimicrobial for } \\
\text { humans? } \\
\text { Concl Q1 }\end{array}$} & \multicolumn{3}{|c|}{$\begin{array}{l}\text { Q2: Have MRLs been set for } \\
\text { this substance in this } \\
\text { animal species? }\end{array}$} & \multicolumn{4}{|c|}{$\begin{array}{l}\text { Q3: were any non-compliant residue } \\
\text { data of the substance found in the } \\
\text { last five years? }\end{array}$} & \multicolumn{3}{|c|}{$\begin{array}{l}\text { Q4: Is the substance } \\
\text { regularly used in this } \\
\text { animal species? }\end{array}$} & \multicolumn{2}{|c|}{$\begin{array}{l}\text { Q5: Do drugs with this } \\
\text { active substance have a } \\
\text { long withdrawal period? }\end{array}$} & \multirow{2}{*}{$\begin{array}{c}\begin{array}{c}\text { Conclusion } \\
\text { priority }\end{array} \\
\text { Milk }\end{array}$} \\
\hline & & $\begin{array}{c}\text { MRL } \\
\text { bovine }\end{array}$ & $\begin{array}{l}\text { MRL } \\
\text { milk }\end{array}$ & $\begin{array}{c}\text { Concl } \\
\text { Q2 }\end{array}$ & KAP & RASFF & EFSA & Concl Q3 & NC? & $\begin{array}{c}\text { SDa }(>50000 \\
\text { DDDA })\end{array}$ & $\begin{array}{c}\text { Concl } \\
\text { Q4 }\end{array}$ & Withdrawal time & Concl Q5 & \\
\hline trimethoprim & $\mathrm{N}$ & $Y$ & $Y$ & $Y$ & & & $Y$ & $Y$ & $\rightarrow$ & $\rightarrow$ & $\rightarrow$ & $\rightarrow$ & $\rightarrow$ & medium \\
\hline tulathromycin & $\mathrm{Y}$ & $\rightarrow$ & $\rightarrow$ & $\rightarrow$ & $\rightarrow$ & $\rightarrow$ & $\rightarrow$ & $\rightarrow$ & $\rightarrow$ & $\rightarrow$ & $\rightarrow$ & $\rightarrow$ & $\rightarrow$ & high \\
\hline tylosin & $Y$ & $\rightarrow$ & $\rightarrow$ & $\rightarrow$ & $\rightarrow$ & $\rightarrow$ & $\rightarrow$ & $\rightarrow$ & $\rightarrow$ & $\rightarrow$ & $\rightarrow$ & $\rightarrow$ & $\rightarrow$ & high \\
\hline tylvalosin & $Y$ & $\rightarrow$ & $\rightarrow$ & $\rightarrow$ & $\rightarrow$ & $\rightarrow$ & $\rightarrow$ & $\rightarrow$ & $\rightarrow$ & $\rightarrow$ & $\rightarrow$ & $\rightarrow$ & $\rightarrow$ & high \\
\hline valnemulin & $\mathrm{N}$ & $\mathrm{N}$ & $N$ & $\mathrm{~N}$ & $\rightarrow$ & $\rightarrow$ & $\rightarrow$ & $\rightarrow$ & $\mathrm{N}$ & $\mathrm{N}$ & $\mathrm{N}$ & $\rightarrow$ & $\rightarrow$ & low \\
\hline virginiamycin & $\mathrm{N}$ & $\mathrm{N}$ & $N$ & $\mathrm{~N}$ & $\rightarrow$ & $\rightarrow$ & $\rightarrow$ & $\rightarrow$ & $\mathrm{N}$ & $\mathrm{N}$ & $\mathrm{N}$ & $\rightarrow$ & $\rightarrow$ & low \\
\hline
\end{tabular}

$\rightarrow$ based on the outcome of the previous question, this question can be skipped. 


\section{Annex 2 Prioritisation of unauthorised antiparasitics using decision tree I for animal products in general}

\begin{tabular}{|c|c|c|c|c|c|c|c|c|c|c|c|}
\hline \multirow[b]{2}{*}{ Substance } & \multicolumn{3}{|c|}{$\begin{array}{l}\text { Q1: Were any non-compliant residue } \\
\text { data of the substance found in the } \\
\text { last five years? }\end{array}$} & \multicolumn{5}{|c|}{$\begin{array}{l}\text { Q3: Are there indications for use of this substance in production systems } \\
\qquad \text { for food producing animals? }\end{array}$} & \multicolumn{2}{|c|}{$\begin{array}{l}\text { Q2: Is a human health risk due to residues } \\
\text { of this substance scientifically proven to be } \\
\text { absent or negligible? }\end{array}$} & \multirow[t]{2}{*}{$\begin{array}{l}\text { Conclusior } \\
\text { priority }\end{array}$} \\
\hline & RASFF & EFSA & Concl Q1 & $\begin{array}{l}\text { NL/EU registered } \\
\text { for companion } \\
\text { animals }\end{array}$ & $\begin{array}{l}\text { Used as } \\
\text { pesticide }\end{array}$ & $\begin{array}{l}\text { Availability- } \\
\text { other }\end{array}$ & $\begin{array}{l}\text { Pesticide residues } \\
\text { found in animal } \\
\text { products? }\end{array}$ & $\begin{array}{l}\text { Concl } \\
\text { Q3 }\end{array}$ & Source & $\begin{array}{c}\text { Concl } \\
\text { Q2 }\end{array}$ & \\
\hline afoxolaner & $\mathrm{N}$ & $\mathrm{U}$ & $\mathrm{N}$ & $\mathrm{Y}$ & $\mathrm{N}$ & & & $\mathrm{Y}$ & $\mathrm{U}$ & $\mathrm{u}$ & high* \\
\hline bithionol & $\mathrm{N}$ & $\mathrm{N}^{\mathrm{a}}$ & $\mathrm{N}$ & $\mathrm{N}$ & $\mathrm{N}$ & bolus (USA) & & $\mathrm{N}$ & $\rightarrow$ & $\rightarrow$ & low \\
\hline emodepside & $\mathrm{N}$ & u & $\mathrm{N}$ & Y & $\mathrm{N}$ & & & $Y$ & U & u & high* \\
\hline fipronil & $\mathrm{N}$ & $\mathrm{N}^{\mathrm{a}}$ & $\mathrm{N}$ & $Y$ & $Y$ & $\begin{array}{l}\text { Pour on (South } \\
\text { America) }\end{array}$ & & $Y$ & $\begin{array}{l}\text { NVWA: human risks are low for poultry } \\
\text { meat and eggs. However, children may } \\
\text { exceed the ADI }\end{array}$ & N & high \\
\hline imidacloprid & $N$ & $\mathrm{~N}$ & $\mathrm{~N}$ & $Y$ & $Y$ & & $U$ & $Y$ & $\begin{array}{l}\text { EFSA/JECFA: residues were found in } \\
\text { animal products }\end{array}$ & N & high \\
\hline indoxacarb & $\mathrm{N}$ & $\mathrm{N}^{\mathrm{a}}$ & $\mathrm{N}$ & $Y$ & $Y$ & & $\mathrm{~N}$ & $\mathrm{~N}$ & $\rightarrow$ & $\rightarrow$ & low \\
\hline lotilaner & $\mathrm{N}$ & $U$ & $\mathrm{~N}$ & $Y$ & $\mathrm{~N}$ & & & $Y$ & U & u & high* \\
\hline lufenuron & $\mathrm{N}$ & $\mathrm{N}$ & $\mathrm{N}$ & Y & $Y$ & & U & Y & $\begin{array}{l}\text { EFSA/JECFA: residues were found in } \\
\text { animal products }\end{array}$ & N & high \\
\hline methopreen & $N$ & $\mathrm{~N}$ & $\mathrm{~N}$ & $Y$ & $Y$ & $\begin{array}{l}\text { Feed additive, } \\
\text { salt-lick (US) }\end{array}$ & U & $Y$ & $\begin{array}{l}\text { EFSA/JECFA: residues were found in } \\
\text { animal products }\end{array}$ & $N$ & high \\
\hline milbemectin & $\mathrm{N}$ & $\mathrm{N}$ & $\mathrm{N}$ & $\mathrm{N}$ & $\mathrm{Y}$ & & & $\mathrm{N}$ & $\rightarrow$ & $\rightarrow$ & low \\
\hline $\begin{array}{l}\text { milbemycine } \\
\text { oxime }\end{array}$ & U & $\mathrm{N}$ & U & $Y$ & $\mathrm{~N}$ & & & $Y$ & U & U & high* \\
\hline niclosamide & $\mathrm{N}$ & $\mathrm{N}$ & $\mathrm{N}$ & $Y$ & $\mathrm{~N}$ & & & $Y$ & U & U & high* \\
\hline nitroscanate & u & $\mathrm{N}$ & u & $\mathrm{Y}$ & $\mathrm{N}$ & & & Y & u & u & high* \\
\hline oxantel & $\mathrm{N}$ & $\mathrm{N}$ & $\mathrm{N}$ & $\mathrm{Y}$ & $\mathrm{N}$ & & & $\mathrm{Y}$ & u & u & high* \\
\hline pyriprole & u & $\mathrm{N}$ & u & $\mathrm{Y}$ & $\mathrm{N}$ & & & $\mathrm{Y}$ & u & u & high* \\
\hline pyriproxyfen & $\mathrm{N}$ & $\mathrm{N}$ & $\mathrm{N}$ & $\mathrm{Y}$ & $\mathrm{Y}$ & & u & Y & EFSA: residues unlikely & $\mathrm{Y}$ & medium \\
\hline sarolaner & u & $\mathrm{N}$ & u & $\mathrm{Y}$ & $\mathrm{N}$ & & & $\mathrm{Y}$ & $\mathrm{u}$ & $\mathrm{u}$ & high* \\
\hline selamectin & u & $\mathrm{N}$ & u & $\mathrm{Y}$ & $\mathrm{N}$ & & & $\mathrm{Y}$ & u & u & high* \\
\hline spinosad & $\mathrm{N}$ & $\mathrm{N}$ & $\mathrm{N}$ & $\mathrm{Y}$ & Y & & $\mathrm{N}$ & $\mathrm{N}$ & $\rightarrow$ & $\rightarrow$ & low \\
\hline
\end{tabular}




\section{Annex 3 Prioritisation of authorised antiparasitics using decision tree III}

Table A3.1 Prioritisation of antiparasitics in horse.

\begin{tabular}{|c|c|c|c|c|c|c|c|c|c|c|c|c|}
\hline \multirow[b]{2}{*}{ Substance } & \multirow{2}{*}{$\begin{array}{l}\text { Q1: is this an } \\
\text { essential } \\
\text { antimicrobial for } \\
\text { humans? } \\
\text { Concl Q1 }\end{array}$} & \multirow{2}{*}{$\begin{array}{l}\text { Q2: Have MRLs been } \\
\text { set for this substance } \\
\text { in this animal } \\
\text { species? } \\
\text { Concl Q2 }\end{array}$} & \multicolumn{4}{|c|}{$\begin{array}{l}\text { Q3: were any non-compliant residue } \\
\text { data of the substance found in the } \\
\text { last five years? }\end{array}$} & \multicolumn{3}{|c|}{$\begin{array}{l}\text { Q4: Is the substance } \\
\text { regularly used in this animal } \\
\text { species? }\end{array}$} & \multicolumn{2}{|c|}{$\begin{array}{l}\text { Q5: Do drugs with this } \\
\text { active substance have a long } \\
\text { withdrawal period? }\end{array}$} & \multirow{2}{*}{$\begin{array}{c}\text { Conclusion } \\
\text { priority } \\
\text { Horse }\end{array}$} \\
\hline & & & KAP & RASFF & EFSA & Concl Q3 & $\begin{array}{c}\text { NC } \\
\text { results? }\end{array}$ & $\begin{array}{c}\text { FIDIN (> } \\
10 \mathrm{~kg})\end{array}$ & $\begin{array}{c}\text { Concl } \\
\text { Q4 }\end{array}$ & Withdrawal time & Concl Q5 & \\
\hline Ivermectin & $\mathrm{N}$ & Y & $\mathrm{N}$ & $\mathrm{N}$ & $\mathrm{N}$ & $\mathrm{N}$ & $\mathrm{N}$ & Y & Y & up to $35 d$ & Y & medium \\
\hline Doramectin & $\mathrm{N}$ & Y & $\mathrm{N}$ & $\mathrm{N}$ & $\mathrm{N}$ & $\mathrm{N}$ & $\mathrm{N}$ & $\mathrm{N}$ & $\mathrm{N}$ & $\rightarrow$ & $\rightarrow$ & low \\
\hline Abamectin & $\mathrm{N}$ & $\mathrm{N}$ & $\rightarrow$ & $\rightarrow$ & $\rightarrow$ & $\rightarrow$ & $\mathrm{N}$ & $\mathrm{N}$ & $\mathrm{N}$ & $\rightarrow$ & $\rightarrow$ & low \\
\hline Moxidectin & $\mathrm{N}$ & Y & $\mathrm{N}$ & $\mathrm{N}$ & $\mathrm{N}$ & $\mathrm{N}$ & $\mathrm{N}$ & Y & Y & up to $64 d$ & $Y$ & medium \\
\hline Emamectin & $\mathrm{N}$ & $\mathrm{N}$ & $\rightarrow$ & $\rightarrow$ & $\rightarrow$ & $\rightarrow$ & $\mathrm{N}$ & $\mathrm{N}$ & $\mathrm{N}$ & $\rightarrow$ & $\rightarrow$ & low \\
\hline Eprinomectin & $\mathrm{N}$ & Y & $\mathrm{N}$ & $\mathrm{N}$ & $\mathrm{N}$ & $\mathrm{N}$ & $\mathrm{N}$ & $\mathrm{N}$ & $\mathrm{N}$ & $\rightarrow$ & $\rightarrow$ & low \\
\hline Albendazole (oxide), Netobimine & $\mathrm{N}$ & $\mathrm{N}$ & $\rightarrow$ & $\rightarrow$ & $\rightarrow$ & $\rightarrow$ & $\mathrm{N}$ & $\mathrm{N}$ & $\mathrm{N}$ & $\rightarrow$ & $\rightarrow$ & low \\
\hline Febantel & $\mathrm{N}$ & Y & $\mathrm{N}$ & $\mathrm{N}$ & $\mathrm{N}$ & $\mathrm{N}$ & $\mathrm{N}$ & $\mathrm{N}$ & $\mathrm{N}$ & & & medium \\
\hline Fenbendazole & $\mathrm{N}$ & Y & $\mathrm{N}$ & $\mathrm{N}$ & $\mathrm{N}$ & $\mathrm{N}$ & N & Y & Y & up to $20 \mathrm{~d}$ & Y & \\
\hline Oxfendazole & $\mathrm{N}$ & $Y$ & $\mathrm{~N}$ & $\mathrm{~N}$ & $\mathrm{~N}$ & $\mathrm{~N}$ & $\mathrm{~N}$ & $\mathrm{~N}$ & $\mathrm{~N}$ & & & \\
\hline Oxibendazole & $\mathrm{N}$ & $\mathrm{N}$ & $\rightarrow$ & $\rightarrow$ & $\rightarrow$ & $\rightarrow$ & $\mathrm{N}$ & $\mathrm{N}$ & $\mathrm{N}$ & $\rightarrow$ & $\rightarrow$ & low \\
\hline Mebendazole & $\mathrm{N}$ & Y & $\mathrm{N}$ & $\mathrm{N}$ & $\mathrm{N}$ & $\mathrm{N}$ & $\mathrm{N}$ & $\mathrm{N}$ & $\mathrm{N}$ & $\rightarrow$ & $\rightarrow$ & low \\
\hline Flubendazole & $\mathrm{N}$ & $\mathrm{N}$ & $\rightarrow$ & $\rightarrow$ & $\rightarrow$ & $\rightarrow$ & $\mathrm{N}$ & $\mathrm{N}$ & $\mathrm{N}$ & $\rightarrow$ & $\rightarrow$ & low \\
\hline Thiabendazole & $\mathrm{N}$ & $\mathrm{N}$ & $\rightarrow$ & $\rightarrow$ & $\rightarrow$ & $\rightarrow$ & $\mathrm{N}$ & $\mathrm{N}$ & $\mathrm{N}$ & $\rightarrow$ & $\rightarrow$ & low \\
\hline Levamisole & $\mathrm{N}$ & $\mathrm{N}$ & $\rightarrow$ & $\rightarrow$ & $\rightarrow$ & $\rightarrow$ & $\mathrm{N}$ & $\mathrm{N}$ & $\mathrm{N}$ & $\rightarrow$ & $\rightarrow$ & low \\
\hline Triclabendazol & $\mathrm{N}$ & $\mathrm{N}$ & $\rightarrow$ & $\rightarrow$ & $\rightarrow$ & $\rightarrow$ & $\mathrm{N}$ & $\mathrm{N}$ & $\mathrm{N}$ & $\rightarrow$ & $\rightarrow$ & low \\
\hline Amitraz & $\mathrm{N}$ & $\mathrm{N}$ & $\rightarrow$ & $\rightarrow$ & $\rightarrow$ & $\rightarrow$ & $\mathrm{N}$ & $\mathrm{N}$ & $\mathrm{N}$ & $\rightarrow$ & $\rightarrow$ & low \\
\hline Clorsulon & $\mathrm{N}$ & $\mathrm{N}$ & $\rightarrow$ & $\rightarrow$ & $\rightarrow$ & $\rightarrow$ & $\mathrm{N}$ & $\mathrm{N}$ & $\mathrm{N}$ & $\rightarrow$ & $\rightarrow$ & low \\
\hline Closantel & $\mathrm{N}$ & $\mathrm{N}$ & $\rightarrow$ & $\rightarrow$ & $\rightarrow$ & $\rightarrow$ & $Y$ & $\rightarrow$ & $\rightarrow$ & cascade & $\rightarrow$ & medium \\
\hline
\end{tabular}




\begin{tabular}{|c|c|c|c|c|c|c|c|c|c|}
\hline & $\begin{array}{c}\text { Q1: is this an } \\
\text { essential } \\
\text { antimicrobial for } \\
\text { humans? }\end{array}$ & $\begin{array}{l}\text { Q2: Have MRLs been } \\
\text { set for this substance } \\
\text { in this animal } \\
\text { species? }\end{array}$ & $\begin{array}{r}\text { Q3: were any r } \\
\text { data of the su } \\
\text { last }\end{array}$ & $\begin{array}{l}\text { compliant residue } \\
\text { ance found in the } \\
\text { years? }\end{array}$ & $\begin{array}{l}\text { Q4: I } \\
\text { regularly }\end{array}$ & $\begin{array}{l}\text { Is the substan } \\
\text { ' used in this : } \\
\text { species? }\end{array}$ & animal & $\begin{array}{l}\text { Q5: Do drugs with this } \\
\text { active substance have a long } \\
\text { withdrawal period? }\end{array}$ & $\begin{array}{c}\text { Conclusion } \\
\text { priority }\end{array}$ \\
\hline Substance & Concl Q1 & Concl Q2 & RASFF & Concl Q3 & $\begin{array}{l}\text { NC } \\
\text { results? }\end{array}$ & $\begin{array}{c}\text { FIDIN (> } \\
10 \mathrm{~kg})\end{array}$ & $\begin{array}{l}\text { Concl } \\
\text { Q4 }\end{array}$ & Withdrawal time & Horse \\
\hline
\end{tabular}

\begin{tabular}{|c|c|c|c|c|c|c|c|c|c|c|c|c|}
\hline Cyromazine & $\mathrm{N}$ & $\mathrm{N}$ & $\rightarrow$ & $\rightarrow$ & $\rightarrow$ & $\rightarrow$ & N & $\mathrm{N}$ & $\mathrm{N}$ & $\rightarrow$ & $\rightarrow$ & low \\
\hline Derquantel & $\mathrm{N}$ & $\mathrm{N}$ & $\rightarrow$ & $\rightarrow$ & $\rightarrow$ & $\rightarrow$ & $\mathrm{N}$ & $\mathrm{N}$ & $\mathrm{N}$ & $\rightarrow$ & $\rightarrow$ & low \\
\hline Dicyclanil & $\mathrm{N}$ & $\mathrm{N}$ & $\rightarrow$ & $\rightarrow$ & $\rightarrow$ & $\rightarrow$ & $\mathrm{N}$ & $\mathrm{N}$ & $\mathrm{N}$ & $\rightarrow$ & $\rightarrow$ & low \\
\hline Diflubenzuron & $\mathrm{N}$ & $\mathrm{N}$ & $\rightarrow$ & $\rightarrow$ & $\rightarrow$ & $\rightarrow$ & $\mathrm{N}$ & $\mathrm{N}$ & $\mathrm{N}$ & $\rightarrow$ & $\rightarrow$ & low \\
\hline Fluazuron & $\mathrm{N}$ & $\mathrm{N}$ & $\rightarrow$ & $\rightarrow$ & $\rightarrow$ & $\rightarrow$ & $\mathrm{N}$ & $\mathrm{N}$ & $\mathrm{N}$ & $\rightarrow$ & $\rightarrow$ & low \\
\hline Fluralaner & $\mathrm{N}$ & $\mathrm{N}$ & $\rightarrow$ & $\rightarrow$ & $\rightarrow$ & $\rightarrow$ & $\mathrm{N}$ & $\mathrm{N}$ & $\mathrm{N}$ & $\rightarrow$ & $\rightarrow$ & low \\
\hline Monepantel & $\mathrm{N}$ & $\mathrm{N}$ & $\rightarrow$ & $\rightarrow$ & $\rightarrow$ & $\rightarrow$ & $\mathrm{N}$ & $\mathrm{N}$ & $\mathrm{N}$ & $\rightarrow$ & $\rightarrow$ & low \\
\hline Morantel & $\mathrm{N}$ & $\mathrm{N}$ & $\rightarrow$ & $\rightarrow$ & $\rightarrow$ & $\rightarrow$ & N & $\mathrm{N}$ & $\mathrm{N}$ & $\rightarrow$ & $\rightarrow$ & low \\
\hline Nitroxinil & $\mathrm{N}$ & $\mathrm{N}$ & $\rightarrow$ & $\rightarrow$ & $\rightarrow$ & $\rightarrow$ & $\mathrm{N}$ & $\mathrm{N}$ & $\mathrm{N}$ & $\rightarrow$ & $\rightarrow$ & low \\
\hline Oxyclozanide & $\mathrm{N}$ & $\mathrm{N}$ & $\rightarrow$ & $\rightarrow$ & $\rightarrow$ & $\rightarrow$ & $Y$ & $\rightarrow$ & $\rightarrow$ & cascade & $\rightarrow$ & medium \\
\hline Piperazine & $\mathrm{N}$ & $\mathrm{N}$ & $\rightarrow$ & $\rightarrow$ & $\rightarrow$ & $\rightarrow$ & $\mathrm{N}$ & $\mathrm{N}$ & $\mathrm{N}$ & $\rightarrow$ & $\rightarrow$ & low \\
\hline Praziquantel & $\mathrm{N}$ & $\mathrm{N}^{\mathrm{a}}$ & $\rightarrow$ & $\rightarrow$ & $\rightarrow$ & $\rightarrow$ & $\mathrm{N}$ & $Y$ & Y & $30-64 d$ & $(Y)^{b}$ & low \\
\hline Pyrantel & $\mathrm{N}$ & $\mathrm{N}^{\mathrm{a}}$ & $\rightarrow$ & $\rightarrow$ & $\rightarrow$ & $\rightarrow$ & $\mathrm{N}$ & $Y$ & Y & $0-7 d$ & $\mathrm{~N}$ & low \\
\hline Rafoxanide & $\mathrm{N}$ & $\mathrm{N}$ & $\rightarrow$ & $\rightarrow$ & $\rightarrow$ & $\rightarrow$ & $\mathrm{N}$ & $\mathrm{N}$ & $\mathrm{N}$ & $\rightarrow$ & $\rightarrow$ & low \\
\hline Sisapronil & $\mathrm{N}$ & N & $\rightarrow$ & $\rightarrow$ & $\rightarrow$ & $\rightarrow$ & $\mathrm{N}$ & $\mathrm{N}$ & N & $\rightarrow$ & $\rightarrow$ & low \\
\hline
\end{tabular}

a No MRL required.

b withdrawal time determined by other substance in product, moxidectin or ivermectin.

$\rightarrow$ based on the outcome of the previous question, this question can be skipped. 
Table A3.2 Prioritisation of antiparasitics in goat.

\begin{tabular}{|c|c|c|c|c|c|c|c|c|c|c|c|c|}
\hline \multirow[b]{2}{*}{ Substance } & \multirow{2}{*}{$\begin{array}{c}\text { Q1: is this an } \\
\text { essential } \\
\text { antimicrobial for } \\
\text { humans? } \\
\text { Concl Q1 }\end{array}$} & \multirow{2}{*}{$\begin{array}{l}\text { Q2: Have MRLs been } \\
\text { set for this } \\
\text { substance in this } \\
\text { animal species? } \\
\text { Concl Q2 }\end{array}$} & \multicolumn{4}{|c|}{$\begin{array}{l}\text { Q3: were any non-compliant } \\
\text { residue data of the substance } \\
\text { found in the last five years? }\end{array}$} & \multicolumn{3}{|c|}{$\begin{array}{l}\text { Q4: Is the substance regularly } \\
\text { used in this animal species? }\end{array}$} & \multicolumn{2}{|c|}{$\begin{array}{l}\text { Q5: Do drugs with this } \\
\text { active substance have a } \\
\text { long withdrawal period? }\end{array}$} & \multirow{2}{*}{$\begin{array}{c}\begin{array}{c}\text { Conclusion } \\
\text { priority }\end{array} \\
\text { Goat }\end{array}$} \\
\hline & & & KAP & RASFF & EFSA & Concl Q3 & $\begin{array}{l}\text { NC } \\
\text { results }\end{array}$ & $\begin{array}{l}\text { Recommended } \\
\text { treatment }\end{array}$ & $\begin{array}{l}\text { Concl } \\
\text { Q4 }\end{array}$ & Withdrawal time & Concl Q5 & \\
\hline Ivermectin & $\mathrm{N}$ & Y & N & $\mathrm{N}$ & $\mathrm{N}$ & $\mathrm{N}$ & $\mathrm{N}$ & Y & Y & cascade & Y & medium \\
\hline Doramectin & $\mathrm{N}$ & $Y$ & $\mathrm{~N}$ & $\mathrm{~N}$ & $\mathrm{~N}$ & $\mathrm{~N}$ & $\mathrm{~N}$ & $Y$ & Y & cascade & $\mathrm{Y}$ & medium \\
\hline Abamectin & $\mathrm{N}$ & $\mathrm{N}$ & $\rightarrow$ & $\rightarrow$ & $\rightarrow$ & $\rightarrow$ & Y & $\mathrm{N}$ & Y & cascade & Y & medium \\
\hline Moxidectin & $\mathrm{N}$ & $\mathrm{N}$ & $\rightarrow$ & $\rightarrow$ & $\rightarrow$ & $\rightarrow$ & $Y$ & $Y$ & $\mathrm{Y}$ & cascade & $\mathrm{Y}$ & medium \\
\hline Emamectin & $\mathrm{N}$ & $\mathrm{N}$ & $\rightarrow$ & $\rightarrow$ & $\rightarrow$ & $\rightarrow$ & $\mathrm{N}$ & $\mathrm{N}$ & $\mathrm{N}$ & $\rightarrow$ & $\rightarrow$ & low \\
\hline Eprinomectin & $\mathrm{N}$ & Y & $\mathrm{N}$ & $\mathrm{N}$ & $\mathrm{N}$ & $\mathrm{N}$ & N & N & $\mathrm{N}$ & $\rightarrow$ & $\rightarrow$ & low \\
\hline Albendazole (oxide), Netobimine & $\mathrm{N}$ & Y & $\mathrm{N}$ & $\mathrm{N}$ & $\mathrm{N}$ & $\mathrm{N}$ & $\mathrm{N}$ & $\mathrm{N}$ & $\mathrm{N}$ & $\rightarrow$ & $\rightarrow$ & low \\
\hline Febantel & $\mathrm{N}$ & $Y$ & $\mathrm{~N}$ & $\mathrm{~N}$ & $\mathrm{~N}$ & $\mathrm{~N}$ & $\mathrm{~N}$ & $\mathrm{~N}$ & $\mathrm{~N}$ & $\rightarrow$ & $\rightarrow$ & low \\
\hline Fenbendazole & $\mathrm{N}$ & $Y$ & $\mathrm{~N}$ & $\mathrm{~N}$ & $\mathrm{~N}$ & $\mathrm{~N}$ & $\mathrm{~N}$ & $\mathrm{~N}$ & $\mathrm{~N}$ & $\rightarrow$ & $\rightarrow$ & low \\
\hline Oxfendazole & $\mathrm{N}$ & $Y$ & $\mathrm{~N}$ & $\mathrm{~N}$ & $\mathrm{~N}$ & $\mathrm{~N}$ & $\mathrm{~N}$ & $\mathrm{~N}$ & $\mathrm{~N}$ & $\rightarrow$ & $\rightarrow$ & low \\
\hline Flubendazole & $\mathrm{N}$ & $\mathrm{N}$ & $\rightarrow$ & $\rightarrow$ & $\rightarrow$ & $\rightarrow$ & $\mathrm{N}$ & $\mathrm{N}$ & $\mathrm{N}$ & $\rightarrow$ & $\rightarrow$ & low \\
\hline Thiabendazole & $\mathrm{N}$ & $Y$ & $\mathrm{~N}$ & $\mathrm{~N}$ & $\mathrm{~N}$ & $\mathrm{~N}$ & $\mathrm{~N}$ & $\mathrm{~N}$ & $\mathrm{~N}$ & $\rightarrow$ & $\rightarrow$ & low \\
\hline Levamisole & $\mathrm{N}$ & $\mathrm{N}$ & $\rightarrow$ & $\rightarrow$ & $\rightarrow$ & $\rightarrow$ & N & Y & Y & cascade & $\mathrm{Y}$ & medium \\
\hline Triclabendazol & $\mathrm{N}$ & $Y$ & $\mathrm{~N}$ & $\mathrm{~N}$ & $\mathrm{~N}$ & $\mathrm{~N}$ & $\mathrm{~N}$ & $\mathrm{~N}$ & $\mathrm{~N}$ & $\rightarrow$ & $\rightarrow$ & low \\
\hline Amitraz & $\mathrm{N}$ & $Y$ & $\mathrm{~N}$ & $\mathrm{~N}$ & $\mathrm{~N}$ & $\mathrm{~N}$ & $\mathrm{~N}$ & $\mathrm{~N}$ & $\mathrm{~N}$ & $\rightarrow$ & $\rightarrow$ & low \\
\hline Clorsulon & $\mathrm{N}$ & $\mathrm{N}$ & $\rightarrow$ & $\rightarrow$ & $\rightarrow$ & $\rightarrow$ & $\mathrm{N}$ & $\mathrm{N}$ & $\mathrm{N}$ & $\rightarrow$ & $\rightarrow$ & low \\
\hline Closantel & $\mathrm{N}$ & $\mathrm{N}$ & $\rightarrow$ & $\rightarrow$ & $\rightarrow$ & $\rightarrow$ & N & Y & Y & cascade & $\mathrm{Y}$ & medium \\
\hline Cyromazine & $\mathrm{N}$ & $\mathrm{N}$ & $\rightarrow$ & $\rightarrow$ & $\rightarrow$ & $\rightarrow$ & $\mathrm{N}$ & $\mathrm{N}$ & $\mathrm{N}$ & $\rightarrow$ & $\rightarrow$ & low \\
\hline Derquantel & $\mathrm{N}$ & $\mathrm{N}$ & $\rightarrow$ & $\rightarrow$ & $\rightarrow$ & $\rightarrow$ & N & N & $\mathrm{N}$ & $\rightarrow$ & $\rightarrow$ & low \\
\hline Dicyclanil & $\mathrm{N}$ & $\mathrm{N}$ & $\rightarrow$ & $\rightarrow$ & $\rightarrow$ & $\rightarrow$ & $\mathrm{N}$ & $\mathrm{N}$ & $\mathrm{N}$ & $\rightarrow$ & $\rightarrow$ & low \\
\hline Diflubenzuron & $\mathrm{N}$ & $\mathrm{N}$ & $\rightarrow$ & $\rightarrow$ & $\rightarrow$ & $\rightarrow$ & N & $\mathrm{N}$ & $\mathrm{N}$ & $\rightarrow$ & $\rightarrow$ & low \\
\hline Fluazuron & $\mathrm{N}$ & $\mathrm{N}$ & $\rightarrow$ & $\rightarrow$ & $\rightarrow$ & $\rightarrow$ & N & N & $\mathrm{N}$ & $\rightarrow$ & $\rightarrow$ & low \\
\hline Fluralaner & $\mathrm{N}$ & $\mathrm{N}$ & $\rightarrow$ & $\rightarrow$ & $\rightarrow$ & $\rightarrow$ & $\mathrm{N}$ & $\mathrm{N}$ & $\mathrm{N}$ & $\rightarrow$ & $\rightarrow$ & low \\
\hline
\end{tabular}




\begin{tabular}{|c|c|c|c|c|c|c|c|c|c|c|c|c|}
\hline \multirow[b]{2}{*}{ Substance } & \multirow{2}{*}{$\begin{array}{c}\text { Q1: is this an } \\
\text { essential } \\
\text { antimicrobial for } \\
\text { humans? } \\
\text { Concl Q1 }\end{array}$} & \multirow{2}{*}{$\begin{array}{l}\text { Q2: Have MRLs been } \\
\text { set for this } \\
\text { substance in this } \\
\text { animal species? } \\
\text { Concl Q2 }\end{array}$} & \multicolumn{4}{|c|}{$\begin{array}{l}\text { Q3: were any non-compliant } \\
\text { residue data of the substance } \\
\text { found in the last five years? }\end{array}$} & \multicolumn{3}{|c|}{$\begin{array}{l}\text { Q4: Is the substance regularly } \\
\text { used in this animal species? }\end{array}$} & \multicolumn{2}{|c|}{$\begin{array}{l}\text { Q5: Do drugs with this } \\
\text { active substance have a } \\
\text { long withdrawal period? }\end{array}$} & \multirow{2}{*}{$\begin{array}{c}\begin{array}{c}\text { Conclusion } \\
\text { priority }\end{array} \\
\text { Goat }\end{array}$} \\
\hline & & & KAP & RASFF & EFSA & Concl Q3 & $\begin{array}{l}\text { NC } \\
\text { results }\end{array}$ & $\begin{array}{l}\text { Recommended } \\
\text { treatment }\end{array}$ & $\begin{array}{c}\text { Concl } \\
\text { Q4 }\end{array}$ & Withdrawal time & Concl Q5 & \\
\hline Monepantel & $\mathrm{N}$ & Y & $\mathrm{N}$ & $\mathrm{N}$ & $\mathrm{N}$ & $\mathrm{N}$ & $\mathrm{N}$ & $\mathrm{N}$ & $\mathrm{N}$ & $\rightarrow$ & $\rightarrow$ & low \\
\hline Morantel & $\mathrm{N}$ & $\mathrm{Y}$ & $\mathrm{N}$ & $\mathrm{N}$ & $\mathrm{N}$ & $\mathrm{N}$ & $\mathrm{N}$ & $\mathrm{N}$ & $\mathrm{N}$ & $\rightarrow$ & $\rightarrow$ & low \\
\hline Nitroxinil & $\mathrm{N}$ & $\mathrm{N}$ & $\rightarrow$ & $\rightarrow$ & $\rightarrow$ & $\rightarrow$ & $\mathrm{N}$ & $\mathrm{N}$ & $\mathrm{N}$ & $\rightarrow$ & $\rightarrow$ & low \\
\hline Oxyclozanide & $\mathrm{N}$ & Y & $\mathrm{N}$ & $\mathrm{N}$ & $\mathrm{N}$ & $\mathrm{N}$ & $\mathrm{N}$ & $\mathrm{N}$ & $\mathrm{N}$ & $\rightarrow$ & $\rightarrow$ & low \\
\hline Piperazine & $\mathrm{N}$ & $\mathrm{N}$ & $\rightarrow$ & $\rightarrow$ & $\rightarrow$ & $\rightarrow$ & $\mathrm{N}$ & $\mathrm{N}$ & $\mathrm{N}$ & $\rightarrow$ & $\rightarrow$ & low \\
\hline Praziquantel & $\mathrm{N}$ & $\mathrm{N}$ & $\rightarrow$ & $\rightarrow$ & $\rightarrow$ & $\rightarrow$ & $\mathrm{N}$ & $\mathrm{N}$ & $\mathrm{N}$ & $\rightarrow$ & $\rightarrow$ & low \\
\hline Pyrantel & $\mathrm{N}$ & $\mathrm{N}$ & $\rightarrow$ & $\rightarrow$ & $\rightarrow$ & $\rightarrow$ & $\mathrm{N}$ & $\mathrm{N}$ & $\mathrm{N}$ & $\rightarrow$ & $\rightarrow$ & low \\
\hline Rafoxanide & $\mathrm{N}$ & $\mathrm{N}$ & $\rightarrow$ & $\rightarrow$ & $\rightarrow$ & $\rightarrow$ & $\mathrm{N}$ & $\mathrm{N}$ & $\mathrm{N}$ & $\rightarrow$ & $\rightarrow$ & low \\
\hline Sisapronil & $\mathrm{N}$ & Y & $\mathrm{N}$ & $\mathrm{N}$ & $\mathrm{N}$ & $\mathrm{N}$ & $\mathrm{N}$ & $\mathrm{N}$ & $\mathrm{N}$ & $\rightarrow$ & $\rightarrow$ & low \\
\hline
\end{tabular}

$\rightarrow$ based on the outcome of the previous question, this question can be skipped. 
Table A3.3 Prioritisation of antiparasitics in sheep.

\begin{tabular}{|c|c|c|c|c|c|c|c|c|c|c|c|c|}
\hline \multirow{2}{*}{ Substance } & \multirow{2}{*}{$\begin{array}{c}\text { Q1: is this an } \\
\text { essential } \\
\text { antimicrobial for } \\
\text { humans? } \\
\text { Concl Q1 }\end{array}$} & \multirow{2}{*}{$\begin{array}{l}\text { Q2: Have MRLs been } \\
\text { set for this substance } \\
\text { in this animal } \\
\text { species? } \\
\text { Concl Q2 }\end{array}$} & \multicolumn{4}{|c|}{$\begin{array}{l}\text { Q3: were any non-compliant residue } \\
\text { data of the substance found in the } \\
\text { last five years? }\end{array}$} & \multicolumn{3}{|c|}{$\begin{array}{l}\text { Q4: Is the substance } \\
\text { regularly used in this animal } \\
\text { species? }\end{array}$} & \multicolumn{2}{|c|}{$\begin{array}{l}\text { Q5: Do drugs with this } \\
\text { active substance have a long } \\
\text { withdrawal period? }\end{array}$} & \multirow[t]{2}{*}{$\begin{array}{l}\text { Conclusion } \\
\text { priority }\end{array}$} \\
\hline & & & KAP & RASFF & EFSA & Concl Q3 & NC results & Survey & $\begin{array}{c}\text { Concl } \\
04\end{array}$ & Withdrawal time & Concl Q5 & \\
\hline Ivermectin & $\mathrm{N}$ & $\mathrm{Y}$ & $\mathrm{N}$ & $\mathrm{N}$ & $\mathrm{Y}$ & $\mathrm{Y}$ & $\mathrm{N}$ & $\rightarrow$ & $\rightarrow$ & $\rightarrow$ & $\rightarrow$ & medium \\
\hline Doramectin & $\mathrm{N}$ & Y & $\mathrm{N}$ & $\mathrm{N}$ & $\mathrm{N}$ & $\mathrm{N}$ & $\mathrm{N}$ & Y & Y & 70 & $\mathrm{Y}$ & medium \\
\hline Abamectin & $\mathrm{N}$ & $\mathrm{Y}$ & $\mathrm{N}$ & $\mathrm{N}$ & $\mathrm{Y}$ & $\mathrm{Y}$ & $\rightarrow$ & $\rightarrow$ & $\rightarrow$ & $\rightarrow$ & $\rightarrow$ & medium \\
\hline Moxidectin & $\mathrm{N}$ & Y & $\mathrm{N}$ & $\mathrm{N}$ & $\mathrm{N}$ & $\mathrm{N}$ & $\mathrm{N}$ & Y & $\mathrm{Y}$ & 31 & $\mathrm{Y}$ & medium \\
\hline Emamectin & $\mathrm{N}$ & $\mathrm{N}$ & $\rightarrow$ & $\rightarrow$ & $\rightarrow$ & $\rightarrow$ & $\mathrm{N}$ & $\mathrm{N}$ & $\mathrm{N}$ & $\rightarrow$ & $\rightarrow$ & low \\
\hline Eprinomectin & $\mathrm{N}$ & Y & $\mathrm{N}$ & $\mathrm{N}$ & $\mathrm{N}$ & $\mathrm{N}$ & $\mathrm{N}$ & $\mathrm{N}$ & $\mathrm{N}$ & $\rightarrow$ & $\rightarrow$ & low \\
\hline Albendazole (oxide), Netobimine & $\mathrm{N}$ & Y & $\mathrm{N}$ & $\mathrm{N}$ & $\mathrm{Y}$ & $Y$ & $\mathrm{~N}$ & $\rightarrow$ & $\rightarrow$ & $\rightarrow$ & $\rightarrow$ & medium \\
\hline Febantel & $\mathrm{N}$ & Y & $\mathrm{N}$ & $\mathrm{N}$ & $\mathrm{N}$ & $\mathrm{N}$ & $\mathrm{N}$ & $\mathrm{N}$ & $\mathrm{N}$ & $\rightarrow$ & $\rightarrow$ & low \\
\hline Fenbendazole & $\mathrm{N}$ & $Y$ & $\mathrm{~N}$ & $\mathrm{~N}$ & $\mathrm{Y}$ & $Y$ & $\rightarrow$ & $\rightarrow$ & $\rightarrow$ & $\rightarrow$ & $\rightarrow$ & medium \\
\hline Oxfendazole & $\mathrm{N}$ & Y & $\mathrm{N}$ & $\mathrm{N}$ & $Y$ & Y & $\rightarrow$ & $\rightarrow$ & $\rightarrow$ & $\rightarrow$ & $\rightarrow$ & medium \\
\hline Mebendazole & $\mathrm{N}$ & Y & $\mathrm{N}$ & $\mathrm{N}$ & $\mathrm{N}$ & $\mathrm{N}$ & $\mathrm{N}$ & Y & Y & 65 & $Y$ & medium \\
\hline Flubendazole & $\mathrm{N}$ & $\mathrm{N}$ & $\rightarrow$ & $\rightarrow$ & $\rightarrow$ & $\rightarrow$ & $Y$ & $\rightarrow$ & $\rightarrow$ & cascade & $\rightarrow$ & medium \\
\hline Thiabendazole & $\mathrm{N}$ & $\mathrm{N}$ & $\rightarrow$ & $\rightarrow$ & $\rightarrow$ & $\rightarrow$ & $\mathrm{N}$ & $\mathrm{N}$ & $\mathrm{N}$ & $\rightarrow$ & $\rightarrow$ & low \\
\hline Levamisole & $\mathrm{N}$ & $Y$ & $\mathrm{~N}$ & $\mathrm{~N}$ & Y & Y & $\mathrm{N}$ & $\rightarrow$ & $\rightarrow$ & $\rightarrow$ & $\rightarrow$ & medium \\
\hline Triclabendazol & $\mathrm{N}$ & Y & $\mathrm{N}$ & $\mathrm{N}$ & $\mathrm{Y}$ & Y & $\mathrm{N}$ & $\rightarrow$ & $\rightarrow$ & $\rightarrow$ & $\rightarrow$ & medium \\
\hline Amitraz & $\mathrm{N}$ & $Y$ & $\mathrm{~N}$ & $\mathrm{~N}$ & $\mathrm{~N}$ & $\mathrm{~N}$ & $\mathrm{~N}$ & $\mathrm{~N}$ & $\mathrm{~N}$ & $\rightarrow$ & $\rightarrow$ & low \\
\hline Clorsulon & $\mathrm{N}$ & $\mathrm{N}$ & $\rightarrow$ & $\rightarrow$ & $\rightarrow$ & $\rightarrow$ & $\mathrm{N}$ & $\mathrm{N}$ & $\mathrm{N}$ & $\rightarrow$ & $\rightarrow$ & low \\
\hline Closantel & $\mathrm{N}$ & $Y$ & $\mathrm{~N}$ & Y & Y & Y & $\rightarrow$ & $\rightarrow$ & $\rightarrow$ & $\rightarrow$ & $\rightarrow$ & medium \\
\hline Cyromazine & $\mathrm{N}$ & Y & $\mathrm{N}$ & $\mathrm{N}$ & $\mathrm{N}$ & $\mathrm{N}$ & $\mathrm{N}$ & $\mathrm{N}$ & $\mathrm{N}$ & $\rightarrow$ & $\rightarrow$ & low \\
\hline Derquantel & $\mathrm{N}$ & Y & $\mathrm{N}$ & $\mathrm{N}$ & $\mathrm{N}$ & $\mathrm{N}$ & $\mathrm{N}$ & $\mathrm{N}$ & $\mathrm{N}$ & $\rightarrow$ & $\rightarrow$ & low \\
\hline Dicyclanil & $\mathrm{N}$ & Y & $\mathrm{N}$ & $\mathrm{N}$ & $\mathrm{N}$ & $\mathrm{N}$ & $\mathrm{N}$ & $\mathrm{N}$ & $\mathrm{N}$ & $\rightarrow$ & $\rightarrow$ & low \\
\hline Diflubenzuron & $\mathrm{N}$ & $\mathrm{N}$ & $\rightarrow$ & $\rightarrow$ & $\rightarrow$ & $\rightarrow$ & $\mathrm{N}$ & $\mathrm{N}$ & $\mathrm{N}$ & $\rightarrow$ & $\rightarrow$ & low \\
\hline Fluazuron & N & $\mathrm{N}$ & $\rightarrow$ & $\rightarrow$ & $\rightarrow$ & $\rightarrow$ & $\mathrm{N}$ & $\mathrm{N}$ & $\mathrm{N}$ & $\rightarrow$ & $\rightarrow$ & low \\
\hline Fluralaner & $\mathrm{N}$ & $\mathrm{N}$ & $\rightarrow$ & $\rightarrow$ & $\rightarrow$ & $\rightarrow$ & $\mathrm{N}$ & $\mathrm{N}$ & $\mathrm{N}$ & $\rightarrow$ & $\rightarrow$ & low \\
\hline
\end{tabular}




\begin{tabular}{|c|c|c|c|c|c|c|c|c|c|c|c|c|}
\hline \multirow[b]{2}{*}{ Substance } & \multirow{2}{*}{$\begin{array}{c}\text { Q1: is this an } \\
\text { essential } \\
\text { antimicrobial for } \\
\text { humans? } \\
\text { Concl Q1 }\end{array}$} & \multirow{2}{*}{$\begin{array}{l}\text { Q2: Have MRLs been } \\
\text { set for this substance } \\
\text { in this animal } \\
\text { species? } \\
\text { Concl Q2 }\end{array}$} & \multicolumn{4}{|c|}{$\begin{array}{l}\text { Q3: were any non-compliant residue } \\
\text { data of the substance found in the } \\
\text { last five years? }\end{array}$} & \multicolumn{3}{|c|}{$\begin{array}{l}\text { Q4: Is the substance } \\
\text { regularly used in this animal } \\
\text { species? }\end{array}$} & \multicolumn{2}{|c|}{$\begin{array}{l}\text { Q5: Do drugs with this } \\
\text { active substance have a long } \\
\text { withdrawal period? }\end{array}$} & \multirow{2}{*}{$\begin{array}{c}\begin{array}{c}\text { Conclusion } \\
\text { priority }\end{array} \\
\text { Sheep }\end{array}$} \\
\hline & & & KAP & RASFF & EFSA & Concl Q3 & NC results & Survey & $\begin{array}{c}\text { Concl } \\
\text { Q4 }\end{array}$ & Withdrawal time & Concl Q5 & \\
\hline Monepantel & $\mathrm{N}$ & $Y$ & $\mathrm{~N}$ & $\mathrm{~N}$ & $\mathrm{~N}$ & $\mathrm{~N}$ & $\mathrm{~N}$ & $Y$ & $Y$ & 7 & $\mathrm{~N}$ & low \\
\hline Morantel & $\mathrm{N}$ & $Y$ & $\mathrm{~N}$ & $\mathrm{~N}$ & $\mathrm{~N}$ & $\mathrm{~N}$ & $\mathrm{~N}$ & $\mathrm{~N}$ & $\mathrm{~N}$ & $\rightarrow$ & $\rightarrow$ & low \\
\hline Nitroxinil & $\mathrm{N}$ & Y & $\mathrm{N}$ & $\mathrm{N}$ & Y & $Y$ & $\rightarrow$ & $\rightarrow$ & $\rightarrow$ & $\rightarrow$ & $\rightarrow$ & medium \\
\hline Oxyclozanide & $\mathrm{N}$ & $Y$ & $\mathrm{~N}$ & $\mathrm{~N}$ & $\mathrm{~N}$ & $\mathrm{~N}$ & $\mathrm{~N}$ & $\mathrm{~N}$ & $\mathrm{~N}$ & $\rightarrow$ & $\rightarrow$ & low \\
\hline Piperazine & $\mathrm{N}$ & $\mathrm{N}$ & $\rightarrow$ & $\rightarrow$ & $\rightarrow$ & $\rightarrow$ & $\mathrm{N}$ & $\mathrm{N}$ & $\mathrm{N}$ & $\rightarrow$ & $\rightarrow$ & low \\
\hline Praziquantel & $\mathrm{N}$ & $\mathrm{N}^{\mathrm{a}}$ & $\rightarrow$ & $\rightarrow$ & $\rightarrow$ & $\rightarrow$ & $\mathrm{N}$ & $\mathrm{N}$ & $\mathrm{N}$ & $\rightarrow$ & $\rightarrow$ & low \\
\hline Pyrantel & $\mathrm{N}$ & $\mathrm{N}$ & $\rightarrow$ & $\rightarrow$ & $\rightarrow$ & $\rightarrow$ & $\mathrm{N}$ & $\mathrm{N}$ & $\mathrm{N}$ & $\rightarrow$ & $\rightarrow$ & low \\
\hline Rafoxanide & $\mathrm{N}$ & Y & N & $\mathrm{N}$ & Y & $Y$ & $\rightarrow$ & $\rightarrow$ & $\rightarrow$ & $\rightarrow$ & $\rightarrow$ & medium \\
\hline Sisapronil & $\mathrm{N}$ & $\mathrm{Y}$ & $\mathrm{N}$ & $\mathrm{N}$ & $\mathrm{N}$ & $\mathrm{N}$ & $\mathrm{N}$ & $\mathrm{N}$ & $\mathrm{N}$ & $\rightarrow$ & $\rightarrow$ & low \\
\hline
\end{tabular}

a No MRL required.

$\rightarrow$ based on the outcome of the previous question, this question can be skipped. 
Table A3.4 Prioritisation of antiparasitics in milk.

\begin{tabular}{|c|c|c|c|c|c|c|c|c|c|c|c|c|c|c|}
\hline \multirow[b]{2}{*}{ Substance } & \multirow{2}{*}{$\begin{array}{c}\text { Q1: is this an } \\
\text { essential } \\
\text { antimicrobial for } \\
\text { humans? } \\
\text { Concl Q1 }\end{array}$} & \multicolumn{3}{|c|}{$\begin{array}{l}\text { Q2: Have MRLs been set } \\
\text { for this substance in this } \\
\text { animal species? }\end{array}$} & \multicolumn{4}{|c|}{$\begin{array}{l}\text { Q3: were any non-compliant } \\
\text { residue data of the substance } \\
\text { found in the last five years? }\end{array}$} & \multicolumn{3}{|c|}{$\begin{array}{l}\text { Q4: Is the substance } \\
\text { regularly used in this } \\
\text { animal species? }\end{array}$} & \multicolumn{2}{|c|}{$\begin{array}{l}\text { Q5: Do drugs with this } \\
\text { active substance have a } \\
\text { long withdrawal period? }\end{array}$} & \multirow{2}{*}{$\begin{array}{c}\begin{array}{c}\text { Conclusion } \\
\text { priority }\end{array} \\
\text { Milk }\end{array}$} \\
\hline & & $\begin{array}{c}\text { MRL } \\
\text { bovine }\end{array}$ & $\begin{array}{l}\text { MRL } \\
\text { milk }\end{array}$ & $\begin{array}{c}\text { Concl } \\
\text { Q2 }\end{array}$ & KAP & RASFF & EFSA & Concl Q3 & $\begin{array}{c}\text { NC } \\
\text { results }\end{array}$ & $\begin{array}{c}\text { FIDIN (> } \\
100 \text { kg) }\end{array}$ & $\begin{array}{c}\text { Concl } \\
\text { Q4 }\end{array}$ & Withdrawal time & Concl Q5 & \\
\hline Ivermectin & $\mathrm{N}$ & Y & $\mathrm{N}$ & Y & Y & $\mathrm{N}$ & Y & Y & $\rightarrow$ & $\rightarrow$ & $\rightarrow$ & $\rightarrow$ & $\rightarrow$ & medium \\
\hline Doramectin & $\mathrm{N}$ & Y & $\mathrm{N}$ & Y & $\mathrm{N}$ & $\mathrm{N}$ & $Y$ & $Y$ & $\rightarrow$ & $\rightarrow$ & $\rightarrow$ & $\rightarrow$ & $\rightarrow$ & medium \\
\hline Abamectin & $\mathrm{N}$ & $Y$ & $\mathrm{~N}$ & $Y$ & $Y$ & $\mathrm{~N}$ & $\mathrm{~N}$ & $Y$ & $\rightarrow$ & $\rightarrow$ & $\rightarrow$ & $\rightarrow$ & $\rightarrow$ & medium \\
\hline Moxidectin & $\mathrm{N}$ & Y & Y & Y & $\mathrm{N}^{\mathrm{b}}$ & $\mathrm{N}$ & $\mathrm{N}$ & $\mathrm{N}$ & $\mathrm{Y}^{\mathrm{b}}$ & $\rightarrow$ & $\rightarrow$ & cascade & $\rightarrow$ & medium \\
\hline Emamectin & $\mathrm{N}$ & $\mathrm{N}$ & $\mathrm{N}$ & $\mathrm{N}$ & $\rightarrow$ & $\rightarrow$ & $\rightarrow$ & $\rightarrow$ & $\mathrm{N}$ & $\mathrm{N}$ & $\mathrm{N}$ & $\rightarrow$ & $\rightarrow$ & low \\
\hline Eprinomectin & $\mathrm{N}$ & Y & Y & Y & $\mathrm{N}$ & $\mathrm{N}$ & $\mathrm{N}$ & $\mathrm{N}$ & $\mathrm{N}$ & $\mathrm{N}$ & $\mathrm{N}$ & $\rightarrow$ & $\rightarrow$ & low \\
\hline Albendazole (oxide), Netobimine & $\mathrm{N}$ & Y & Y & Y & $\mathrm{N}$ & $\mathrm{N}$ & Y & Y & $\rightarrow$ & $\rightarrow$ & $\rightarrow$ & $\rightarrow$ & $\rightarrow$ & medium \\
\hline Febantel & $\mathrm{N}$ & Y & Y & Y & $\mathrm{N}$ & $\mathrm{N}$ & $\mathrm{N}$ & $\mathrm{N}$ & $\mathrm{N}$ & $\mathrm{N}$ & $\mathrm{N}$ & $\rightarrow$ & $\rightarrow$ & low \\
\hline Fenbendazole & $\mathrm{N}$ & Y & $\mathrm{Y}$ & $\mathrm{Y}$ & $\mathrm{N}$ & $\mathrm{N}$ & $\mathrm{N}$ & $\mathrm{N}$ & $\mathrm{N}$ & $\mathrm{N}$ & $\mathrm{N}$ & $\rightarrow$ & $\rightarrow$ & low \\
\hline Oxfendazole & $\mathrm{N}$ & Y & $\mathrm{Y}$ & $\mathrm{Y}$ & $\mathrm{N}$ & $\mathrm{N}$ & $\mathrm{N}$ & $\mathrm{N}$ & $\mathrm{N}$ & Y & Y & cascade & Y & medium \\
\hline Mebendazole & $\mathrm{N}$ & $\mathrm{N}$ & $\mathrm{N}$ & $\mathrm{N}$ & $\rightarrow$ & $\rightarrow$ & $\rightarrow$ & $\rightarrow$ & $\mathrm{N}$ & $\mathrm{N}$ & $\mathrm{N}$ & $\rightarrow$ & $\rightarrow$ & low \\
\hline Flubendazole & $\mathrm{N}$ & $\mathrm{N}$ & $\mathrm{N}$ & $\mathrm{N}$ & $\rightarrow$ & $\rightarrow$ & $\rightarrow$ & $\rightarrow$ & $\mathrm{N}$ & $\mathrm{N}$ & $\mathrm{N}$ & $\rightarrow$ & $\rightarrow$ & low \\
\hline Thiabendazole & $\mathrm{N}$ & $Y$ & $\mathrm{Y}$ & $Y$ & $\mathrm{~N}$ & $\mathrm{~N}$ & $\mathrm{~N}$ & $\mathrm{~N}$ & $\mathrm{~N}$ & $\mathrm{~N}$ & $\mathrm{~N}$ & $\rightarrow$ & $\rightarrow$ & low \\
\hline Levamisole & $\mathrm{N}$ & Y & $\mathrm{N}$ & Y & $\mathrm{N}$ & $\mathrm{N}$ & Y & Y & $\rightarrow$ & $\rightarrow$ & $\rightarrow$ & $\rightarrow$ & $\rightarrow$ & medium \\
\hline Triclabendazol & $\mathrm{N}$ & Y & $\mathrm{N}$ & Y & $\mathrm{N}$ & $\mathrm{N}$ & Y & Y & $\rightarrow$ & $\rightarrow$ & $\rightarrow$ & $\rightarrow$ & $\rightarrow$ & medium \\
\hline Amitraz & $\mathrm{N}$ & $Y$ & Y & $Y$ & $\mathrm{~N}$ & $\mathrm{~N}$ & $\mathrm{~N}$ & $\mathrm{~N}$ & $\mathrm{~N}$ & $Y$ & Y & $4 d$ & $\mathrm{~N}$ & low \\
\hline Clorsulon & $\mathrm{N}$ & $Y$ & Y & $Y$ & $\mathrm{~N}$ & $\mathrm{~N}$ & Y & Y & $\rightarrow$ & $\rightarrow$ & $\rightarrow$ & $\rightarrow$ & $\rightarrow$ & medium \\
\hline Closantel & $\mathrm{N}$ & Y & $\mathrm{Y}$ & Y & $\mathrm{N}$ & $\mathrm{N}$ & Y & Y & $\rightarrow$ & $\rightarrow$ & $\rightarrow$ & $\rightarrow$ & $\rightarrow$ & medium \\
\hline Cyromazine & $\mathrm{N}$ & $\mathrm{N}$ & $\mathrm{N}$ & $\mathrm{N}$ & $\rightarrow$ & $\rightarrow$ & $\rightarrow$ & $\rightarrow$ & $\mathrm{N}$ & $\mathrm{N}$ & $\mathrm{N}$ & $\rightarrow$ & $\rightarrow$ & low \\
\hline Derquantel & $N$ & $\mathrm{~N}$ & $\mathrm{~N}$ & $\mathrm{~N}$ & $\rightarrow$ & $\rightarrow$ & $\rightarrow$ & $\rightarrow$ & $N$ & $\mathrm{~N}$ & $\mathrm{~N}$ & $\rightarrow$ & $\rightarrow$ & low \\
\hline Dicyclanil & $\mathrm{N}$ & $\mathrm{N}$ & $\mathrm{N}$ & $\mathrm{N}$ & $\rightarrow$ & $\rightarrow$ & $\rightarrow$ & $\rightarrow$ & $\mathrm{N}$ & $\mathrm{N}$ & $\mathrm{N}$ & $\rightarrow$ & $\rightarrow$ & low \\
\hline Diflubenzuron & $\mathrm{N}$ & $\mathrm{N}$ & $\mathrm{N}$ & $\mathrm{N}$ & $\rightarrow$ & $\rightarrow$ & $\rightarrow$ & $\rightarrow$ & $\mathrm{N}$ & $\mathrm{N}$ & $\mathrm{N}$ & $\rightarrow$ & $\rightarrow$ & low \\
\hline Fluazuron & N & Y & $\mathrm{N}$ & Y & $\mathrm{N}$ & $\mathrm{N}$ & $\mathrm{N}$ & $\mathrm{N}$ & $N$ & $\mathrm{~N}$ & $\mathrm{~N}$ & $\rightarrow$ & $\rightarrow$ & low \\
\hline Fluralaner & $\mathrm{N}$ & $\mathrm{N}$ & $\mathrm{N}$ & $\mathrm{N}$ & $\rightarrow$ & $\rightarrow$ & $\rightarrow$ & $\rightarrow$ & $\mathrm{N}$ & $\mathrm{N}$ & $\mathrm{N}$ & $\rightarrow$ & $\rightarrow$ & low \\
\hline
\end{tabular}




\begin{tabular}{|c|c|c|c|c|c|c|c|c|c|c|c|c|c|c|}
\hline \multirow[b]{2}{*}{ Substance } & \multirow{2}{*}{$\begin{array}{c}\text { Q1: is this an } \\
\text { essential } \\
\text { antimicrobial for } \\
\text { humans? } \\
\text { Concl Q1 }\end{array}$} & \multicolumn{3}{|c|}{$\begin{array}{l}\text { Q2: Have MRLs been set } \\
\text { for this substance in this } \\
\text { animal species? }\end{array}$} & \multicolumn{4}{|c|}{$\begin{array}{l}\text { Q3: were any non-compliant } \\
\text { residue data of the substance } \\
\text { found in the last five years? }\end{array}$} & \multicolumn{3}{|c|}{$\begin{array}{l}\text { Q4: Is the substance } \\
\text { regularly used in this } \\
\text { animal species? }\end{array}$} & \multicolumn{2}{|c|}{$\begin{array}{l}\text { Q5: Do drugs with this } \\
\text { active substance have a } \\
\text { long withdrawal period? }\end{array}$} & \multirow{2}{*}{$\begin{array}{c}\begin{array}{c}\text { Conclusion } \\
\text { priority }\end{array} \\
\text { Milk }\end{array}$} \\
\hline & & $\begin{array}{c}\text { MRL } \\
\text { bovine }\end{array}$ & $\begin{array}{l}\text { MRL } \\
\text { milk }\end{array}$ & $\begin{array}{c}\text { Concl } \\
\text { Q2 }\end{array}$ & KAP & RASFF & EFSA & Concl Q3 & $\begin{array}{l}\text { NC } \\
\text { results }\end{array}$ & $\begin{array}{c}\text { FIDIN (> } \\
100 \mathrm{~kg})\end{array}$ & $\begin{array}{c}\text { Concl } \\
\text { Q4 }\end{array}$ & Withdrawal time & Concl Q5 & \\
\hline Monepantel & $\mathrm{N}$ & Y & $\mathrm{N}^{\mathrm{a}}$ & Y & $\mathrm{N}$ & $\mathrm{N}$ & $\mathrm{N}$ & $\mathrm{N}$ & $\mathrm{N}$ & $\mathrm{N}$ & $\mathrm{N}$ & $\rightarrow$ & $\rightarrow$ & low \\
\hline Morantel & $\mathrm{N}$ & Y & Y & Y & $\mathrm{N}$ & $\mathrm{N}$ & $\mathrm{N}$ & $\mathrm{N}$ & $\mathrm{N}$ & $\mathrm{N}$ & $\mathrm{N}$ & $\rightarrow$ & $\rightarrow$ & low \\
\hline Nitroxinil & $\mathrm{N}$ & Y & Y & Y & $\mathrm{N}$ & $\mathrm{N}$ & Y & Y & $\rightarrow$ & $\rightarrow$ & $\rightarrow$ & $\rightarrow$ & $\rightarrow$ & medium \\
\hline Oxyclozanide & $\mathrm{N}$ & Y & Y & Y & $\mathrm{N}$ & $\mathrm{N}$ & $\mathrm{N}$ & $\mathrm{N}$ & $\mathrm{N}$ & $\mathrm{N}$ & $\mathrm{N}$ & $\rightarrow$ & $\rightarrow$ & low \\
\hline Piperazine & $\mathrm{N}$ & $\mathrm{N}$ & $\mathrm{N}$ & $\mathrm{N}$ & $\rightarrow$ & $\rightarrow$ & $\rightarrow$ & $\rightarrow$ & $\mathrm{N}$ & N & $\mathrm{N}$ & $\rightarrow$ & $\rightarrow$ & low \\
\hline Praziquantel & $\mathrm{N}$ & $\mathrm{N}$ & $\mathrm{N}$ & $\mathrm{N}$ & $\rightarrow$ & $\rightarrow$ & $\rightarrow$ & $\rightarrow$ & $\mathrm{N}$ & $\mathrm{N}$ & $\mathrm{N}$ & $\rightarrow$ & $\rightarrow$ & low \\
\hline Pyrantel & $\mathrm{N}$ & $\mathrm{N}$ & $\mathrm{N}$ & $\mathrm{N}$ & $\rightarrow$ & $\rightarrow$ & $\rightarrow$ & $\rightarrow$ & $\mathrm{N}$ & $\mathrm{N}$ & $\mathrm{N}$ & $\rightarrow$ & $\rightarrow$ & low \\
\hline Rafoxanide & $\mathrm{N}$ & Y & Y & Y & $\mathrm{N}$ & $\mathrm{N}$ & Y & Y & $\rightarrow$ & $\rightarrow$ & $\rightarrow$ & $\rightarrow$ & $\rightarrow$ & medium \\
\hline Sisapronil & $\mathrm{N}$ & $Y$ & $\mathrm{~N}$ & $Y$ & $N$ & $\mathrm{~N}$ & $\mathrm{~N}$ & $\mathrm{~N}$ & $\mathrm{~N}$ & $\mathrm{~N}$ & $\mathrm{~N}$ & $\rightarrow$ & $\rightarrow$ & low \\
\hline
\end{tabular}

a MRL ovine and caprine milk only.

b $1 / 2 \mathrm{MRL}$ in caprine milk.

$\rightarrow$ based on the outcome of the previous question, this question can be skipped. 


\section{Annex 4 Prioritisation of unauthorised carbamates using decision tree I}

Table A4.1 Prioritisation of unauthorised carbamates in animal products currently not included in the NP Residues. See also (van Asselt et al., 2019).

\begin{tabular}{|c|c|c|c|c|c|c|c|c|c|c|c|c|c|c|c|}
\hline \multirow[b]{2}{*}{ Carbamates } & $\begin{array}{l}\text { Q1: Whe } \\
\text { residue dat } \\
\text { in }\end{array}$ & $\begin{array}{l}\text { e any } n \\
\text { of the } \\
\text { he last }\end{array}$ & $\begin{array}{l}\text { on-com } \\
\text { substan } \\
\text { years? }\end{array}$ & $\begin{array}{l}\text { liant } \\
\text { e found }\end{array}$ & Q3: & re there inc & cations for $\mathrm{t}$ & se of this substa & ance in produ & ction systems & for food pro & Jucing anir & mals? & \multirow[t]{2}{*}{$\begin{array}{l}\text { Q2: Is a } \\
\text { human health } \\
\text { risk due to } \\
\text { residues of } \\
\text { this substance } \\
\text { scientifically } \\
\text { proven to be } \\
\text { absent or } \\
\text { negligible? } \\
\text { Concl. }\end{array}$} & \multirow[t]{2}{*}{$\begin{array}{c}\text { General } \\
\text { conclusion }\end{array}$} \\
\hline & $\begin{array}{c}\text { EU } \\
\text { monitoring } \\
\text { EFSA } \\
\text { reports }\end{array}$ & RASFF & $\begin{array}{l}\text { KAP } \\
\text { data > } \\
\text { MRL }\end{array}$ & Concl. & $\begin{array}{l}\text { Residues } \\
\text { >LOD? }\end{array}$ & $\begin{array}{l}\text { Listed as } \\
\text { obsolete } \\
\text { (Pesticide } \\
\text { Manual) }\end{array}$ & $\begin{array}{l}\text { Listed as } \\
\text { obsolete } \\
\text { (Pesticide } \\
\text { Properties } \\
\text { Database) }\end{array}$ & $\begin{array}{c}\text { Product } \\
\text { available in US? } \\
\text { (PAN pesticide } \\
\text { database) }\end{array}$ & $\begin{array}{l}\text { Registration } \\
\text { in other } \\
\text { countries? }\end{array}$ & $\begin{array}{l}\text { Available at } \\
\text { alibaba.com? }\end{array}$ & $\begin{array}{l}\text { Break down } \\
\text { product } \\
\text { monitored? }\end{array}$ & $\begin{array}{l}\text { Pesticide } \\
\text { residues } \\
\text { found in } \\
\text { food }\end{array}$ & Concl. & & \\
\hline allyxycarb & $\mathrm{N}$ & $N$ & $U$ & U & U & Y & Y & $\rightarrow$ & $\rightarrow$ & $\rightarrow$ & $\rightarrow$ & $\rightarrow$ & $\mathrm{N}$, obsolete & $\rightarrow$ & low \\
\hline aminocarb & $\mathrm{N}$ & N & $U$ & $U$ & U & Y & Y & $\rightarrow$ & $\rightarrow$ & $\rightarrow$ & $\rightarrow$ & $\rightarrow$ & $\mathrm{N}$, obsolete & $\rightarrow$ & low \\
\hline bufencarb & $\mathrm{N}$ & $N$ & U & U & U & $Y$ & $Y$ & $\rightarrow$ & $\rightarrow$ & $\rightarrow$ & $\rightarrow$ & $\rightarrow$ & $\mathrm{N}$, obsolete & $\rightarrow$ & low \\
\hline butacarb & $\mathrm{N}$ & $\mathrm{N}$ & u & u & u & Y & nd & $\rightarrow$ & $\rightarrow$ & $\rightarrow$ & $\rightarrow$ & $\rightarrow$ & $\mathrm{N}$, obsolete & $\rightarrow$ & low \\
\hline carbanolate & $\mathrm{N}$ & $\mathrm{N}$ & $u$ & U & U & $\mathrm{Y}$ & Y & $\rightarrow$ & $\rightarrow$ & $\rightarrow$ & $\rightarrow$ & $\rightarrow$ & $\mathrm{N}$, obsolete & $\rightarrow$ & low \\
\hline cloethocarb & $\mathrm{N}$ & $\mathrm{N}$ & $u$ & U & U & $\mathrm{Y}$ & $Y$ & $\rightarrow$ & $\rightarrow$ & $\rightarrow$ & $\rightarrow$ & $\rightarrow$ & $\mathrm{N}$, obsolete & $\rightarrow$ & low \\
\hline decarbofuran & $\mathrm{N}$ & $\mathrm{N}$ & U & U & U & $Y$ & nd & $\rightarrow$ & $\rightarrow$ & $\rightarrow$ & $\rightarrow$ & $\rightarrow$ & $\mathrm{N}$, obsolete & $\rightarrow$ & low \\
\hline dioxacarb & $\mathrm{N}$ & $\mathrm{N}$ & $U$ & $U$ & $u$ & $Y$ & $Y$ & $\rightarrow$ & $\rightarrow$ & $\rightarrow$ & $\rightarrow$ & $\rightarrow$ & $\mathrm{N}$, obsolete & $\rightarrow$ & low \\
\hline EMPC & $\mathrm{N}$ & $\mathrm{N}$ & $U$ & U & U & $Y$ & nd & $\rightarrow$ & $\rightarrow$ & $\rightarrow$ & $\rightarrow$ & $\rightarrow$ & $\mathrm{N}$, obsolete & $\rightarrow$ & low \\
\hline fenethacarb & $\mathrm{N}$ & $\mathrm{N}$ & U & U & U & $Y$ & nd & $\rightarrow$ & $\rightarrow$ & $\rightarrow$ & $\rightarrow$ & $\rightarrow$ & $\mathrm{N}$, obsolete & $\rightarrow$ & low \\
\hline hyquincarb & $\mathrm{N}$ & $\mathrm{N}$ & U & U & u & $\mathrm{Y}$ & Y & $\rightarrow$ & $\rightarrow$ & $\rightarrow$ & $\rightarrow$ & $\rightarrow$ & $\mathrm{N}$, obsolete & $\rightarrow$ & low \\
\hline isolan & $\mathrm{N}$ & $\mathrm{N}$ & $u$ & U & U & $Y$ & $Y$ & $\rightarrow$ & $\rightarrow$ & $\rightarrow$ & $\rightarrow$ & $\rightarrow$ & $\mathrm{N}$, obsolete & $\rightarrow$ & low \\
\hline metolcarb & $\mathrm{N}$ & $\mathrm{N}$ & U & U & u & $Y$ & $Y$ & $\rightarrow$ & $\rightarrow$ & $\rightarrow$ & $\rightarrow$ & $\rightarrow$ & $\mathrm{N}$, obsolete & $\rightarrow$ & low \\
\hline mexacarbate & $\mathrm{N}$ & $\mathrm{N}$ & U & U & U & $Y$ & Y & $\rightarrow$ & $\rightarrow$ & $\rightarrow$ & $\rightarrow$ & $\rightarrow$ & $\mathrm{N}$, obsolete & $\rightarrow$ & low \\
\hline nitrilacarb & $\mathrm{N}$ & N & $U$ & U & U & Y & Y & $\rightarrow$ & $\rightarrow$ & $\rightarrow$ & $\rightarrow$ & $\rightarrow$ & $\mathrm{N}$, obsolete & $\rightarrow$ & low \\
\hline promacyl & $\mathrm{N}$ & $\mathrm{N}$ & U & U & U & Y & $\mathrm{Y}$ & $\rightarrow$ & $\rightarrow$ & $\rightarrow$ & $\rightarrow$ & $\rightarrow$ & $\mathrm{N}$, obsolete & $\rightarrow$ & low \\
\hline
\end{tabular}




\begin{tabular}{|c|c|c|c|c|c|c|c|c|c|c|c|c|c|c|c|}
\hline & $\begin{array}{l}\text { Q1: Whe } \\
\text { residue dat } \\
\text { in }\end{array}$ & $\begin{array}{l}\text { re any } n \\
\text { of the } \\
\text { he last }\end{array}$ & $\begin{array}{l}\text { on-com } \\
\text { substan } \\
5 \text { years? }\end{array}$ & oliant & Q3: 1 & re there inc & cations for & Ise of this substa & ance in produ & Iction systems & $s$ for food pro & ducing ani & mals? & $\begin{array}{l}\text { Q2: Is a } \\
\text { human health } \\
\text { risk due to } \\
\text { residues of } \\
\text { this substance } \\
\text { scientifically } \\
\text { proven to be } \\
\text { absent or } \\
\text { negligible? }\end{array}$ & $\begin{array}{l}\text { General } \\
\text { conclusion }\end{array}$ \\
\hline Carbamates & $\begin{array}{c}\text { EU } \\
\text { monitoring } \\
\text { EFSA } \\
\text { reports }\end{array}$ & RASFF & $\begin{array}{c}\text { KAP } \\
\text { data > } \\
\text { MRL }\end{array}$ & Concl. & $\begin{array}{l}\text { Residues } \\
\text { >LOD? }\end{array}$ & $\begin{array}{c}\text { Listed as } \\
\text { obsolete } \\
\text { (Pesticide } \\
\text { Manual) }\end{array}$ & $\begin{array}{l}\text { Listed as } \\
\text { obsolete } \\
\text { (Pesticide } \\
\text { Properties } \\
\text { Database) }\end{array}$ & $\begin{array}{c}\text { Product } \\
\text { available in US? } \\
\text { (PAN pesticide } \\
\text { database) }\end{array}$ & $\begin{array}{l}\text { Registration } \\
\text { in other } \\
\text { countries? }\end{array}$ & $\begin{array}{l}\text { Available at } \\
\text { alibaba.com? }\end{array}$ & $\begin{array}{l}\text { Break down } \\
\text { product } \\
\text { monitored? }\end{array}$ & $\begin{array}{l}\text { Pesticide } \\
\text { residues } \\
\text { found in } \\
\text { food }\end{array}$ & Concl. & Concl. & \\
\hline promecarb & $\mathrm{N}$ & $\mathrm{N}$ & $u$ & $u$ & $u$ & $Y$ & $Y$ & $\rightarrow$ & $\rightarrow$ & $\rightarrow$ & $\rightarrow$ & $\rightarrow$ & $\mathrm{N}$, obsolete & $\rightarrow$ & low \\
\hline pyramat & $\mathrm{N}$ & $\mathrm{N}$ & u & u & u & nd & $Y$ & $\rightarrow$ & $\rightarrow$ & $\rightarrow$ & $\rightarrow$ & $\rightarrow$ & $\mathrm{N}$, obsolete & $\rightarrow$ & low \\
\hline tazimcarb & $\mathrm{N}$ & $\mathrm{N}$ & $u$ & $u$ & $u$ & $Y$ & nd & $\rightarrow$ & $\rightarrow$ & $\rightarrow$ & $\rightarrow$ & $\rightarrow$ & $\mathrm{N}$, obsolete & $\rightarrow$ & low \\
\hline thiocarboxime & $\mathrm{N}$ & $\mathrm{N}$ & $u$ & $u$ & $u$ & $Y$ & $\mathrm{Y}$ & $\rightarrow$ & $\rightarrow$ & $\rightarrow$ & $\rightarrow$ & $\rightarrow$ & $\mathrm{N}$, obsolete & $\rightarrow$ & low \\
\hline thiofanox & $\mathrm{N}$ & $\mathrm{N}$ & $u$ & $u$ & $u$ & $Y$ & $u$ & $\rightarrow$ & $\rightarrow$ & $\rightarrow$ & $\rightarrow$ & $\rightarrow$ & $\mathrm{N}$, obsolete & $\rightarrow$ & low \\
\hline trimethacarb & $\mathrm{N}$ & $\mathrm{N}$ & $u$ & $u$ & $u$ & $Y$ & $Y$ & $\rightarrow$ & $\rightarrow$ & $\rightarrow$ & $\rightarrow$ & $\rightarrow$ & $\mathrm{N}$, obsolete & $\rightarrow$ & low \\
\hline$X M C$ & $\mathrm{~N}$ & $\mathrm{~N}$ & $u$ & $u$ & $u$ & $Y$ & $u$ & $\rightarrow$ & $\rightarrow$ & $\rightarrow$ & $\rightarrow$ & $\rightarrow$ & $\mathrm{N}$, obsolete & $\rightarrow$ & low \\
\hline xylylcarb & $\mathrm{N}$ & $\mathrm{N}$ & U & U & U & $\mathrm{Y}$ & $\mathrm{Y}$ & $\rightarrow$ & $\rightarrow$ & $\rightarrow$ & $\rightarrow$ & $\rightarrow$ & $\mathrm{N}$, obsolete & $\rightarrow$ & low \\
\hline dimetan & $\mathrm{N}$ & $\mathrm{N}$ & $u$ & U & u & nd & nd & $\mathrm{N}$ & $\begin{array}{l}\text { not listed in } \\
\text { Asia list }\end{array}$ & $\mathrm{N}$ & nd & nd & $\begin{array}{c}\mathrm{N}, \mathrm{no} \\
\text { indications } \\
\text { for use }\end{array}$ & $\rightarrow$ & low \\
\hline dimethacarb & $\mathrm{N}$ & $\mathrm{N}$ & $u$ & $u$ & $u$ & nd & nd & nd & $\begin{array}{l}\text { banned in } \\
\text { China }\end{array}$ & N & nd & nd & $\begin{array}{c}\mathrm{N}, \text { no } \\
\text { indications } \\
\text { for use }\end{array}$ & $\rightarrow$ & low \\
\hline alanycarb & $\mathrm{N}$ & $\mathrm{N}$ & $u$ & U & $u$ & nd & & $\mathrm{N}$ & Japan & $Y$ & nd & $\mathrm{N}$ & $\begin{array}{c}\mathrm{N}, \mathrm{no} \\
\text { indications } \\
\text { for use }\end{array}$ & $\rightarrow$ & low \\
\hline butocarboxim & $\mathrm{N}$ & $\mathrm{N}$ & U & U & $u$ & nd & $\mathrm{N}$ & $\mathrm{N}$ & $\begin{array}{l}\text { restricted } \\
\text { use in } \\
\text { Cambodia }\end{array}$ & $\mathrm{N}$ & nd & $\mathrm{N}$ & $\begin{array}{c}\mathrm{N}, \mathrm{no} \\
\text { indications } \\
\text { for use }\end{array}$ & $\rightarrow$ & low \\
\hline butoxycarboxim & $\mathrm{N}$ & $\mathrm{N}$ & $u$ & U & u & nd & $\mathrm{N}$ & $\mathrm{N}$ & $\begin{array}{l}\text { not listed in } \\
\text { Asia list }\end{array}$ & $Y$ & nd & $\mathrm{N}$ & $\begin{array}{c}\mathrm{N}, \text { no } \\
\text { indications } \\
\text { for use }\end{array}$ & $\rightarrow$ & low \\
\hline $\begin{array}{l}\text { CPMC, etrofol, } \\
\text { 2-chlorophenyl }\end{array}$ & $\mathrm{N}$ & $\mathrm{N}$ & U & U & U & nd & nd & nd & $\begin{array}{l}\text { not listed in } \\
\text { Asia list }\end{array}$ & $Y$ & nd & nd & $u$ & u & high* \\
\hline
\end{tabular}




\begin{tabular}{|c|c|c|c|c|c|c|c|c|c|c|c|c|c|c|c|}
\hline \multirow[b]{2}{*}{ Carbamates } & $\begin{array}{l}\text { Q1: Whe } \\
\text { residue dat } \\
\text { in }\end{array}$ & $\begin{array}{l}\text { e any } n \\
\text { of the } \\
\text { he last }\end{array}$ & $\begin{array}{l}\text { on-com } \\
\text { substan } \\
\text {; years? }\end{array}$ & $\begin{array}{l}\text { liant } \\
\text { e found }\end{array}$ & Q3: A & re there ind & cations for & Ise of this substa & ance in produ & Iction systems & for food pro & ducing ani & imals? & \multirow[t]{2}{*}{$\begin{array}{l}\text { Q2: Is a } \\
\text { human health } \\
\text { risk due to } \\
\text { residues of } \\
\text { this substance } \\
\text { scientifically } \\
\text { proven to be } \\
\text { absent or } \\
\text { negligible? } \\
\text { Concl. }\end{array}$} & \multirow[t]{2}{*}{$\begin{array}{c}\text { General } \\
\text { conclusion }\end{array}$} \\
\hline & $\begin{array}{c}\text { EU } \\
\text { monitoring } \\
\text { EFSA } \\
\text { reports }\end{array}$ & RASFF & $\begin{array}{c}\text { KAP } \\
\text { data > } \\
\text { MRL }\end{array}$ & Concl. & $\begin{array}{l}\text { Residues } \\
>\text { LOD? }\end{array}$ & $\begin{array}{c}\text { Listed as } \\
\text { obsolete } \\
\text { (Pesticide } \\
\text { Manual) }\end{array}$ & $\begin{array}{l}\text { Listed as } \\
\text { obsolete } \\
\text { (Pesticide } \\
\text { Properties } \\
\text { Database) }\end{array}$ & $\begin{array}{c}\text { Product } \\
\text { available in US? } \\
\text { (PAN pesticide } \\
\text { database) }\end{array}$ & $\begin{array}{l}\text { Registration } \\
\text { in other } \\
\text { countries? }\end{array}$ & $\begin{array}{l}\text { Available at } \\
\text { alibaba.com? }\end{array}$ & $\begin{array}{l}\text { Break down } \\
\text { product } \\
\text { monitored? }\end{array}$ & $\begin{array}{l}\text { Pesticide } \\
\text { residues } \\
\text { found in } \\
\text { food }\end{array}$ & Concl. & & \\
\hline \multicolumn{16}{|c|}{$\begin{array}{l}\text { methylcarbamate, } \\
\text { hopcide }\end{array}$} \\
\hline dicresyl & N & $\mathrm{N}$ & u & u & U & nd & nd & nd & $\begin{array}{c}\text { not listed in } \\
\text { Asia list }\end{array}$ & Y & nd & nd & $U$ & $u$ & high* \\
\hline pyrolan & $\mathrm{N}$ & $\mathrm{N}$ & U & $u$ & 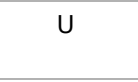 & nd & nd & $\mathrm{N}$ & $\begin{array}{c}\text { not listed in } \\
\text { Asia list }\end{array}$ & $Y$ & nd & nd & U & U & high* \\
\hline benomyl & $\mathrm{N}$ & $\mathrm{N}$ & u & u & u & nd & $\mathrm{N}$ & $\mathrm{N}$ & Asia & Y & nd & nd & $\begin{array}{l}Y \text {, could be } \\
\text { used }\end{array}$ & $\begin{array}{c}\mathrm{Y} \text {, by EFSA and } \\
\mathrm{FAO} / \mathrm{WHO}\end{array}$ & medium \\
\hline bendiocarb & $\mathrm{N}$ & $\mathrm{N}$ & U & U & U & nd & $\mathrm{N}$ & $\mathrm{N}$ & $\begin{array}{l}\text { Australia, } \\
\text { Asia }\end{array}$ & Y & nd & Y & $\begin{array}{l}Y, \text { could be } \\
\text { used }\end{array}$ & U & high \\
\hline fenobucarb & $\mathrm{N}$ & $\mathrm{N}$ & u & u & u & nd & u & $\mathrm{N}$ & Asia & Y & nd & Y & $\begin{array}{l}Y \text {, could be } \\
\text { used }\end{array}$ & u & high \\
\hline isoprocarb & $\mathrm{N}$ & $\mathrm{N}$ & U & $U$ & U & nd & U & $\mathrm{N}$ & Asia & Y & nd & Y & $\begin{array}{l}Y, \text { could be } \\
\text { used }\end{array}$ & U & high \\
\hline
\end{tabular}

$\rightarrow$ based on the outcome of the previous question, this question can be skipped.

* these substances only have the classification of high priority because there is no occurrence data or information available to answer the questions. 
Table A4.2 Prioritisation of unauthorised carbamates that are currently included in the NP Residues for horse.

\begin{tabular}{|c|c|c|c|c|c|c|c|c|c|c|c|c|c|c|c|}
\hline \multirow[b]{2}{*}{ Carbamates } & $\begin{array}{l}\text { Q1: W } \\
\text { residt } \\
\text { fout }\end{array}$ & $\begin{array}{l}\text { ere any } \\
\text { data o } \\
\text { d in the }\end{array}$ & $\begin{array}{l}\text { on-c } \\
\text { he s } \\
\text { st } 5\end{array}$ & $\begin{array}{l}\text { npliant } \\
\text { stance } \\
\text { ars? }\end{array}$ & Q3: Ar & there indic & tions for us & of this subs & stance in proc & duction systei & ms for food & oroducing a & nimals? & \multirow[t]{2}{*}{$\begin{array}{l}\text { Q2: Is a human } \\
\text { health risk due } \\
\text { to residues of } \\
\text { this substance } \\
\text { scientifically } \\
\text { proven to be } \\
\text { absent or } \\
\text { negligible? } \\
\text { Concl. }\end{array}$} & \multirow[t]{2}{*}{$\begin{array}{c}\text { General } \\
\text { conclusion } \\
\\
\text { Horse }\end{array}$} \\
\hline & EFSA & RASFF & NP & Concl. & $\begin{array}{l}\text { Residues } \\
>\text { LOD? }\end{array}$ & $\begin{array}{c}\text { Listed as } \\
\text { obsolete } \\
\text { (Pesticide } \\
\text { Manual) }\end{array}$ & $\begin{array}{l}\text { Listed as } \\
\text { obsolete } \\
\text { (Pesticide } \\
\text { Properties } \\
\text { Database) }\end{array}$ & $\begin{array}{l}\text { Product } \\
\text { available in } \\
\text { US? } \\
\text { (PAN } \\
\text { pesticide } \\
\text { database) }\end{array}$ & $\begin{array}{l}\text { Registration } \\
\text { in other } \\
\text { countries? }\end{array}$ & $\begin{array}{l}\text { Available at } \\
\text { alibaba.com? }\end{array}$ & $\begin{array}{l}\text { Break down } \\
\text { product } \\
\text { monitored? }\end{array}$ & $\begin{array}{l}\text { Pesticide } \\
\text { residues } \\
\text { found in } \\
\text { food }\end{array}$ & Concl. & & \\
\hline 3-hydroxy carbofuran & $\mathrm{N}$ & $\mathrm{N}$ & $\mathrm{N}$ & $\mathrm{N}$ & $\mathrm{U},<10 / y$ & nd & $\mathrm{N}$ & N & $\mathrm{N}$ & N & $\mathrm{N}$ & $\begin{array}{l}Y \text {, in plant } \\
\text { products }\end{array}$ & $\begin{array}{c}\text { Y, } \\
\text { metabolite } \\
\text { of } \\
\text { carbofuran }\end{array}$ & $\mathrm{N}$ & high \\
\hline aldicarb & $\mathrm{N}$ & $\mathrm{N}$ & $\mathrm{N}$ & N & N & $\rightarrow$ & $\rightarrow$ & $\rightarrow$ & $\rightarrow$ & $\rightarrow$ & $\rightarrow$ & $\rightarrow$ & $\begin{array}{c}\mathrm{N} \text {, not found } \\
\text { in } \\
\text { monitoring }\end{array}$ & $\rightarrow$ & low \\
\hline $\begin{array}{l}\text { Aldicarb (aldicarb- } \\
\text { sulfone) }\end{array}$ & $\mathrm{N}$ & $\mathrm{N}$ & $\mathrm{N}$ & $\mathrm{N}$ & $\mathrm{N}$ & $\rightarrow$ & $\rightarrow$ & $\rightarrow$ & $\rightarrow$ & $\rightarrow$ & $\rightarrow$ & $\rightarrow$ & $\begin{array}{c}\mathrm{N} \text {, not found } \\
\text { in } \\
\text { monitoring }\end{array}$ & $\rightarrow$ & low \\
\hline $\begin{array}{l}\text { Aldoxycarb (aldicarb- } \\
\text { sulfoxide) }\end{array}$ & $\mathrm{N}$ & $\mathrm{N}$ & $\mathrm{N}$ & $\mathrm{N}$ & $\mathrm{N}$ & $\rightarrow$ & $\rightarrow$ & $\rightarrow$ & $\rightarrow$ & $\rightarrow$ & $\rightarrow$ & $\rightarrow$ & $\begin{array}{c}\mathrm{N} \text {, not found } \\
\text { in } \\
\text { monitoring }\end{array}$ & $\rightarrow$ & low \\
\hline benfuracarb & $\mathrm{N}$ & $\mathrm{N}$ & U & U & U & nd & u & $\mathrm{N}$ & Asia & Y & $U,<10 / y$ & nd & Y & $\begin{array}{l}\mathrm{N} \text {, metabolite is } \\
\text { carbofuran }\end{array}$ & high \\
\hline carbaryl & $\mathrm{N}$ & $\mathrm{N}$ & $N$ & $\mathrm{~N}$ & $\mathrm{~N}$ & $\rightarrow$ & $\rightarrow$ & $\rightarrow$ & $\rightarrow$ & $\rightarrow$ & $\rightarrow$ & $\rightarrow$ & $\begin{array}{c}\mathrm{N} \text {, not found } \\
\text { in } \\
\text { monitoring }\end{array}$ & $\rightarrow$ & low \\
\hline carbofuran & $\mathrm{N}$ & $\mathrm{N}$ & $\mathrm{N}$ & $\mathrm{N}$ & $U,<10 / y$ & nd & $\mathrm{N}$ & Y & $\begin{array}{l}\text { Australia, } \\
\text { Asia }\end{array}$ & Y & $\mathrm{N}$ & $\begin{array}{l}\mathrm{Y} \text {, in plant } \\
\text { products }\end{array}$ & Y & $\mathrm{N}$ & high \\
\hline carbosulfan & $\mathrm{N}$ & $\mathrm{N}$ & $U$ & U & u & nd & $\mathrm{N}$ & $\mathrm{N}$ & Asia & Y & $\mathrm{U},<10 / \mathrm{y}$ & nd & Y & $\begin{array}{l}\mathrm{N} \text {, metabolite is } \\
\text { carbofuran }\end{array}$ & high \\
\hline
\end{tabular}




\begin{tabular}{|c|c|c|c|c|c|c|c|c|c|c|c|c|c|c|c|}
\hline & $\begin{array}{l}\text { Q1: W } \\
\text { residu } \\
\text { four }\end{array}$ & $\begin{array}{l}\text { ere any } \\
\text { data o } \\
d \text { in the }\end{array}$ & $\begin{array}{l}\text { on-c } \\
\text { he st } \\
\text { st } 5\end{array}$ & $\begin{array}{l}\text { mpliant } \\
\text { ostance } \\
\text { ears? }\end{array}$ & Q3: Ar & there indice & tions for us & of this subst & stance in proc & duction syster & ems for food & oroducing : & Inimals? & $\begin{array}{l}\text { Q2: Is a human } \\
\text { health risk due } \\
\text { to residues of } \\
\text { this substance } \\
\text { scientifically } \\
\text { proven to be } \\
\text { absent or } \\
\text { negligible? }\end{array}$ & $\begin{array}{c}\text { General } \\
\text { conclusion }\end{array}$ \\
\hline Carbamates & EFSA & RASFF & NP & Concl. & $\begin{array}{l}\text { Residues } \\
>\text { LOD? }\end{array}$ & $\begin{array}{c}\text { Listed as } \\
\text { obsolete } \\
\text { (Pesticide } \\
\text { Manual) }\end{array}$ & $\begin{array}{l}\text { Listed as } \\
\text { obsolete } \\
\text { (Pesticide } \\
\text { Properties } \\
\text { Database) }\end{array}$ & $\begin{array}{l}\text { Product } \\
\text { available in } \\
\text { US? } \\
\text { (PAN } \\
\text { pesticide } \\
\text { database) }\end{array}$ & $\begin{array}{l}\text { Registration } \\
\text { in other } \\
\text { countries? }\end{array}$ & $\begin{array}{l}\text { Available at } \\
\text { alibaba.com? }\end{array}$ & $\begin{array}{l}\text { Break down } \\
\text { product } \\
\text { monitored? }\end{array}$ & $\begin{array}{l}\text { Pesticide } \\
\text { residues } \\
\text { found in } \\
\text { food }\end{array}$ & Concl. & Concl. & Horse \\
\hline ethiofencarb & $\mathrm{N}$ & $\mathrm{N}$ & $\mathrm{N}$ & $\mathrm{N}$ & $\mathrm{N}$ & $\rightarrow$ & $\rightarrow$ & $\rightarrow$ & $\rightarrow$ & $\rightarrow$ & $\rightarrow$ & $\rightarrow$ & $\begin{array}{c}\mathrm{N} \text {, not found } \\
\text { in } \\
\text { monitoring }\end{array}$ & $\rightarrow$ & low \\
\hline $\begin{array}{l}\text { Ethiofencarb } \\
\text { (ethiofencarb-sulfone) }\end{array}$ & $\mathrm{N}$ & $\mathrm{N}$ & $\mathrm{N}$ & $\mathrm{N}$ & $\mathrm{N}$ & $\rightarrow$ & $\rightarrow$ & $\rightarrow$ & $\rightarrow$ & $\rightarrow$ & $\rightarrow$ & $\rightarrow$ & $\begin{array}{c}\mathrm{N} \text {, not found } \\
\text { in } \\
\text { monitoring }\end{array}$ & $\rightarrow$ & low \\
\hline $\begin{array}{l}\text { Ethiofencarb } \\
\text { (ethiofencarb-sulfoxide) }\end{array}$ & $\mathrm{N}$ & $\mathrm{N}$ & $\mathrm{N}$ & $\mathrm{N}$ & $\mathrm{N}$ & $\rightarrow$ & $\rightarrow$ & $\rightarrow$ & $\rightarrow$ & $\rightarrow$ & $\rightarrow$ & $\rightarrow$ & $\begin{array}{c}\mathrm{N}, \text { not found } \\
\text { in } \\
\text { monitoring }\end{array}$ & $\rightarrow$ & low \\
\hline furathiocarb & $\mathrm{N}$ & $\mathrm{N}$ & u & u & u & nd & $\mathrm{N}$ & $\mathrm{N}$ & Australia & Y & $U,<10 / y$ & nd & $Y$ & $\begin{array}{l}\mathrm{N} \text {, metabolite is } \\
\text { carbofuran }\end{array}$ & high \\
\hline propoxur & $\mathrm{N}$ & $\mathrm{N}$ & $\mathrm{N}$ & $\mathrm{N}$ & $\mathrm{N}$ & $\rightarrow$ & $\rightarrow$ & $\rightarrow$ & $\rightarrow$ & $\rightarrow$ & $\rightarrow$ & $\rightarrow$ & $\begin{array}{c}\mathrm{N} \text {, not found } \\
\text { in } \\
\text { monitoring }\end{array}$ & $\rightarrow$ & low \\
\hline thiodicarb & $\mathrm{N}$ & $\mathrm{N}$ & $u$ & u & u & nd & $\mathrm{N}$ & $Y$ & $\begin{array}{l}\text { Australia, } \\
\text { Asia }\end{array}$ & Y & Y & nd & $\begin{array}{l}\mathrm{N}, \\
\text { breakdown } \\
\text { product } \\
\text { monitored } \\
\text { and not } \\
\text { found }\end{array}$ & $\rightarrow$ & low \\
\hline
\end{tabular}


Table A4.3 Prioritisation of unauthorised carbamates that are currently included in the NP Residues for goat.

\begin{tabular}{|c|c|c|c|c|c|c|c|c|c|c|c|c|c|c|c|}
\hline \multirow[b]{2}{*}{ Carbamates } & $\begin{array}{l}\text { Q1: } \\
\text { residue }\end{array}$ & $\begin{array}{l}\text { here any } \\
\text { ata of th } \\
n \text { the las }\end{array}$ & $\begin{array}{l}\text { on-ca } \\
\text { yest } \\
\text { yea }\end{array}$ & $\begin{array}{l}\text { liant } \\
\text { e found }\end{array}$ & Q3: Are $\mathrm{t}$ & ere indicati & ons for use & of this subs & stance in proc & duction syste & ms for food & producing & animals? & \multirow[t]{2}{*}{$\begin{array}{c}\text { Q2: Is a human } \\
\text { health risk due } \\
\text { to residues of } \\
\text { this substance } \\
\text { scientifically } \\
\text { proven to be } \\
\text { absent or } \\
\text { negligible? } \\
\text { Concl. }\end{array}$} & \multirow[t]{2}{*}{$\begin{array}{c}\begin{array}{c}\text { General } \\
\text { conclusion }\end{array} \\
\text { Goat }\end{array}$} \\
\hline & EFSA & RASFF & NP & Concl. & $\begin{array}{l}\text { Residues } \\
>\text { LOD? }\end{array}$ & $\begin{array}{c}\text { Listed as } \\
\text { obsolete } \\
\text { (Pesticide } \\
\text { Manual) }\end{array}$ & $\begin{array}{l}\text { Listed as } \\
\text { obsolete } \\
\text { (Pesticide } \\
\text { Properties } \\
\text { Database) }\end{array}$ & $\begin{array}{l}\text { Product } \\
\text { available in } \\
\text { US? } \\
\text { (PAN } \\
\text { pesticide } \\
\text { database) }\end{array}$ & $\begin{array}{l}\text { Registration } \\
\text { in other } \\
\text { countries? }\end{array}$ & $\begin{array}{l}\text { Available at } \\
\text { alibaba.com? }\end{array}$ & $\begin{array}{c}\text { Break } \\
\text { down } \\
\text { product } \\
\text { monitored? }\end{array}$ & $\begin{array}{l}\text { Pesticide } \\
\text { residues } \\
\text { found in } \\
\text { food }\end{array}$ & Concl. & & \\
\hline 3-hydroxy carbofuran & $\mathrm{N}$ & $\mathrm{N}$ & $\mathrm{N}$ & $\mathrm{N}$ & $\mathrm{U},<10 / \mathrm{y}$ & nd & $\mathrm{N}$ & N & $\mathrm{N}$ & $\mathrm{N}$ & $\mathrm{N}$ & $\begin{array}{l}\mathrm{Y} \text {, in plant } \\
\text { products }\end{array}$ & $\begin{array}{c}\mathrm{Y} \\
\text { metabolite } \\
\text { of } \\
\text { carbofuran }\end{array}$ & $\mathrm{N}$ & high \\
\hline aldicarb & $\mathrm{N}$ & $\mathrm{N}$ & $\mathrm{N}$ & $\mathrm{N}$ & $U,<10 / y$ & nd & $\mathrm{N}$ & Y & Asia & $\mathrm{N}$ & $\mathrm{N}$ & $\begin{array}{l}\mathrm{Y} \text {, in plant } \\
\text { products }\end{array}$ & Y & $u$ & high* \\
\hline $\begin{array}{l}\text { Aldicarb (aldicarb- } \\
\text { sulfone) }\end{array}$ & $\mathrm{N}$ & $\mathrm{N}$ & $\mathrm{N}$ & $\mathrm{N}$ & $\mathrm{U},<10 / \mathrm{y}$ & nd & $\mathrm{N}$ & $\mathrm{N}$ & N & $\mathrm{N}$ & $\mathrm{N}$ & $\begin{array}{l}\mathrm{Y} \text {, in plant } \\
\text { products }\end{array}$ & $\begin{array}{c}\mathrm{Y} \\
\text { metabolite } \\
\text { of aldicarb }\end{array}$ & 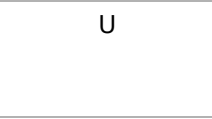 & high* \\
\hline $\begin{array}{l}\text { Aldoxycarb (aldicarb- } \\
\text { sulfoxide) }\end{array}$ & $\mathrm{N}$ & $\mathrm{N}$ & $\mathrm{N}$ & $\mathrm{N}$ & $\mathrm{U},<10 / \mathrm{y}$ & nd & $\mathrm{N}$ & N & $\begin{array}{l}\text { Australia, } \\
\text { Asia }\end{array}$ & $\mathrm{N}$ & $\mathrm{N}$ & $\begin{array}{l}\mathrm{Y} \text {, in plant } \\
\text { products }\end{array}$ & $\begin{array}{c}\mathrm{Y} \\
\text { metabolite } \\
\text { of aldicarb }\end{array}$ & $u$ & high* \\
\hline benfuracarb & $\mathrm{N}$ & N & $U$ & $u$ & $\mathrm{U},<10 / \mathrm{y}$ & nd & $u$ & N & Asia & $Y$ & $\mathrm{U},<10 / \mathrm{y}$ & nd & Y & $\begin{array}{l}\mathrm{N} \text {, metabolite is } \\
\text { carbofuran }\end{array}$ & high \\
\hline carbaryl & $\mathrm{N}$ & $\mathrm{N}$ & $\mathrm{N}$ & $\mathrm{N}$ & $U,<10 / y$ & nd & $\mathrm{N}$ & Y & $\begin{array}{l}\text { Australia, } \\
\text { Asia }\end{array}$ & Y & $\mathrm{N}$ & $\begin{array}{l}\mathrm{Y} \text {, in plant } \\
\text { products }\end{array}$ & Y & u & high* \\
\hline carbofuran & $\mathrm{N}$ & $N$ & $\mathrm{~N}$ & $\mathrm{~N}$ & $\mathrm{U},<10 / \mathrm{y}$ & nd & $\mathrm{N}$ & Y & $\begin{array}{c}\text { Australia, } \\
\text { Asia }\end{array}$ & Y & $\mathrm{N}$ & $\begin{array}{l}\mathrm{Y} \text {, in plant } \\
\text { products }\end{array}$ & Y & $\mathrm{N}$ & high \\
\hline carbosulfan & $\mathrm{N}$ & $\mathrm{N}$ & $U$ & U & $\mathrm{U},<10 / \mathrm{y}$ & nd & $N$ & N & Asia & Y & $\mathrm{U},<10 / \mathrm{y}$ & nd & Y & $\begin{array}{l}\mathrm{N} \text {, metabolite is } \\
\text { carbofuran }\end{array}$ & high \\
\hline ethiofencarb & $\mathrm{N}$ & $\mathrm{N}$ & $\mathrm{N}$ & $\mathrm{N}$ & $\mathrm{U},<10 / \mathrm{y}$ & nd & u & $\mathrm{N}$ & $\mathrm{N}$ & $Y$ & $\mathrm{~N}$ & $Y$ & Y & u & high* \\
\hline $\begin{array}{l}\text { Ethiofencarb } \\
\text { (ethiofencarb-sulfone) }\end{array}$ & $\mathrm{N}$ & $\mathrm{N}$ & $N$ & $\mathrm{~N}$ & $\mathrm{U},<10 / \mathrm{y}$ & nd & U & N & $\mathrm{N}$ & $\mathrm{N}$ & $\mathrm{N}$ & N & Y & U & high* \\
\hline
\end{tabular}




\begin{tabular}{|c|c|c|c|c|c|c|c|c|c|c|c|c|c|c|c|}
\hline & $\begin{array}{l}\text { Q1: } \\
\text { residue }\end{array}$ & $\begin{array}{l}\text { here any } \\
\text { ata of th } \\
n \text { the las }\end{array}$ & $\begin{array}{l}\text { on-c } \\
\text { ubs } \\
\text { yea }\end{array}$ & liant & Q3: Are t & lere indicat & ons for use & of this subst & tance in pro & duction syste & ms for food & producing & nimals? & $\begin{array}{l}\text { Q2: Is a human } \\
\text { health risk due } \\
\text { to residues of } \\
\text { this substance } \\
\text { scientifically } \\
\text { proven to be } \\
\text { absent or } \\
\text { negligible? }\end{array}$ & $\begin{array}{l}\text { General } \\
\text { conclusion }\end{array}$ \\
\hline Carbamates & EFSA & RASFF & NP & Concl. & $\begin{array}{l}\text { Residues } \\
\text { > LOD? }\end{array}$ & $\begin{array}{c}\text { Listed as } \\
\text { obsolete } \\
\text { (Pesticide } \\
\text { Manual) }\end{array}$ & $\begin{array}{l}\text { Listed as } \\
\text { obsolete } \\
\text { (Pesticide } \\
\text { Properties } \\
\text { Database) }\end{array}$ & $\begin{array}{l}\text { Product } \\
\text { available in } \\
\text { US? } \\
\text { (PAN } \\
\text { pesticide } \\
\text { database) }\end{array}$ & $\begin{array}{l}\text { Registration } \\
\text { in other } \\
\text { countries? }\end{array}$ & $\begin{array}{l}\text { Available at } \\
\text { alibaba.com? }\end{array}$ & $\begin{array}{c}\text { Break } \\
\text { down } \\
\text { product } \\
\text { monitored? }\end{array}$ & $\begin{array}{l}\text { Pesticide } \\
\text { residues } \\
\text { found in } \\
\text { food }\end{array}$ & Concl. & Concl. & Goat \\
\hline $\begin{array}{l}\text { Ethiofencarb } \\
\text { (ethiofencarb-sulfoxide) }\end{array}$ & $\mathrm{N}$ & $\mathrm{N}$ & $N$ & N & $\mathrm{U},<10 / \mathrm{y}$ & nd & U & N & $\mathrm{N}$ & $\mathrm{N}$ & $\mathrm{N}$ & $\mathrm{N}$ & $Y$ & U & high* \\
\hline furathiocarb & N & N & U & U & $\mathrm{U},<10 / \mathrm{y}$ & nd & $\mathrm{N}$ & N & Australia & $Y$ & $\mathrm{U},<10 / \mathrm{y}$ & nd & $Y$ & $\begin{array}{l}\mathrm{N} \text {, metabolite is } \\
\text { carbofuran }\end{array}$ & high \\
\hline propoxur & N & N & $N$ & N & $\mathrm{U},<10 / \mathrm{y}$ & nd & N & $Y$ & $\begin{array}{c}\text { Australia, } \\
\text { Asia }\end{array}$ & $Y$ & N & $\begin{array}{l}\mathrm{Y} \text {, in plant } \\
\text { products }\end{array}$ & Y & U & high* \\
\hline thiodicarb & $N$ & N & U & U & $\mathrm{U},<10 / \mathrm{y}$ & nd & N & $Y$ & $\begin{array}{c}\text { Australia, } \\
\text { Asia }\end{array}$ & $Y$ & $\mathrm{U},<10 / \mathrm{y}$ & nd & Y & $\begin{array}{l}\text { Y, metabolite is } \\
\text { methomyl, no } \\
\text { risk }\end{array}$ & medium \\
\hline
\end{tabular}

$\rightarrow$ based on the outcome of the previous question, this question can be skipped.

* these substances only have the classification of high priority because there is no occurrence data or information available to answer the questions. 
Table A4.4 Prioritisation of unauthorised carbamates that are currently included in the NP Residues for sheep.

\begin{tabular}{|c|c|c|c|c|c|c|c|c|c|c|c|c|c|c|c|}
\hline \multirow[b]{2}{*}{ Carbamates } & $\begin{array}{l}\text { Q1: Wh } \\
\text { data c }\end{array}$ & $\begin{array}{r}\text { any no } \\
\text { he subs } \\
\text { last } 5\end{array}$ & $\begin{array}{l}\text { ompl } \\
\text { ce fol } \\
\text { ars? }\end{array}$ & $\begin{array}{l}\text { residue } \\
\text { in the }\end{array}$ & Q3: Are th & re indicatic & ons for use & of this subs & stance in proc & duction syste & ems for food & producing & g animals? & \multirow[t]{2}{*}{$\begin{array}{l}\text { Q2: Is a human } \\
\text { health risk due } \\
\text { to residues of } \\
\text { this substance } \\
\text { scientifically } \\
\text { proven to be } \\
\text { absent or } \\
\text { negligible? } \\
\text { Concl. }\end{array}$} & \multirow[t]{2}{*}{$\begin{array}{c}\begin{array}{c}\text { General } \\
\text { conclusion }\end{array} \\
\text { Sheep }\end{array}$} \\
\hline & EFSA & RASFF & NP & Concl. & $\begin{array}{l}\text { Residues } \\
\text { >LOD? }\end{array}$ & $\begin{array}{l}\text { Listed as } \\
\text { obsolete } \\
\text { (Pesticide } \\
\text { Manual) }\end{array}$ & $\begin{array}{l}\text { Listed as } \\
\text { obsolete } \\
\text { (Pesticide } \\
\text { Properties } \\
\text { Database) }\end{array}$ & $\begin{array}{l}\text { Product } \\
\text { available } \\
\text { in US? } \\
\text { (PAN } \\
\text { pesticide } \\
\text { database) }\end{array}$ & $\begin{array}{l}\text { Registration } \\
\text { in other } \\
\text { countries? }\end{array}$ & $\begin{array}{l}\text { Available at } \\
\text { alibaba.com? }\end{array}$ & $\begin{array}{l}\text { Break down } \\
\text { product } \\
\text { monitored? }\end{array}$ & $\begin{array}{l}\text { Pesticide } \\
\text { residues } \\
\text { found in } \\
\text { food }\end{array}$ & Concl. & & \\
\hline 3-hydroxy carbofuran & $\mathrm{N}$ & N & $\mathrm{N}$ & $\mathrm{N}$ & $\mathrm{U},<10 / \mathrm{y}$ & nd & $\mathrm{N}$ & N & $\mathrm{N}$ & $\mathrm{N}$ & $\mathrm{N}$ & $\begin{array}{l}\mathrm{Y} \text {, in plant } \\
\text { products }\end{array}$ & $\begin{array}{c}\text { Y, } \\
\text { metabolite } \\
\text { of } \\
\text { carbofuran }\end{array}$ & N & high \\
\hline aldicarb & N & $\mathrm{N}$ & $\mathrm{N}$ & $\mathrm{N}$ & $\mathrm{N}$ & $\rightarrow$ & $\rightarrow$ & $\rightarrow$ & $\rightarrow$ & $\rightarrow$ & $\rightarrow$ & $\rightarrow$ & $\begin{array}{l}\mathrm{N} \text {, not } \\
\text { found in } \\
\text { monitoring }\end{array}$ & $\rightarrow$ & low \\
\hline Aldicarb (aldicarb-sulfone) & $\mathrm{N}$ & $\mathrm{N}$ & $\mathrm{N}$ & $\mathrm{N}$ & $\mathrm{N}$ & $\rightarrow$ & $\rightarrow$ & $\rightarrow$ & $\rightarrow$ & $\rightarrow$ & $\rightarrow$ & $\rightarrow$ & $\begin{array}{l}\mathrm{N} \text {, not } \\
\text { found in } \\
\text { monitoring }\end{array}$ & $\rightarrow$ & low \\
\hline $\begin{array}{l}\text { Aldoxycarb (aldicarb- } \\
\text { sulfoxide) }\end{array}$ & $\mathrm{N}$ & $\mathrm{N}$ & $\mathrm{N}$ & $\mathrm{N}$ & $\mathrm{N}$ & $\rightarrow$ & $\rightarrow$ & $\rightarrow$ & $\rightarrow$ & $\rightarrow$ & $\rightarrow$ & $\rightarrow$ & $\begin{array}{l}\mathrm{N} \text {, not } \\
\text { found in } \\
\text { monitoring }\end{array}$ & $\rightarrow$ & low \\
\hline benfuracarb & N & N & U & U & $u$ & nd & U & $\mathrm{N}$ & Asia & Y & $\mathrm{U},<10 / \mathrm{y}$ & nd & Y & $\begin{array}{l}\mathrm{N} \text {, metabolite is } \\
\text { carbofuran }\end{array}$ & high \\
\hline carbaryl & $\mathrm{N}$ & $\mathrm{N}$ & $\mathrm{N}$ & $\mathrm{N}$ & $\mathrm{N}$ & $\rightarrow$ & $\rightarrow$ & $\rightarrow$ & $\rightarrow$ & $\rightarrow$ & $\rightarrow$ & $\rightarrow$ & $\begin{array}{l}\mathrm{N} \text {, not } \\
\text { found in } \\
\text { monitoring }\end{array}$ & $\rightarrow$ & low \\
\hline carbofuran & $\mathrm{N}$ & $\mathrm{N}$ & $\mathrm{N}$ & $\mathrm{N}$ & $U,<10 / y$ & nd & $\mathrm{N}$ & Y & $\begin{array}{c}\text { Australia, } \\
\text { Asia }\end{array}$ & Y & $\mathrm{N}$ & $\begin{array}{l}Y \text {, in plant } \\
\text { products }\end{array}$ & Y & $\mathrm{N}$ & high \\
\hline carbosulfan & $\mathrm{N}$ & N & U & U & U & nd & $\mathrm{N}$ & $\mathrm{N}$ & Asia & Y & $\mathrm{U},<10 / \mathrm{y}$ & nd & Y & $\begin{array}{l}\mathrm{N} \text {, metabolite is } \\
\text { carbofuran }\end{array}$ & high \\
\hline
\end{tabular}




\begin{tabular}{|c|c|c|c|c|c|c|c|c|c|c|c|c|c|c|c|}
\hline \multirow[b]{2}{*}{ Carbamates } & $\begin{array}{l}\text { Q1: Wh } \\
\text { data }\end{array}$ & $\begin{array}{r}\text { any nor } \\
\text { the subst } \\
\text { last } 5\end{array}$ & $\begin{array}{l}\text { ompl } \\
\text { ce fo } \\
\text { ars? }\end{array}$ & $\begin{array}{l}\text { in the } \\
\text { indue }\end{array}$ & Q3: Are th & re indicati & ons for use & of this sub. & stance in proc & duction syste & ems for food & producing & g animals? & \multirow[t]{2}{*}{$\begin{array}{l}\text { Q2: Is a human } \\
\text { health risk due } \\
\text { to residues of } \\
\text { this substance } \\
\text { scientifically } \\
\text { proven to be } \\
\text { absent or } \\
\text { negligible? } \\
\text { Concl. }\end{array}$} & \multirow[t]{2}{*}{$\begin{array}{c}\begin{array}{c}\text { General } \\
\text { conclusion }\end{array} \\
\text { Sheep }\end{array}$} \\
\hline & EFSA & RASFF & NP & Concl. & $\begin{array}{l}\text { Residues } \\
\text { >LOD? }\end{array}$ & $\begin{array}{l}\text { Listed as } \\
\text { obsolete } \\
\text { (Pesticide } \\
\text { Manual) }\end{array}$ & $\begin{array}{l}\text { Listed as } \\
\text { obsolete } \\
\text { (Pesticide } \\
\text { Properties } \\
\text { Database) }\end{array}$ & $\begin{array}{c}\text { Product } \\
\text { available } \\
\text { in US? } \\
\text { (PAN } \\
\text { pesticide } \\
\text { database) }\end{array}$ & $\begin{array}{l}\text { Registration } \\
\text { in other } \\
\text { countries? }\end{array}$ & $\begin{array}{l}\text { Available at } \\
\text { alibaba.com? }\end{array}$ & $\begin{array}{l}\text { Break down } \\
\text { product } \\
\text { monitored? }\end{array}$ & $\begin{array}{l}\text { Pesticide } \\
\text { residues } \\
\text { found in } \\
\text { food }\end{array}$ & Concl. & & \\
\hline ethiofencarb & $\mathrm{N}$ & $\mathrm{N}$ & $N$ & $N$ & N & $\rightarrow$ & $\rightarrow$ & $\rightarrow$ & $\rightarrow$ & $\rightarrow$ & $\rightarrow$ & $\rightarrow$ & $\begin{array}{c}\mathrm{N}, \text { not } \\
\text { found in } \\
\text { monitoring }\end{array}$ & $\rightarrow$ & low \\
\hline $\begin{array}{l}\text { Ethiofencarb } \\
\text { (ethiofencarb-sulfone) }\end{array}$ & $\mathrm{N}$ & $N$ & $\mathrm{~N}$ & $\mathrm{~N}$ & $\mathrm{~N}$ & $\rightarrow$ & $\rightarrow$ & $\rightarrow$ & $\rightarrow$ & $\rightarrow$ & $\rightarrow$ & $\rightarrow$ & $\begin{array}{c}\mathrm{N}, \text { not } \\
\text { found in } \\
\text { monitoring }\end{array}$ & $\rightarrow$ & low \\
\hline $\begin{array}{l}\text { Ethiofencarb } \\
\text { (ethiofencarb-sulfoxide) }\end{array}$ & $\mathrm{N}$ & $\mathrm{N}$ & $\mathrm{N}$ & $\mathrm{N}$ & $\mathrm{N}$ & $\rightarrow$ & $\rightarrow$ & $\rightarrow$ & $\rightarrow$ & $\rightarrow$ & $\rightarrow$ & $\rightarrow$ & $\begin{array}{l}\mathrm{N}, \text { not } \\
\text { found in } \\
\text { monitoring }\end{array}$ & $\rightarrow$ & low \\
\hline furathiocarb & $N$ & $N$ & $U$ & U & U & nd & N & N & Australia & $Y$ & $\mathrm{U},<10 / \mathrm{y}$ & nd & Y & $\begin{array}{l}\mathrm{N} \text {, metabolite is } \\
\text { carbofuran }\end{array}$ & high \\
\hline propoxur & $\mathrm{N}$ & $\mathrm{N}$ & $\mathrm{N}$ & $N$ & $\mathrm{~N}$ & $\rightarrow$ & $\rightarrow$ & $\rightarrow$ & $\rightarrow$ & $\rightarrow$ & $\rightarrow$ & $\rightarrow$ & $\begin{array}{l}\mathrm{N}, \text { not } \\
\text { found in } \\
\text { monitoring }\end{array}$ & $\rightarrow$ & low \\
\hline thiodicarb & $\mathrm{N}$ & $\mathrm{N}$ & $U$ & U & U & nd & N & Y & $\begin{array}{l}\text { Australia, } \\
\text { Asia }\end{array}$ & $Y$ & $U,<10 / y$ & nd & Y & $\begin{array}{l}\mathrm{Y} \text {, metabolite is } \\
\text { methomyl, no } \\
\text { risk }\end{array}$ & medium \\
\hline
\end{tabular}

$\rightarrow$ based on the outcome of the previous question, this question can be skipped.

* these substances only have the classification of high priority because there is no occurrence data or information available to answer the questions. 
Table A4.5 Prioritisation of unauthorised carbamates that are currently included in the NP Residues for milk.

\begin{tabular}{|c|c|c|c|c|c|c|c|c|c|c|c|c|c|c|c|}
\hline & $\begin{array}{l}\text { Q1: Wh } \\
\text { data c }\end{array}$ & $\begin{array}{r}\text { any no } \\
\text { he subs } \\
\text { last } 5\end{array}$ & $\begin{array}{l}\text { ompl } \\
\text { ce fo } \\
\text { ars? }\end{array}$ & $\begin{array}{l}\text { residue } \\
\text { in the }\end{array}$ & Q3: Are $\mathrm{t}$ & there indic & ations for $u$ & se of this $s$ & ubstance in p & roduction sys & tems for food & d producin & Ig animals? & $\begin{array}{l}\text { Q2: Is a human } \\
\text { health risk due to } \\
\text { residues of this } \\
\text { substance } \\
\text { scientifically } \\
\text { proven to be } \\
\text { absent or } \\
\text { negligible? }\end{array}$ & $\begin{array}{l}\text { General } \\
\text { conclusion }\end{array}$ \\
\hline Carbamates & EFSA & RASFF & NP & Concl. & $\begin{array}{l}\text { Residues } \\
\text { >LOD? }\end{array}$ & $\begin{array}{l}\text { Listed as } \\
\text { obsolete } \\
\text { (Pesticide } \\
\text { Manual) }\end{array}$ & $\begin{array}{l}\text { Listed as } \\
\text { obsolete } \\
\text { (Pesticide } \\
\text { Properties } \\
\text { Database) }\end{array}$ & $\begin{array}{l}\text { Product } \\
\text { available } \\
\text { in US? } \\
\text { (PAN } \\
\text { pesticide } \\
\text { database) }\end{array}$ & $\begin{array}{l}\text { Registration } \\
\text { in other } \\
\text { countries? }\end{array}$ & $\begin{array}{l}\text { Available at } \\
\text { alibaba.com? }\end{array}$ & $\begin{array}{l}\text { Break down } \\
\text { product } \\
\text { monitored? }\end{array}$ & $\begin{array}{l}\text { Pesticide } \\
\text { residues } \\
\text { found in } \\
\text { food }\end{array}$ & Concl. & Concl. & Milk \\
\hline 3-hydroxy carbofuran & $\mathrm{N}$ & $\mathrm{N}$ & N & $\mathrm{N}$ & $\mathrm{U},<10 / \mathrm{y}$ & nd & $\mathrm{N}$ & $\mathrm{N}$ & N & $\mathrm{N}$ & N & $\begin{array}{l}\mathrm{Y} \text {, in plant } \\
\text { products }\end{array}$ & $\begin{array}{c}\mathrm{Y}, \\
\text { metabolite } \\
\text { of } \\
\text { carbofuran }\end{array}$ & $\mathrm{N}$ & high \\
\hline aldicarb & $\mathrm{N}$ & $\mathrm{N}$ & $\mathrm{N}$ & $\mathrm{N}$ & $\mathrm{N}$ & $\rightarrow$ & $\rightarrow$ & $\rightarrow$ & $\rightarrow$ & $\rightarrow$ & $\rightarrow$ & $\rightarrow$ & $\begin{array}{l}\mathrm{N}, \text { not } \\
\text { found in } \\
\text { monitoring }\end{array}$ & $\rightarrow$ & low \\
\hline Aldicarb (aldicarb-sulfone) & $\mathrm{N}$ & $\mathrm{N}$ & $\mathrm{N}$ & $\mathrm{N}$ & $\mathrm{N}$ & $\rightarrow$ & $\rightarrow$ & $\rightarrow$ & $\rightarrow$ & $\rightarrow$ & $\rightarrow$ & $\rightarrow$ & $\begin{array}{c}\mathrm{N}, \mathrm{not} \\
\text { found in } \\
\text { monitoring }\end{array}$ & $\rightarrow$ & low \\
\hline $\begin{array}{l}\text { Aldoxycarb (aldicarb- } \\
\text { sulfoxide) }\end{array}$ & $\mathrm{N}$ & $\mathrm{N}$ & $\mathrm{N}$ & $\mathrm{N}$ & $\mathrm{N}$ & $\rightarrow$ & $\rightarrow$ & $\rightarrow$ & $\rightarrow$ & $\rightarrow$ & $\rightarrow$ & $\rightarrow$ & $\begin{array}{c}\mathrm{N}, \text { not } \\
\text { found in } \\
\text { monitoring }\end{array}$ & $\rightarrow$ & low \\
\hline benfuracarb & $\mathrm{N}$ & $\mathrm{N}$ & U & U & U & nd & $u$ & $\mathrm{~N}$ & Asia & Y & $\mathrm{U},<10 / \mathrm{y}$ & nd & Y & $\begin{array}{l}\mathrm{N}, \text { metabolite is } \\
\text { carbofuran }\end{array}$ & high \\
\hline carbaryl & $\mathrm{N}$ & $\mathrm{N}$ & $\mathrm{N}$ & $\mathrm{N}$ & $\mathrm{N}$ & $\rightarrow$ & $\rightarrow$ & $\rightarrow$ & $\rightarrow$ & $\rightarrow$ & $\rightarrow$ & $\rightarrow$ & $\begin{array}{c}\mathrm{N}, \text { not } \\
\text { found in } \\
\text { monitoring }\end{array}$ & $\rightarrow$ & low \\
\hline carbofuran & $\mathrm{N}$ & $\mathrm{N}$ & $\mathrm{N}$ & $\mathrm{N}$ & $U,<10 / y$ & nd & $\mathrm{N}$ & $\mathrm{Y}$ & $\begin{array}{c}\text { Australia, } \\
\text { Asia }\end{array}$ & $\mathrm{Y}$ & $\mathrm{N}$ & $\begin{array}{l}\mathrm{Y} \text {, in plant } \\
\text { products }\end{array}$ & $\mathrm{Y}$ & $\mathrm{N}$ & high \\
\hline carbosulfan & $\mathrm{N}$ & $\mathrm{N}$ & U & U & U & nd & N & $\mathrm{N}$ & Asia & Y & $\mathrm{U},<10 / \mathrm{Y}$ & nd & Y & $\begin{array}{l}\mathrm{N} \text {, metabolite is } \\
\text { carbofuran }\end{array}$ & high \\
\hline
\end{tabular}




\begin{tabular}{|c|c|c|c|c|c|c|c|c|c|c|c|c|c|c|c|}
\hline & $\begin{array}{l}\text { Q1: Wh } \\
\text { data c }\end{array}$ & $\begin{array}{r}\text { any no } \\
\text { he subs } \\
\text { last } 5\end{array}$ & $\begin{array}{l}\text { omp } \\
\text { ce fc } \\
\text { ars? }\end{array}$ & $\begin{array}{l}\text { tresidue } \\
\text { In the }\end{array}$ & Q3: Are t & there indic & ations for $u$ & se of this $s$ & ubstance in p & roduction sys & tems for food & d producin & g animals? & $\begin{array}{l}\text { Q2: Is a human } \\
\text { health risk due to } \\
\text { residues of this } \\
\text { substance } \\
\text { scientifically } \\
\text { proven to be } \\
\text { absent or } \\
\text { negligible? }\end{array}$ & $\begin{array}{c}\text { General } \\
\text { conclusion }\end{array}$ \\
\hline Carbamates & EFSA & RASFF & NP & Concl. & $\begin{array}{l}\text { Residues } \\
>\text { LOD? }\end{array}$ & $\begin{array}{l}\text { Listed as } \\
\text { obsolete } \\
\text { (Pesticide } \\
\text { Manual) }\end{array}$ & $\begin{array}{l}\text { Listed as } \\
\text { obsolete } \\
\text { (Pesticide } \\
\text { Properties } \\
\text { Database) }\end{array}$ & $\begin{array}{l}\text { Product } \\
\text { available } \\
\text { in US? } \\
\text { (PAN } \\
\text { pesticide } \\
\text { database) }\end{array}$ & $\begin{array}{l}\text { Registration } \\
\text { in other } \\
\text { countries? }\end{array}$ & $\begin{array}{l}\text { Available at } \\
\text { alibaba.com? }\end{array}$ & $\begin{array}{l}\text { Break down } \\
\text { product } \\
\text { monitored? }\end{array}$ & $\begin{array}{l}\text { Pesticide } \\
\text { residues } \\
\text { found in } \\
\text { food }\end{array}$ & Concl. & Concl. & Milk \\
\hline ethiofencarb & $N$ & $N$ & $\mathrm{~N}$ & $\mathrm{~N}$ & $\mathrm{~N}$ & $\rightarrow$ & $\rightarrow$ & $\rightarrow$ & $\rightarrow$ & $\rightarrow$ & $\rightarrow$ & $\rightarrow$ & $\begin{array}{l}\mathrm{N}, \text { not } \\
\text { found in } \\
\text { monitoring }\end{array}$ & $\rightarrow$ & low \\
\hline $\begin{array}{l}\text { Ethiofencarb } \\
\text { (ethiofencarb-sulfone) }\end{array}$ & $N$ & $N$ & $\mathrm{~N}$ & $\mathrm{~N}$ & N & $\rightarrow$ & $\rightarrow$ & $\rightarrow$ & $\rightarrow$ & $\rightarrow$ & $\rightarrow$ & $\rightarrow$ & $\begin{array}{l}\mathrm{N}, \text { not } \\
\text { found in } \\
\text { monitoring }\end{array}$ & $\rightarrow$ & low \\
\hline $\begin{array}{l}\text { Ethiofencarb } \\
\text { (ethiofencarb-sulfoxide) }\end{array}$ & $N$ & $N$ & $\mathrm{~N}$ & $\mathrm{~N}$ & $\mathrm{~N}$ & $\rightarrow$ & $\rightarrow$ & $\rightarrow$ & $\rightarrow$ & $\rightarrow$ & $\rightarrow$ & $\rightarrow$ & $\begin{array}{l}\mathrm{N}, \text { not } \\
\text { found in } \\
\text { monitoring }\end{array}$ & $\rightarrow$ & low \\
\hline furathiocarb & $\mathrm{N}$ & $N$ & U & U & U & nd & $\mathrm{N}$ & $\mathrm{N}$ & Australia & $Y$ & $\mathrm{U},<10 / \mathrm{y}$ & nd & $Y$ & $\begin{array}{l}\mathrm{N} \text {, metabolite is } \\
\text { carbofuran }\end{array}$ & high \\
\hline propoxur & $\mathrm{N}$ & $N$ & $\mathrm{~N}$ & $\mathrm{~N}$ & $\mathrm{~N}$ & $\rightarrow$ & $\rightarrow$ & $\rightarrow$ & $\rightarrow$ & $\rightarrow$ & $\rightarrow$ & $\rightarrow$ & $\begin{array}{l}\mathrm{N}, \text { not } \\
\text { found in } \\
\text { monitoring }\end{array}$ & $\rightarrow$ & low \\
\hline thiodicarb & $N$ & $N$ & U & U & U & nd & $\mathrm{N}$ & $Y$ & $\begin{array}{l}\text { Australia, } \\
\text { Asia }\end{array}$ & $Y$ & $U,<10 / y$ & nd & $Y$ & $\begin{array}{l}Y \text {, metabolite is } \\
\text { methomyl, no risk }\end{array}$ & medium \\
\hline
\end{tabular}

\section{$\rightarrow$ based on the outcome of the previous question, this question can be skipped.}

* these substances only have the classification of high priority because there is no occurrence data or information available to answer the question. 


\section{Annex 5 Prioritisation of unauthorised NSAIDs using decision tree I}

Table A5.1 Prioritisation of unauthorised NSAIDs in horse.

\begin{tabular}{|c|c|c|c|c|c|c|c|c|c|c|c|}
\hline \multirow[b]{2}{*}{ Substance } & \multicolumn{4}{|c|}{$\begin{array}{l}\text { Q1: Were any non-compliant residue data of the } \\
\text { substance found in the last five years? }\end{array}$} & \multicolumn{5}{|c|}{$\begin{array}{l}\text { Q3: Are there indications for use of this substance in } \\
\text { production systems for food producing animals? }\end{array}$} & \multirow{2}{*}{$\begin{array}{l}\text { Q2: Is a human health risk due } \\
\text { to residues of this substance } \\
\text { scientifically proven to be } \\
\text { absent or negligible? } \\
\text { Concl. }\end{array}$} & \multirow{2}{*}{$\begin{array}{c}\begin{array}{c}\text { Conclusion } \\
\text { priority }\end{array} \\
\text { Horse }\end{array}$} \\
\hline & EFSA 2013-2017 & RASFF $2013-2017$ & $\begin{array}{l}\text { NP data } \\
2013- \\
2017\end{array}$ & Concl. & $\begin{array}{c}\text { Non- } \\
\text { compliances } \\
\text { other } \\
\text { mammals }\end{array}$ & $\begin{array}{l}\text { Residues } \\
>\text { LOD? }\end{array}$ & $\begin{array}{l}\text { Registered } \\
\text { product EU for } \\
\text { companion } \\
\text { animals }\end{array}$ & $\begin{array}{c}\text { Availability } \\
\text { (Alibaba/eBay) }\end{array}$ & Concl. & & \\
\hline Cimicoxib & $u$ & $u$ & $u$ & $u$ & $U$ & $\mathrm{U}, \mathrm{n}<10$ & $Y^{d}$ & $\mathrm{~N}$ & $\mathrm{~N}$ & $\rightarrow$ & Low \\
\hline Eltenac & $u$ & $u$ & $u$ & $u$ & $u$ & $\mathrm{U}, \mathrm{n}<10$ & $Y^{h}$ & $\rightarrow$ & $\mathrm{Y}$ & $U$ & High* \\
\hline Fenbufen & $\mathrm{N}$ & $\mathrm{N}$ & $\mathrm{N}$ & $\mathrm{N}$ & $\mathrm{N}$ & $\mathrm{N}$ & $\rightarrow$ & $\rightarrow$ & $\mathrm{N}$ & $\rightarrow$ & Low \\
\hline Flufenamic acid & $\mathrm{N}$ & $\mathrm{Y}$ & $\mathrm{N}$ & $\mathrm{Y}$ & $\rightarrow$ & $\rightarrow$ & $\rightarrow$ & $\rightarrow$ & $\rightarrow$ & $\mathrm{u}$ & High* \\
\hline Grapiprant & $u$ & $u$ & $u$ & $u$ & $u$ & $\mathrm{U}, \mathrm{n}<10$ & $Y^{d}$ & $\mathrm{Y}$ & $Y$ & $u$ & High* \\
\hline Ibuprofen & Y & $\mathrm{N}$ & $\mathrm{N}$ & $\mathrm{Y}$ & $\rightarrow$ & $\rightarrow$ & $\rightarrow$ & $\rightarrow$ & $\rightarrow$ & $\mathrm{Y}$ & Medium \\
\hline Indoprofen & $\mathrm{N}$ & $\mathrm{N}$ & $\mathrm{N}$ & $\mathrm{N}$ & $\mathrm{N}$ & $\mathrm{N}$ & $\rightarrow$ & $\rightarrow$ & $\mathrm{N}$ & $\rightarrow$ & Low \\
\hline Mavacoxib & u & u & u & u & u & $\mathrm{U}, \mathrm{n}<10$ & $Y^{d}$ & $\mathrm{~N}$ & $\mathrm{~N}$ & $\rightarrow$ & Low \\
\hline Meclofenamic acid & $\mathrm{N}$ & $\mathrm{N}$ & $\mathrm{N}$ & $\mathrm{N}$ & $\mathrm{N}$ & $\mathrm{N}$ & $\rightarrow$ & $\rightarrow$ & $\mathrm{N}$ & $\rightarrow$ & Low \\
\hline Mefenamic acid & $\mathrm{N}$ & $\mathrm{N}$ & $\mathrm{N}$ & $\mathrm{N}$ & $Y^{b}$ & $\rightarrow$ & $\rightarrow$ & $\rightarrow$ & $\mathrm{Y}$ & $\mathrm{N}$ & High \\
\hline Naproxen & $\mathrm{N}$ & $Y$ & $\mathrm{~N}$ & $\mathrm{Y}$ & $\rightarrow$ & $\rightarrow$ & $\rightarrow$ & $\rightarrow$ & $\rightarrow$ & $Y$ & Medium \\
\hline Niflumic acid & $\mathrm{N}$ & $\mathrm{N}$ & $\mathrm{N}$ & $\mathrm{N}$ & $\mathrm{N}$ & $\mathrm{N}$ & $\rightarrow$ & $\rightarrow$ & $\mathrm{N}$ & $\rightarrow$ & Low \\
\hline Nimesulide & u & u & u & $\mathrm{u}$ & u & $\mathrm{U}, \mathrm{n}<10$ & $Y^{d}$ & $\mathrm{Y}$ & $Y$ & $\mathrm{u}$ & High* \\
\hline Phenylbutazone/Oxy FBZ & $\mathrm{Y}$ & $\mathrm{Y}$ & $\mathrm{N}$ & $\mathrm{Y}$ & $\rightarrow$ & $\rightarrow$ & $\rightarrow$ & $\rightarrow$ & $\rightarrow$ & $\mathrm{N}$ & High \\
\hline Piroxicam & $\mathrm{N}$ & $\mathrm{N}$ & $\mathrm{N}$ & $\mathrm{N}$ & $\mathrm{N}$ & $\mathrm{N}$ & $\rightarrow$ & $\rightarrow$ & $\mathrm{N}$ & $\rightarrow$ & Low \\
\hline Propyphenazone & $\mathrm{N}$ & $\mathrm{N}$ & $\mathrm{N}$ & $\mathrm{N}$ & $\mathrm{N}$ & $\mathrm{N}$ & $\rightarrow$ & $\rightarrow$ & $\mathrm{N}$ & $\rightarrow$ & Low \\
\hline Robenacoxib & $\mathrm{u}$ & $\mathrm{u}$ & $\mathrm{u}$ & $\mathrm{u}$ & $\mathrm{u}$ & $\mathrm{U}, \mathrm{n}<10$ & $Y^{c, d}$ & $\mathrm{~N}$ & $\mathrm{~N}$ & $\rightarrow$ & Low \\
\hline Tolmetin & $\mathrm{N}$ & $\mathrm{N}$ & $\mathrm{N}$ & $\mathrm{N}$ & $\mathrm{N}$ & $\mathrm{N}$ & $\rightarrow$ & $\rightarrow$ & $\mathrm{N}$ & $\rightarrow$ & Low \\
\hline \multicolumn{12}{|l|}{ b bovine. } \\
\hline \multicolumn{12}{|l|}{${ }^{h}$ horse. } \\
\hline \multicolumn{12}{|l|}{ c cat. } \\
\hline \multicolumn{12}{|l|}{ d dog. } \\
\hline \multicolumn{12}{|c|}{$\mathrm{n}<10$ : Number of samples analysed is below $10 / \mathrm{y}$. } \\
\hline \multicolumn{12}{|c|}{$\rightarrow$ based on the outcome of the previous question, this question can be skipped. } \\
\hline
\end{tabular}


Table A5.2 Prioritisation of unauthorised NSAIDs in goat.

\begin{tabular}{|c|c|c|c|c|c|c|c|c|c|c|c|}
\hline \multirow[b]{2}{*}{ Substance } & \multicolumn{4}{|c|}{$\begin{array}{l}\text { Q1: Were any non-compliant residue data of the } \\
\text { substance found in the last five years? }\end{array}$} & \multicolumn{5}{|c|}{$\begin{array}{l}\text { Q3: Are there indications for use of this substance in production } \\
\text { systems for food producing animals? }\end{array}$} & \multirow{2}{*}{$\begin{array}{l}\text { Q2: Is a human health risk } \\
\text { due to residues of this } \\
\text { substance scientifically } \\
\text { proven to be absent or } \\
\text { negligible? } \\
\text { Concl. }\end{array}$} & \multirow{2}{*}{$\begin{array}{c}\text { Conclusion } \\
\text { priority } \\
\text { Goat }\end{array}$} \\
\hline & EFSA 2013-2017 & RASFF $2013-2017$ & $\begin{array}{l}\text { KAP data } \\
2012 \\
2013 \\
2017\end{array}$ & Concl. & $\begin{array}{c}\text { Non- } \\
\text { compliances } \\
\text { mammals }\end{array}$ & $\begin{array}{l}\text { Residues } \\
>\text { LOD? }\end{array}$ & $\begin{array}{l}\text { Registered } \\
\text { product EU for } \\
\text { companion } \\
\text { animals }\end{array}$ & $\begin{array}{c}\text { Availability } \\
\text { (Alibaba/eBay) }\end{array}$ & Concl. & & \\
\hline Cimicoxib & U & u & $U$ & u & u & $\mathrm{U}, \mathrm{n}<10$ & $Y^{d}$ & $\mathrm{~N}$ & $\mathrm{~N}$ & $\rightarrow$ & Low \\
\hline Eltenac & U & u & U & $u$ & $u$ & $\mathrm{U}, \mathrm{n}<10$ & $Y^{h}$ & $\mathrm{~N}$ & $\mathrm{~N}$ & $\rightarrow$ & Low \\
\hline Fenbufen & $\mathrm{N}$ & $\mathrm{N}$ & u & u & $\mathrm{N}$ & $\mathrm{U}, \mathrm{n}<10$ & $\mathrm{~N}$ & $\mathrm{~N}$ & $\mathrm{~N}$ & $\rightarrow$ & Low \\
\hline Flufenamic acid & $\mathrm{N}$ & $\mathrm{N}$ & u & $\mathrm{u}$ & $\mathrm{N}$ & $\mathrm{U}, \mathrm{n}<10$ & $\mathrm{~N}$ & $\mathrm{~N}$ & $\mathrm{~N}$ & $\rightarrow$ & Low \\
\hline Grapiprant & U & u & U & u & U & $\mathrm{U}, \mathrm{n}<10$ & $Y^{d}$ & $Y$ & Y & u & High* \\
\hline Ibuprofen & $\mathrm{N}$ & $\mathrm{N}$ & $u$ & $\mathrm{u}$ & $Y^{b, h}$ & $\rightarrow$ & $\rightarrow$ & $\rightarrow$ & $Y$ & $Y$ & Medium \\
\hline Indoprofen & $\mathrm{N}$ & $\mathrm{N}$ & $U$ & $u$ & $\mathrm{~N}$ & $\mathrm{U}, \mathrm{n}<10$ & $\mathrm{~N}$ & $\mathrm{~N}$ & $\mathrm{~N}$ & $\rightarrow$ & Low \\
\hline Mavacoxib & u & $\mathrm{u}$ & u & $\mathrm{u}$ & $u$ & $\mathrm{U}, \mathrm{n}<10$ & $Y$ & $\mathrm{~N}$ & $\mathrm{~N}$ & $\rightarrow$ & Low \\
\hline Meclofenamic acid & $\mathrm{N}$ & $\mathrm{N}$ & $\mathrm{U}$ & $u$ & $\mathrm{~N}$ & $\mathrm{U}, \mathrm{n}<10$ & $\mathrm{~N}$ & $\mathrm{~N}$ & $\mathrm{~N}$ & $\rightarrow$ & Low \\
\hline Mefenamic acid & $Y^{a}$ & $\mathrm{~N}$ & $\mathrm{U}$ & $\mathrm{Y}$ & $\rightarrow$ & $\rightarrow$ & $\rightarrow$ & $\rightarrow$ & $\rightarrow$ & $\mathrm{N}$ & High \\
\hline Naproxen & $\mathrm{N}$ & $\mathrm{N}$ & $U$ & $u$ & $Y^{b}$ & $\rightarrow$ & $\rightarrow$ & $\rightarrow$ & $\mathrm{Y}$ & $\mathrm{Y}$ & Medium \\
\hline Niflumic acid & $\mathrm{N}$ & $\mathrm{N}$ & $u$ & $\mathrm{u}$ & $\mathrm{N}$ & $\mathrm{U}, \mathrm{n}<10$ & $\mathrm{~N}$ & $\mathrm{~N}$ & $\mathrm{~N}$ & $\rightarrow$ & Low \\
\hline Nimesulide & U & $u$ & $u$ & $u$ & $u$ & $\mathrm{U}, \mathrm{n}<10$ & $\mathrm{Y}$ & $\mathrm{Y}$ & Y & $u$ & High* \\
\hline Phenylbutazone/Oxy FBZ & $\mathrm{N}$ & $\mathrm{N}$ & $u$ & $u$ & $Y^{b, h}$ & $\rightarrow$ & $\rightarrow$ & $\rightarrow$ & $\mathrm{Y}$ & $\mathrm{N}$ & High \\
\hline Piroxicam & $\mathrm{N}$ & $\mathrm{N}$ & u & u & $\mathrm{N}$ & $\mathrm{U}, \mathrm{n}<10$ & $Y^{c, d}$ & Y & $\mathrm{Y}$ & u & High* \\
\hline Propyphenazone & $\mathrm{N}$ & $\mathrm{N}$ & $\mathrm{U}$ & $u$ & $\mathrm{~N}$ & $\mathrm{U}, \mathrm{n}<10$ & $\mathrm{~N}$ & $\mathrm{~N}$ & $\mathrm{~N}$ & $\rightarrow$ & Low \\
\hline Robenacoxib & u & $u$ & u & $u$ & $u$ & $\mathrm{U}, \mathrm{n}<10$ & $\mathrm{Y}$ & $\mathrm{N}$ & $\mathrm{N}$ & $\rightarrow$ & Low \\
\hline Tolmetin & $\mathrm{N}$ & $\mathrm{N}$ & $u$ & $u$ & $\mathrm{~N}$ & $\mathrm{U}, \mathrm{n}<10$ & $\mathrm{~N}$ & $\mathrm{~N}$ & $\mathrm{~N}$ & $\rightarrow$ & Low \\
\hline \multicolumn{12}{|l|}{ b bovine. } \\
\hline \multicolumn{12}{|l|}{ h horse. } \\
\hline \multicolumn{12}{|l|}{ c cat. } \\
\hline \multicolumn{12}{|l|}{ d dog. } \\
\hline \multicolumn{12}{|c|}{$\mathrm{n}<10$ : Number of samples analysed is below $10 / \mathrm{y}$. } \\
\hline \multicolumn{12}{|c|}{ a Not specified whether found in goat or sheep. } \\
\hline based on the outcome of th & previous question, $\mathrm{t}$ & estion can be skipped & & & & & & & & & \\
\hline
\end{tabular}


Table A5.3 Prioritisation of unauthorised NSAIDs in sheep.

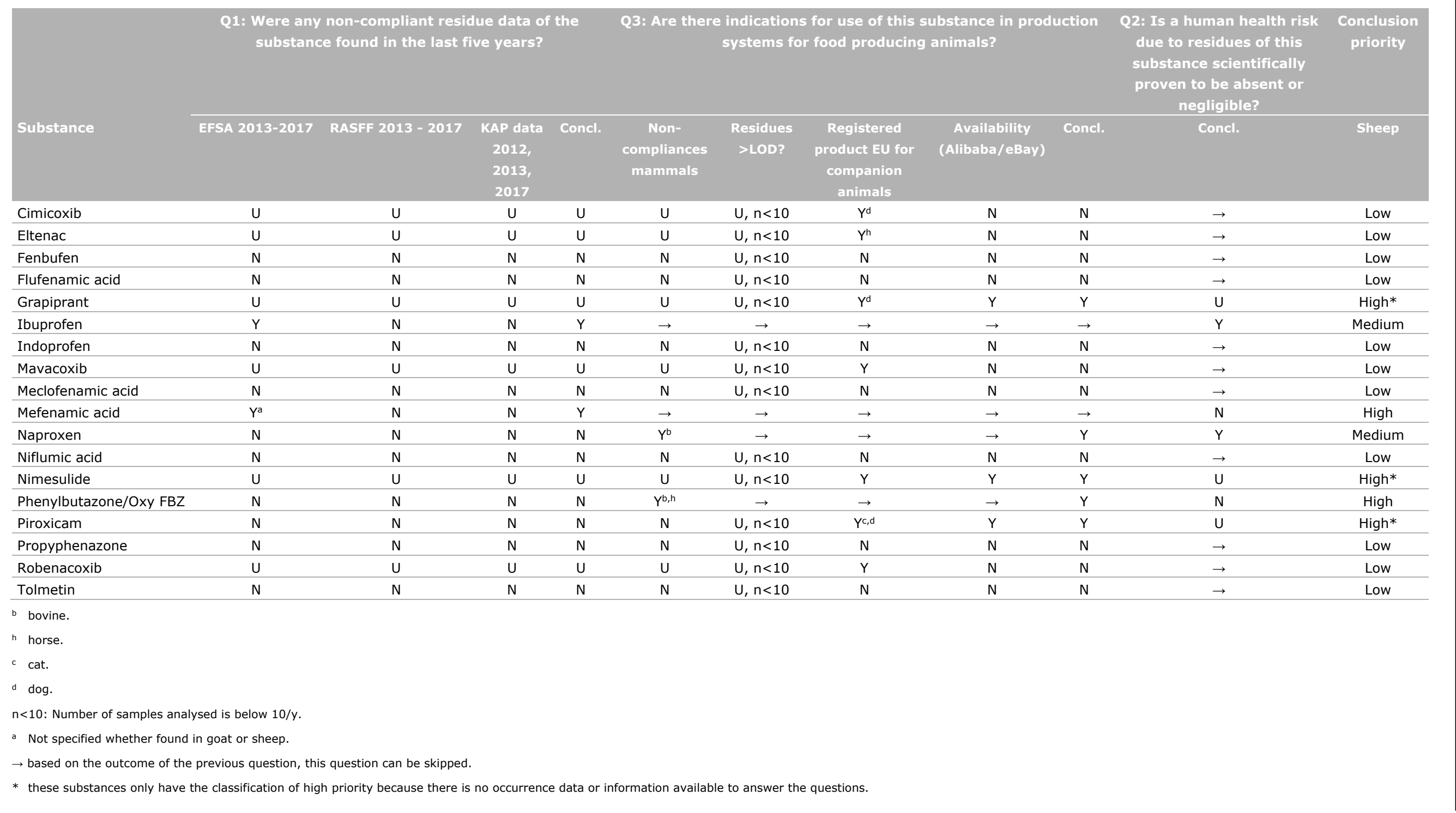


Table A5.4 Prioritisation of unauthorised NSAIDs in milk.






\section{Annex 6 Prioritisation of authorised NSAIDs using decision tree III}

Table A6.1 Prioritisation of authorised NSAIDs in horse.

\begin{tabular}{|c|c|c|c|c|c|c|c|c|c|c|c|c|c|c|}
\hline \multirow[b]{2}{*}{ Substance } & \multirow[t]{2}{*}{$\begin{array}{l}\text { Q1: is this an } \\
\text { essential } \\
\text { antimicrobial } \\
\text { for humans? }\end{array}$} & \multirow[t]{2}{*}{$\begin{array}{l}\text { Q2: Have } \\
\text { MRLs been } \\
\text { set for this } \\
\text { substance } \\
\text { in this } \\
\text { animal } \\
\text { species? }\end{array}$} & \multicolumn{4}{|c|}{$\begin{array}{l}\text { Q3: were any non-compliant residue data of the } \\
\text { substance found in the last five years? }\end{array}$} & \multicolumn{5}{|c|}{$\begin{array}{l}\text { Q4: Is the substance regularly used in this animal } \\
\qquad \text { species? }\end{array}$} & \multicolumn{2}{|c|}{$\begin{array}{l}\text { Q5: Do drugs with this } \\
\text { active substance have a } \\
\text { long withdrawal period? }\end{array}$} & \multirow[t]{2}{*}{$\begin{array}{c}\text { Conclusion } \\
\text { priority }\end{array}$} \\
\hline & & & $\begin{array}{c}\text { EFSA } \\
2013-2017\end{array}$ & $\begin{array}{c}\text { RASFF } \\
2013-2017\end{array}$ & $\begin{array}{l}\text { KAP data 2012, } \\
2013,2017\end{array}$ & Concl & $\begin{array}{l}\text { NC } \\
\text { results }\end{array}$ & $\begin{array}{l}\text { Monitored } \\
\text { and found } \\
\text { in NP }\end{array}$ & $\begin{array}{l}\text { Registration } \\
\text { EU for horse }\end{array}$ & $\begin{array}{l}\text { FIDIN } \\
(>10 \mathrm{~kg})\end{array}$ & Concl & Withdrawal period & Concl & \\
\hline Acetylsalicylic acid (aspirin) & $\mathrm{N}$ & $\mathrm{N}^{\mathrm{a}}$ & $\rightarrow$ & $\rightarrow$ & $\rightarrow$ & $\rightarrow$ & $Y^{b}$ & $\rightarrow$ & $\rightarrow$ & $\rightarrow$ & Y & 7 days (cascade) & Y & Medium $^{b}$ \\
\hline Na-Salicylate ${ }^{b}$ & $\mathrm{~N}$ & $\mathrm{~N}$ & $\rightarrow$ & $\rightarrow$ & $\rightarrow$ & $\rightarrow$ & $Y^{b}$ & $\rightarrow$ & $\rightarrow$ & $\rightarrow$ & $\mathrm{Y}$ & 0 days & $\mathrm{N}$ & Low \\
\hline Al-Salicylate $^{\mathrm{b}}$ & $\mathrm{N}$ & $Y$ & $\mathrm{Y}^{\mathrm{b}}$ & $\mathrm{N}$ & $Y^{b}$ & $Y$ & $\rightarrow$ & $\rightarrow$ & $\rightarrow$ & $\rightarrow$ & $\rightarrow$ & $\rightarrow$ & $\rightarrow$ & Medium $^{b}$ \\
\hline Carprofen & N & Y & $\mathrm{N}$ & $\mathrm{N}$ & $\mathrm{N}$ & $\mathrm{N}$ & N & $\mathrm{N}$ & Y & $\mathrm{N}$ & N & $\rightarrow$ & $\rightarrow$ & Low \\
\hline Diclofenac & N & $\mathrm{N}$ & $\rightarrow$ & $\rightarrow$ & $\rightarrow$ & $\rightarrow$ & Y & $\rightarrow$ & $\rightarrow$ & $\rightarrow$ & Y & 28 days (cascade) & Y & Medium \\
\hline Firocoxib & $\mathrm{N}$ & Y & $\mathrm{N}$ & $\mathrm{N}$ & $\mathrm{N}$ & $\mathrm{N}$ & N & $\mathrm{N}$ & Y & $\mathrm{N}$ & $\mathrm{N}$ & $\rightarrow$ & $\rightarrow$ & Low \\
\hline Flunixin / OH-flunixin & $\mathrm{N}$ & $Y$ & $\mathrm{~N}$ & $\mathrm{~N}$ & $\mathrm{~N}$ & $\mathrm{~N}$ & $\mathrm{~N}$ & $\mathrm{~N}$ & $Y$ & $Y$ & $\mathrm{Y}$ & up to 28 days & $Y$ & Medium \\
\hline Ketoprofen & N & $\mathrm{N}^{\mathrm{a}}$ & $\rightarrow$ & $\rightarrow$ & $\rightarrow$ & $\rightarrow$ & N & $\mathrm{N}$ & Y & $\mathrm{N}$ & $\mathrm{N}$ & $\rightarrow$ & $\rightarrow$ & Low \\
\hline Meloxicam & $\mathrm{N}$ & $Y$ & $\mathrm{~N}$ & $\mathrm{~N}$ & $\mathrm{~N}$ & $\mathrm{~N}$ & $\mathrm{~N}$ & $\mathrm{~N}$ & $Y$ & $\mathrm{Y}$ & Y & 3-5 days & $\mathrm{N}$ & Low \\
\hline Metamizole (MAA) & $\mathrm{N}$ & Y & $\mathrm{Y}$ & $\mathrm{N}$ & $\mathrm{N}$ & $Y$ & $\rightarrow$ & $\rightarrow$ & $\rightarrow$ & $\rightarrow$ & $\rightarrow$ & $\rightarrow$ & $\rightarrow$ & Medium \\
\hline Paracetamol & $\mathrm{N}$ & $\mathrm{N}^{\mathrm{a}}$ & $\rightarrow$ & $\rightarrow$ & $\rightarrow$ & $\rightarrow$ & $\mathrm{N}$ & $\mathrm{N}$ & $\mathrm{N}$ & $\mathrm{N}$ & $\mathrm{N}$ & $\rightarrow$ & $\rightarrow$ & Low \\
\hline Tolfenamic acid & $\mathrm{N}$ & $\mathrm{N}$ & $\rightarrow$ & $\rightarrow$ & $\rightarrow$ & $\rightarrow$ & $\mathrm{N}$ & $\mathrm{N}$ & $\mathrm{N}$ & $\mathrm{N}$ & $\mathrm{N}$ & $\rightarrow$ & $\rightarrow$ & Low \\
\hline Vedaprofen & $\mathrm{N}$ & $Y$ & $\mathrm{~N}$ & $\mathrm{~N}$ & $\mathrm{~N}$ & $\mathrm{~N}$ & $\mathrm{~N}$ & $\mathrm{~N}$ & $Y$ & $\mathrm{~N}$ & $\mathrm{~N}$ & $\rightarrow$ & $\rightarrow$ & Low \\
\hline
\end{tabular}

a No MRL necessary based on certain matrices, but present in 37/2010.

b Based on salicylic acid, a marker for al-salicylate, Na-salicylate and acetyl salicylic acid. 
Table A6.2 Prioritisation of authorised NSAIDs in goat.

\begin{tabular}{|c|c|c|c|c|c|c|c|c|c|c|c|c|c|c|}
\hline \multirow[b]{2}{*}{ Substance } & \multirow[t]{2}{*}{$\begin{array}{l}\text { Q1: is this an } \\
\text { essential } \\
\text { antimicrobial } \\
\text { for humans? }\end{array}$} & \multirow[t]{2}{*}{$\begin{array}{l}\text { Q2: Have } \\
\text { MRLs been } \\
\text { set for this } \\
\text { substance } \\
\text { in this } \\
\text { animal } \\
\text { species? }\end{array}$} & \multicolumn{4}{|c|}{$\begin{array}{l}\text { Q3: were any non-compliant residue data of the } \\
\text { substance found in the last five years? }\end{array}$} & \multicolumn{5}{|c|}{$\begin{array}{l}\text { Q4: Is the substance regularly used in this animal } \\
\text { species? }\end{array}$} & \multicolumn{2}{|c|}{$\begin{array}{l}\text { Q5: Do drugs with this } \\
\text { active substance have a } \\
\text { long withdrawal period? }\end{array}$} & \multirow[t]{2}{*}{$\begin{array}{c}\text { Conclusion } \\
\text { priority }\end{array}$} \\
\hline & & & $\begin{array}{c}\text { EFSA } \\
2012-2016\end{array}$ & $\begin{array}{c}\text { RASFF } \\
2012-2016\end{array}$ & $\begin{array}{l}\text { KAP data 2012, } \\
2013,2017\end{array}$ & Concl. & $\begin{array}{l}\text { NC } \\
\text { results }\end{array}$ & $\begin{array}{l}\text { Monitored } \\
\text { and found } \\
\text { in NP }\end{array}$ & $\begin{array}{l}\text { Registration } \\
\text { EU for goat }\end{array}$ & $\begin{array}{c}\text { FIDIN } \\
>100 \mathrm{~kg}\end{array}$ & Concl & Withdrawal period & Concl & \\
\hline Acetylsalicylic acid (aspirin) & $\mathrm{N}$ & $\mathrm{N}^{\mathrm{a}}$ & $\rightarrow$ & $\rightarrow$ & $\rightarrow$ & $\rightarrow$ & $\mathrm{N}$ & $\mathrm{U}, \mathrm{n}<10$ & $Y$ & U & U & $\rightarrow$ & $\rightarrow$ & Start Survey \\
\hline Na-Salicylate ${ }^{b}$ & $\mathrm{~N}$ & $\mathrm{~N}$ & $\rightarrow$ & $\rightarrow$ & $\rightarrow$ & $\rightarrow$ & $\mathrm{N}$ & $\mathrm{U}, \mathrm{n}<10$ & $\mathrm{~N}$ & $u$ & $u$ & $\rightarrow$ & $\rightarrow$ & Start Survey \\
\hline Al-Salicylate $^{\mathrm{b}}$ & $\mathrm{N}$ & $Y$ & $\mathrm{~N}$ & $\mathrm{~N}$ & $\mathrm{U}$ & $u$ & $\mathrm{~N}$ & $\mathrm{U}, \mathrm{n}<10$ & $\mathrm{~N}$ & $u$ & $u$ & $\rightarrow$ & $\rightarrow$ & Start Survey \\
\hline Carprofen & $\mathrm{N}$ & $\mathrm{N}$ & $\rightarrow$ & $\rightarrow$ & $\rightarrow$ & $\rightarrow$ & $\mathrm{N}$ & $\mathrm{U}, \mathrm{n}<10$ & $\mathrm{~N}$ & $u$ & $u$ & $\rightarrow$ & $\rightarrow$ & Start Survey \\
\hline Diclofenac & $\mathrm{N}$ & $\mathrm{N}$ & $\rightarrow$ & $\rightarrow$ & $\rightarrow$ & $\rightarrow$ & $Y^{c}$ & $\rightarrow$ & $\rightarrow$ & $\rightarrow$ & $\mathrm{Y}$ & 28 days (cascade) & $\mathrm{Y}$ & Medium \\
\hline Firocoxib & $\mathrm{N}$ & $\mathrm{N}$ & $\rightarrow$ & $\rightarrow$ & $\rightarrow$ & $\rightarrow$ & $\mathrm{N}$ & $\mathrm{U}, \mathrm{n}<10$ & $\mathrm{~N}$ & $u$ & $u$ & $\rightarrow$ & $\rightarrow$ & Start Survey \\
\hline Flunixin / OH-flunixin & $\mathrm{N}$ & $\mathrm{N}$ & $\rightarrow$ & $\rightarrow$ & $\rightarrow$ & $\rightarrow$ & $\mathrm{N}$ & $\mathrm{U}, \mathrm{n}<10$ & $\mathrm{~N}$ & u & u & $\rightarrow$ & $\rightarrow$ & Start Survey \\
\hline Ketoprofen & $\mathrm{N}$ & $\mathrm{N}^{\mathrm{a}}$ & $\rightarrow$ & $\rightarrow$ & $\rightarrow$ & $\rightarrow$ & N & $\mathrm{U}, \mathrm{n}<10$ & $\mathrm{~N}$ & $u$ & $u$ & $\rightarrow$ & $\rightarrow$ & Start Survey \\
\hline Meloxicam & $\mathrm{N}$ & Y & $\mathrm{N}$ & $\mathrm{N}$ & $U$ & $U$ & N & $\mathrm{U}, \mathrm{n}<10$ & $\mathrm{~N}$ & $u$ & $u$ & $\rightarrow$ & $\rightarrow$ & Start Survey \\
\hline Metamizole (MAA) & $\mathrm{N}$ & $\mathrm{N}$ & $\rightarrow$ & $\rightarrow$ & $\rightarrow$ & $\rightarrow$ & $Y^{c}$ & $\rightarrow$ & $\rightarrow$ & $\rightarrow$ & $\mathrm{Y}$ & 28 days (cascade) & Y & Medium \\
\hline Paracetamol & $\mathrm{N}$ & $\mathrm{N}^{\mathrm{a}}$ & $\rightarrow$ & $\rightarrow$ & $\rightarrow$ & $\rightarrow$ & $\mathrm{N}$ & $\mathrm{U}, \mathrm{n}<10$ & $\mathrm{~N}$ & $u$ & $u$ & $\rightarrow$ & $\rightarrow$ & Start Survey \\
\hline Tolfenamic acid & $\mathrm{N}$ & $\mathrm{N}$ & $\rightarrow$ & $\rightarrow$ & $\rightarrow$ & $\rightarrow$ & $\mathrm{N}$ & $\mathrm{U}, \mathrm{n}<10$ & $\mathrm{~N}$ & $u$ & $u$ & $\rightarrow$ & $\rightarrow$ & Start Survey \\
\hline Vedaprofen & $\mathrm{N}$ & $\mathrm{N}$ & $\rightarrow$ & $\rightarrow$ & $\rightarrow$ & $\rightarrow$ & $\mathrm{N}$ & $\mathrm{U}, \mathrm{n}<10$ & $\mathrm{~N}$ & U & U & $\rightarrow$ & $\rightarrow$ & Start Survey \\
\hline
\end{tabular}

a No MRL necessary based on certain matrices, but present in 37/2010.

b Based on salicylic acid, a marker for al-salicylate, Na-salicylate and acetyl salicylic acid.

c Not specified whether found in goat or sheep. 
Table A6.3 Prioritisation of authorised NSAIDs in sheep.

\begin{tabular}{|c|c|c|c|c|c|c|c|c|c|c|c|c|c|c|}
\hline \multirow[b]{2}{*}{ Substance } & \multirow[t]{2}{*}{$\begin{array}{l}\text { Q1: is this an } \\
\text { essential } \\
\text { antimicrobial } \\
\text { for humans? }\end{array}$} & \multirow[t]{2}{*}{$\begin{array}{l}\text { Q2: Have } \\
\text { MRLs been } \\
\text { set for this } \\
\text { substance } \\
\text { in this } \\
\text { animal } \\
\text { species? }\end{array}$} & \multicolumn{4}{|c|}{$\begin{array}{l}\text { Q3: were any non-compliant residue data of the } \\
\text { substance found in the last five years? }\end{array}$} & Q4: Is & 5 the substa & $\begin{array}{l}\text { ance regularly } \\
\text { species? }\end{array}$ & sed in this & nimal & $\begin{array}{l}\text { Q5: Do drugs wit } \\
\text { active substance } \\
\text { long withdrawal p }\end{array}$ & $\begin{array}{l}\text { h this } \\
\text { have a } \\
\text { eriod? }\end{array}$ & $\begin{array}{c}\text { Conclusion } \\
\text { priority }\end{array}$ \\
\hline & & & $\begin{array}{c}\text { EFSA } \\
2012-2016\end{array}$ & $\begin{array}{c}\text { RASFF } \\
2012-2016\end{array}$ & $\begin{array}{l}\text { KAP data 2012, } \\
2013,2017\end{array}$ & Concl. & $\begin{array}{c}\text { NC } \\
\text { results }\end{array}$ & $\begin{array}{l}\text { Monitored } \\
\text { and found } \\
\text { in NP }\end{array}$ & $\begin{array}{l}\text { Registration } \\
\text { EU for sheep }\end{array}$ & $\begin{array}{c}\text { FIDIN } \\
>100 \mathrm{~kg}\end{array}$ & Concl. & Withdrawal period & Concl. & Sheep \\
\hline Acetylsalicylic acid (aspirin) & $\mathrm{N}$ & $\mathrm{N}^{\mathrm{a}}$ & $\rightarrow$ & $\rightarrow$ & $\rightarrow$ & $\rightarrow$ & $\mathrm{N}$ & $\mathrm{U}, \mathrm{n}<10$ & $Y$ & $u$ & $u$ & $\rightarrow$ & $\rightarrow$ & Start survey \\
\hline Na-Salicylate ${ }^{b}$ & $\mathrm{~N}$ & $\mathrm{~N}$ & $\rightarrow$ & $\rightarrow$ & $\rightarrow$ & $\rightarrow$ & $\mathrm{N}$ & $\mathrm{U}, \mathrm{n}<10$ & $\mathrm{~N}$ & $u$ & $u$ & $\rightarrow$ & $\rightarrow$ & Start survey \\
\hline Al-Salicylate ${ }^{b}$ & $\mathrm{~N}$ & $\mathrm{~N}$ & $\rightarrow$ & $\rightarrow$ & $\rightarrow$ & $\rightarrow$ & $\mathrm{N}$ & $\mathrm{U}, \mathrm{n}<10$ & $\mathrm{~N}$ & $u$ & $u$ & $\rightarrow$ & $\rightarrow$ & Start survey \\
\hline Carprofen & $\mathrm{N}$ & $\mathrm{N}$ & $\rightarrow$ & $\rightarrow$ & $\rightarrow$ & $\rightarrow$ & $\mathrm{N}$ & $\mathrm{U}, \mathrm{n}<10$ & $\mathrm{~N}$ & $u$ & $u$ & $\rightarrow$ & $\rightarrow$ & Start survey \\
\hline Diclofenac & $\mathrm{N}$ & $\mathrm{N}$ & $\rightarrow$ & $\rightarrow$ & $\rightarrow$ & $\rightarrow$ & $\mathrm{Y}$ & $\rightarrow$ & $\rightarrow$ & $\rightarrow$ & $\mathrm{Y}$ & 28 days (cascade) & $\mathrm{Y}$ & Medium \\
\hline Firocoxib & $\mathrm{N}$ & $\mathrm{N}$ & $\rightarrow$ & $\rightarrow$ & $\rightarrow$ & $\rightarrow$ & $\mathrm{N}$ & $\mathrm{U}, \mathrm{n}<10$ & $\mathrm{~N}$ & u & u & $\rightarrow$ & $\rightarrow$ & Start survey \\
\hline Flunixin / OH-flunixin & $\mathrm{N}$ & N & $\rightarrow$ & $\rightarrow$ & $\rightarrow$ & $\rightarrow$ & $Y$ & $\rightarrow$ & $\rightarrow$ & $\rightarrow$ & $\mathrm{Y}$ & 28 days (cascade) & $Y$ & Medium \\
\hline Ketoprofen & $\mathrm{N}$ & $\mathrm{N}^{\mathrm{a}}$ & $\rightarrow$ & $\rightarrow$ & $\rightarrow$ & $\rightarrow$ & $Y^{d}$ & $\rightarrow$ & $\rightarrow$ & $\rightarrow$ & Y & 28 days (cascade) & Y & Medium $^{d}$ \\
\hline Meloxicam & $\mathrm{N}$ & $\mathrm{N}$ & $\rightarrow$ & $\rightarrow$ & $\rightarrow$ & $\rightarrow$ & $\mathrm{N}$ & $\mathrm{U}, \mathrm{n}<10$ & $\mathrm{~N}$ & $u$ & $u$ & $\rightarrow$ & $\rightarrow$ & Start survey \\
\hline Metamizole (MAA) & $\mathrm{N}$ & $\mathrm{N}$ & $\rightarrow$ & $\rightarrow$ & $\rightarrow$ & $\rightarrow$ & $Y^{c}$ & $\rightarrow$ & $\rightarrow$ & $\rightarrow$ & Y & 28 days (cascade) & Y & Medium \\
\hline Paracetamol & $\mathrm{N}$ & $\mathrm{N}^{\mathrm{a}}$ & $\rightarrow$ & $\rightarrow$ & $\rightarrow$ & $\rightarrow$ & $\mathrm{N}$ & $\mathrm{U}, \mathrm{n}<10$ & $\mathrm{~N}$ & $u$ & $u$ & $\rightarrow$ & $\rightarrow$ & Start survey \\
\hline Tolfenamic acid & $\mathrm{N}$ & $\mathrm{N}$ & $\rightarrow$ & $\rightarrow$ & $\rightarrow$ & $\rightarrow$ & $\mathrm{N}$ & $\mathrm{U}, \mathrm{n}<10$ & $\mathrm{~N}$ & $u$ & $u$ & $\rightarrow$ & $\rightarrow$ & Start survey \\
\hline Vedaprofen & $\mathrm{N}$ & $\mathrm{N}$ & $\rightarrow$ & $\rightarrow$ & $\rightarrow$ & $\rightarrow$ & $\mathrm{N}$ & $\mathrm{U}, \mathrm{n}<10$ & $\mathrm{~N}$ & U & U & $\rightarrow$ & $\rightarrow$ & Start survey \\
\hline
\end{tabular}

a No MRL necessary based on certain matrices, but present in 37/2010.

b Based on salicylic acid, a marker for al-salicylate, Na-salicylate and acetyl salicylic acid.

c Not specified whether found in goat or sheep.

d Based on a non-compliant result in sheep milk. 
Table A6.4 Prioritisation of authorised NSAIDs in milk.

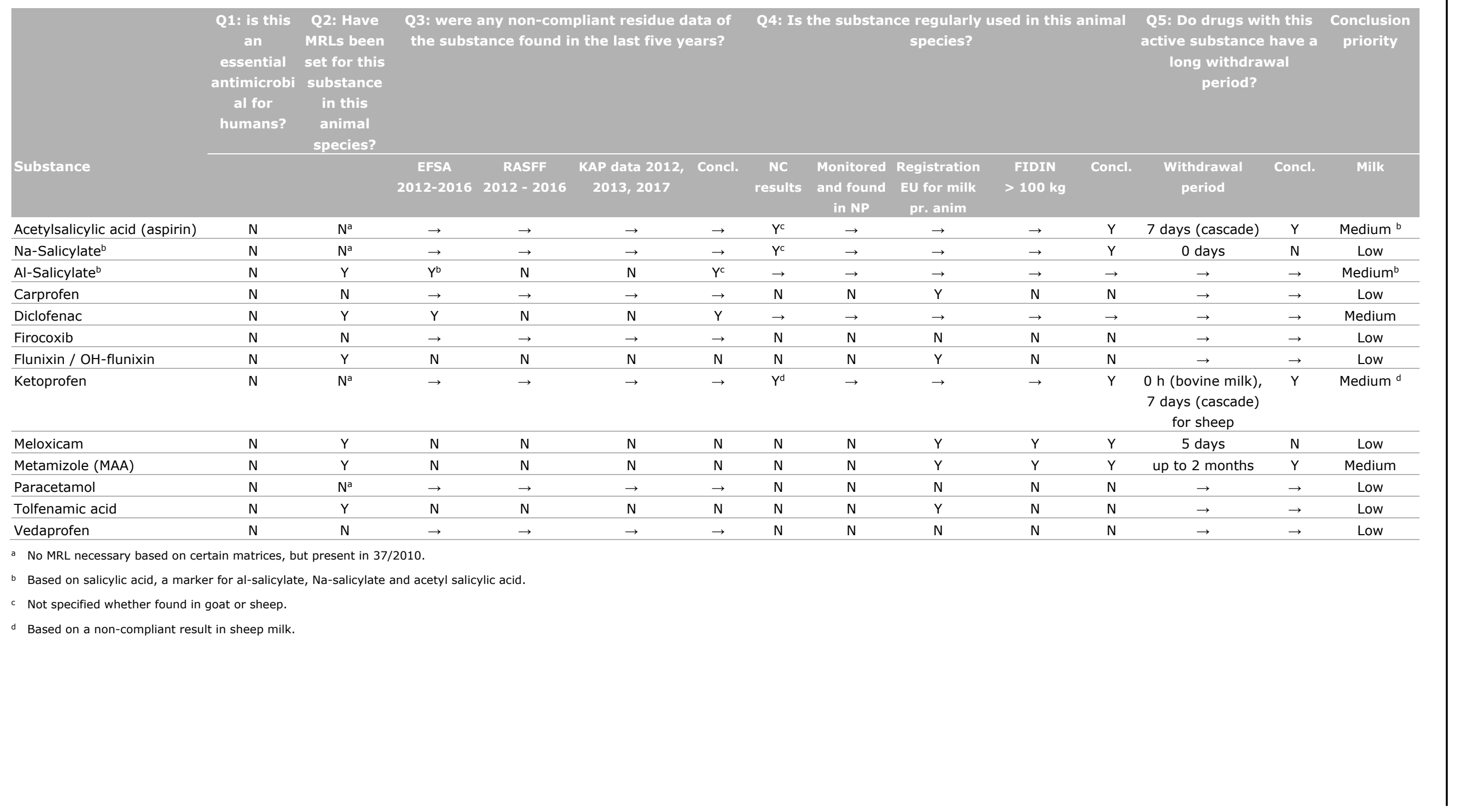




\section{Annex 7 List of substances essential for treatment of equidae and substances bringing added clinical benefit according to EU $122 / 2013$}

\begin{tabular}{|c|c|}
\hline \multirow{10}{*}{$\begin{array}{l}\text { Sedation and premedication } \\
\text { (and antagonism) }\end{array}$} & Acepromazine \\
\hline & Atipamezole \\
\hline & Diazepam \\
\hline & Flumazenil \\
\hline & Midazolam \\
\hline & Naloxone \\
\hline & Propofol \\
\hline & Sarmazenil \\
\hline & Tiletamine \\
\hline & Zolazepam \\
\hline \multirow{5}{*}{$\begin{array}{l}\text { Hypotension or respiratory } \\
\text { stimulation during } \\
\text { anaesthesia }\end{array}$} & Dobutamine \\
\hline & Dopamine \\
\hline & Ephedrine \\
\hline & Glycopyrrolate \\
\hline & Noradrenaline (norepinephrine) \\
\hline \multirow[t]{4}{*}{ Analgesia } & Buprenorphine \\
\hline & Fentanyl \\
\hline & Morphine \\
\hline & Pethidine \\
\hline \multirow{3}{*}{$\begin{array}{l}\text { Muscle relaxants and } \\
\text { associated substances }\end{array}$} & Atracurium \\
\hline & Edrophonium \\
\hline & Guaifenesin \\
\hline Inhalation anaesthetics & Sevoflurane \\
\hline \multirow[t]{3}{*}{ Local anaesthetics } & Bupivacaine \\
\hline & Oxybuprocaine \\
\hline & Prilocaine \\
\hline \multicolumn{2}{|l|}{ Anti-inflammatory substances } \\
\hline \multirow[t]{2}{*}{ Corticosteroids } & Triamcinolone acetonide \\
\hline & Flumethasone \\
\hline \multirow[t]{2}{*}{ Anti-endotoxins } & Pentoxifylline \\
\hline & Polymycin B \\
\hline \multicolumn{2}{|l|}{ Cardiovascular medicines } \\
\hline & Amiodarone \\
\hline & Allopurinol \\
\hline & Vasopressin \\
\hline & Digoxin \\
\hline & $\begin{array}{l}\text { Quinidine sulphate and } \\
\text { quinidine gluconate }\end{array}$ \\
\hline & Procainamide \\
\hline & Propranolol \\
\hline \multicolumn{2}{|l|}{ Convulsions } \\
\hline & Phenytoin \\
\hline & Primidone \\
\hline \multicolumn{2}{|l|}{ Gastrointestinal agents } \\
\hline & Bethanechol \\
\hline & Codeine \\
\hline
\end{tabular}


Loperamide

Metoclopramide

Phenoxybenzamine

Propantheline bromide

Ranitidine

Sucralfate

Rabdomyolysis

Antimicrobials

Klebsiella spp.-infections

Dantrolene sodium

Rhodococcus equi-infections

Ticarcillin

Azithromycin

Rifampicin

Septic arthritis

Amikacin

Respiratory medicines

Ambroxol

Budesonide

Fluticasone

Ipratropium bromide

Oxymetazolin

Antiprotozoal agents

Isometamidium

Ponazuril

Pyrimethamine

Ophthalmic medicines

Ocular ulcers

Acyclovir

Idoxuridine

Glaucoma

Phenylephrine

Tropicamide

Dorzolamide

Latanoprost

Timolol maleate

Cyclosporin A

Ketorolac

Ofloxacin

Fluoresceine

Rose Bengal

Hyperlipaemia

Insulin

Fungal infections

Griseofulvin

Ketoconazole

Miconazole

Nystatin

Diagnostic imaging

Radiopharmaceutical Tc99m

Miscellaneous

Carbamazepine

Cyproheptadine

Domperidone

Gabapentin

Hydroxyethyl-starch

Imipramine

Thyrotropin releasing hormone (TRH)

Barium sulphate

Iohexol

Iopamidol 
Wageningen Food Safety Research

P.O. Box 230

6700 AE Wageningen

The Netherlands

T +31 (0)317480256

www.wur.eu/food-safety-research

WFSR report 2020.007
The mission of Wageningen University \& Research is "To explore the potential of nature to improve the quality of life". Under the banner Wageningen University \& Research, Wageningen University and the specialised research institutes of the Wageningen Research Foundation have joined forces in contributing to finding solutions to important questions in the domain of healthy food and living environment. With its roughly 30 branches, 5,000 employees and 10,000 students, Wageningen University \& Research is one of the leading organisations in its domain. The unique Wageningen approach lies in its integrated approach to issues and the collaboration between different disciplines. 



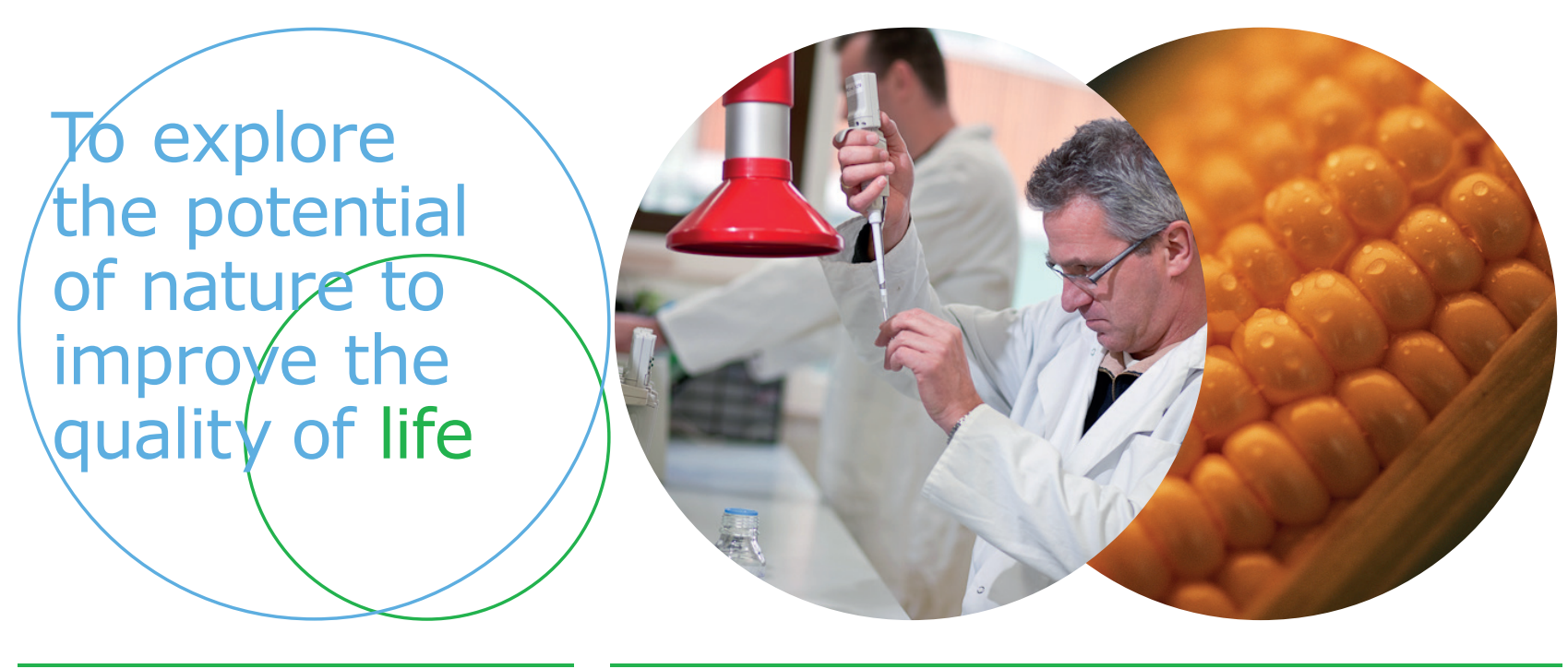

Wageningen Food Safety Research P.O. Box 230

6700 AE Wageningen

The Netherlands

T +31 (0)317480256

www.wur.eu/food-safety-research

WFSR report 2020.007
The mission of Wageningen University \& Research is "To explore the potential of nature to improve the quality of life". Under the banner Wageningen University $\&$ Research, Wageningen University and the specialised research institutes of the Wageningen Research Foundation have joined forces in contributing to inding solutions to important questions in the domain of healthy food and living environment. With its roughly 30 branches, 5,000 employees and 12,000 students, Wageningen University \& Research is one of the leading organisations in its domain. The unique Wageningen approach lies in its integrated approach to issues and the collaboration between different disciplines. 